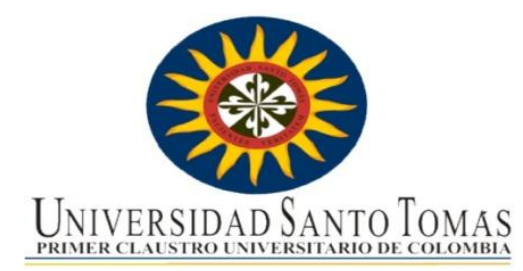

\title{
Educomunicación y cultura de convivencia en escuelas de educación alternativas. El caso de la Escuela Mediática
}

\section{Claudia Lorena Ayala Carvajal}

\author{
Universidad Santo Tomás
}

Maestría en Comunicación, Desarrollo y Cambio Social

Bogotá, Colombia

2018 


\title{
Educomunicación y cultura de convivencia en escuelas de educación alternativas. El caso de la Escuela Mediática.
}

\author{
Claudia Lorena Ayala Carvajal \\ Magister en Comunicación, Desarrollo y Cambio Social \\ Director (a): \\ Bernardo Alfredo Hernández-Umaña \\ Línea de Investigación: \\ Comunicación, gobierno y ciudadanía. \\ Universidad Santo Tomás \\ Facultad de Comunicación Social \\ Bogotá, Colombia \\ 2018
}

Trabajo de investigación presentado como requisito parcial para optar al título de: 
Primeramente a Dios por darme el privilegio de vivir, a mi familia por su apoyo incondicional, a la Escuela Mediática por abrir las puertas de su institución y al docente y tutor Bernardo Hernández, por su infinita colaboración. 


\section{Resumen}

La educación está atravesando un momento fundamental, son muchas las instituciones que se están preguntando la aplicabilidad del modelo educativo tradicional en el momento histórico actual. Esta investigación tiene como propósito principal estudiar el modelo educomunicativo que se lleva a cabo en la Escuela Mediática, una institución de educación alternativa; comprendiendo la manera en la que se construye convivencia escolar desde este enfoque y por lo tanto se aporta a la mitigación de la violencia escolar. Todo lo anterior, con el fin de demostrar cómo la educomunicación posibilita otras formas de ver el sistema educativo y presentarlo como un constructor de cultura ciudadana.

Palabras clave: Educomunicación, educación alternativa, violencia escolar, cultura de convivencia, ciudadanía. 


\section{Índice}

1. Introducción.

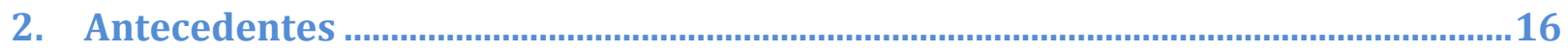

3. Marco teórico

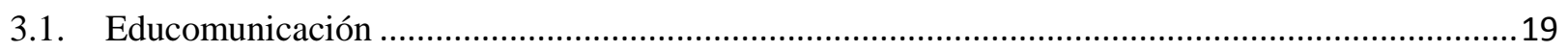

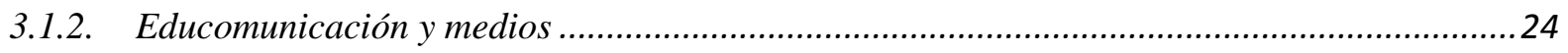

3.1.2. Educomunicación para la participación y ciudadanía....................................................... 27

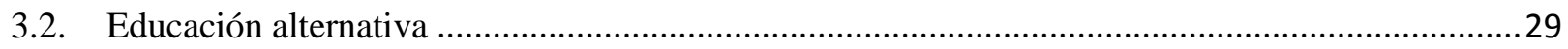

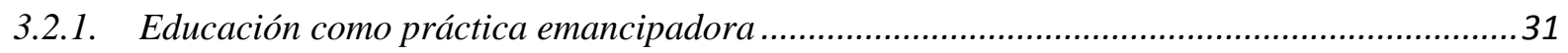

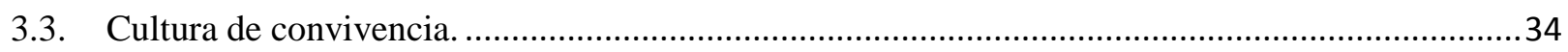

3.1.1 Importancia de la cultura dentro de la escuela .....................................................................36

3.1.2 Contrucción de cultura de convivencia, un camino hacia la mitigación de la violencia escolar 38

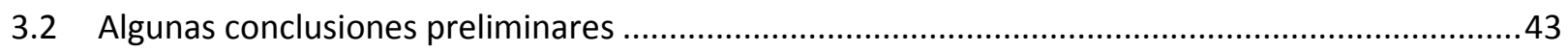

4. Metodología de Investigación ................... 44

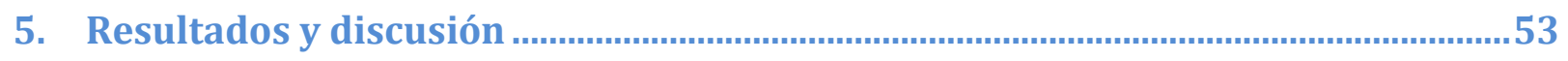

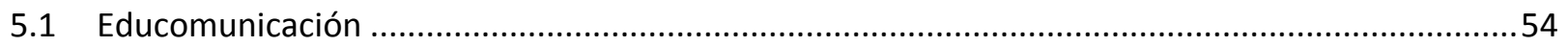

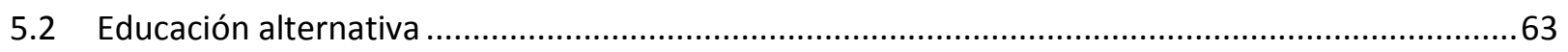

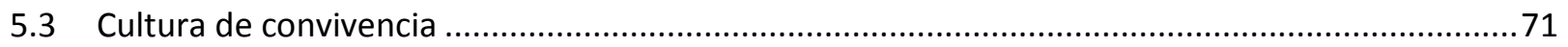

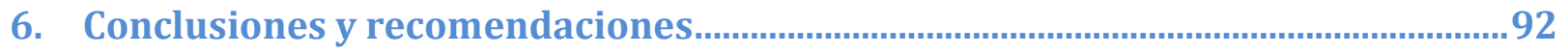

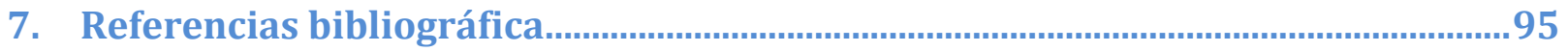




\section{Introducción}

La educación y la comunicación cumplen un papel fundamental en el desarrollo de todas las comunidades y orientan a los seres humanos principalmente a construir su concepción de ciudadanía, es en esta medida en que la educación tiene que responder a esta necesidad y ofrecer a los distintos participantes de ella la posibilidad de descubrir su potencial creador dentro de la colectividad en la que se encuentran. Esta investigación busca darle protagonismo a la contra parte de la educación tradicional y abrir un espacio en el que se visibilicen nuevas apuestas alternativas.

Entender los alcances de una propuesta de educación alternativa basada en la educomunicación, como la que se presenta en esta investigación es la oportunidad para que se pueda seguir cultivando el interés de distintos agentes que quieran aportar al campo de la educación desde otra mirada diferente a la tradicional, ya que se hace urgente una renovación de los esquemas y sistemas educativos actuales, para la construcción de una Colombia en paz, constructora y gestora de cambio social. Es por esto que visibilizar esta clase de esfuerzos se hace apremiante en el momento coyuntural que como país atravesamos.

Este proyecto de tesis es un aporte teórico y práctico, para aquellas instituciones que afrontan la problemática de la violencia escolar y tienen la intención de trabajar en este problema desde la base, construyendo ecosistemas educativos fundamentados en una comunicación dialógica, que se convierte en la artífice de pactos de convivencia que median las dinámicas educativas y por tanto reducen dicha problemática. Todo lo anterior, con el fin de que se evidencien los alcances transformadores que posee una educación alternativa basada en el factor educomunicativo y como este es movilizador de convivencia escolar.

Las estrategias en las escuelas para abordar el tema de la violencia escolar no dejan de ser relevantes, el fortalecimiento de la cultura de convivencia es sin lugar a duda, una de las preocupaciones de los docentes e investigadores interesados que Colombia sea un territorio de Paz desde la escuela. Esta investigación responde al interés de evidenciar aquellas propuestas 
educomunicativas que se forjan en una escuela de educación alternativa tomando como ejemplo el trabajo realizado en la Escuela Mediática; que como se va a evidenciar con la lectura del documento, aporta a la cultura de convivencia desde su enfoque educomunicativo, diminuyendo de esta forma la violencia escolar.

Esta investigación escoge para el estudio de caso la Escuela Mediática, una institución de educación alternativa que cuenta con los grados decimo y once, esta forma parte de la media vocacional del CEL (Centro Educativo Libertad) que ofrece a sus estudiantes un énfasis importante en el aspecto comunicativo, además de ser una propuesta que se fundamenta en teóricos que trabajan la educomunicación como Huergo, Barbero, García entre otros. Esta institución educativa plantea desde la práctica elementos teóricos, como por ejemplo fragmentar con un modelo de comunicación desfasado que niega el descentramiento del libro, obstaculizando el acceso al mundo del saber diseminado en la multiplicidad de los medios de comunicación. También se reconoce que las expresiones comunicativas pueden devenir en una herramienta contra hegemónica de emancipación social. La Escuela Mediática postula la necesidad que tiene la escuela al enfrentar y asimilar a la juventud contemporánea en cuanto esta es cambiante y heterogénea (Gómez, 2012). Dicha institución busca que sus estudiantes sean jóvenes críticos frente a un mundo en el que la información y los medios ordenan socialmente cada relación. Por consiguiente, la investigación se centra en dicho espacio, dado que esta institución profundiza en la relación entre comunicación y medios en el proceso educativo de los estudiantes, teniendo fundamentos desde la teoría y la práctica, pertinentes en esta exploración.

Ahora bien la relevancia y los alcances de esta investigación dentro de la Maestría de Comunicación, Desarrollo y Cambio Social, son claros, ya que busca profundizar la manera en la que la relación comunicación y educación están ligados a la transformación social, procurando ofrecer otras maneras en la construcción de sujetos en la escuela que tengan claridades, en cuanto a la gestión de los conflictos y una cultura de convivencia a través de la educomunicación. Esta investigación permitirá que se evidencien los esfuerzos en cuanto a este aspecto y va a abrir un campo de interés a docentes e investigadores que quieran profundizar en el tema, tomando como referente la educación alternativa. Por otra parte, prestará una guía a aquellos colegios que quieran abordar el problema de la violencia escolar desde una mirada 
práctica y que esté inmersa en el contexto educativo, promoviendo así una verdadera cultura de convivencia.

Añadiendo a lo anterior, esta investigación desde su planteamiento teórico y metodológico le apuesta a otras maneras de ver el desarrollo. No desde los modelos neoliberales que plantean competencia y consumo, sino por el contrario, desde otras miradas, por ejemplo; la decolonial y la de la promoción de las capacidades planteada por Martha Nussbaum en la medida en la que esta propuesta no busca disminuir únicamente índices de violencia escolar, por el contrario, busca a partir de las experiencias humanas dotar de sentido las prácticas de convivencia y en esa medida "pone el enfoque al servicio de la construcción de una teoría de la justicia social básica (Nusbaum, 2012)” pensada dentro y para la escuela. Es por eso también que m

Por último, este estudio esta inscrito a la línea de investigación de comunicación, desarrollo y ciudadanía de la Maestría en comunicación, desarrollo y cambio social, pues como se menciono anteriormente no solo destaca propuestas alternativas de educación, además permite comprender la manera en la que modelos comunicativos aportan al cambio social desde la disminución de la violencia escolar, generando espacios donde la gestión de conflictos se da a partir de la palabra. Es por lo anterior, que se inscribe a esta línea, ya que su enfoque le permite analizar otras formas de contribuir a una formación ciudadana desde la convivencia, el respeto y el reconocimiento del otro, que inicia en la escuela y termina reflejándose en cada comunidad.

\section{Planteamiento del problema}

La educación es inherente a las sociedades humanas. El hombre tiene la necesidad de aprender de su contexto desde sus primeros años de vida. En la actualidad, la escuela es uno de los primeros escenarios de aprendizaje de cada sujeto y el lugar en el que se da la formación de ciudadanía que luego se ejercerá dentro de cualquier civilización. Dentro de ésta existen aprendizajes en torno a las ciencias básicas pero también sobre el comportamiento de los sujetos dentro de una comunidad. Por lo tanto, ésta tiene la oportunidad de influenciar vidas 
humanas moldeando su visión y conducta; convirtiéndose en una herramienta de transformación, ya que de ésta depende en gran medida el destino de cada colectividad.

La educación y la escuela en general, al cumplir una función tan importante en las sociedades se ha encontrado inmersa en problemáticas características de cada sociedad. Un ejemplo de esto es el fenómeno de violencia escolar que cada vez es más difícil de ignorar. Latinoamérica es uno de las regiones del mundo con mayores problemas de violencia escolar en el mundo. Según Mónica Darer, especialista en Derechos de la Niñez de la ONG Plan Internacional, en América Latina el 70\% de los niños son directa o indirectamente afectados por la violencia en la escuela. Esta cifra incluye, niños que han sido acosados o han sido testigos del acoso (El universal, 2013).

Otro ejemplo de lo anterior, es una de las más rigurosas fuentes de información sobre el tema en América Latina es el estudio sobre violencia escolar realizado en Bogotá en los años 2006 y 2011. Este estudio incluyó la medición de múltiples indicadores relacionados con la agresión y la violencia en colegios públicos y privados. En el año 2006 participaron más de 87 mil estudiantes, y en el año 2011 participaron más de cien mil estudiantes de 19 de las 20 localidades de Bogotá (Chaux, 2013). En esta investigación se abordan los distintos tipos de violencia físicas, psicológicas, sexuales, con armas; por parte de los estudiantes o docentes. A continuación se presentan datos que dan cuenta del aumento de la violencia escolar en el periodo anteriormente mencionado.

Primero se presentan los estudiantes que reportan haber sido golpeados por compañeros en el mes pasado según el sexo, grado, sector y localidad del colegio, respectivamente en los años 2006 y 2011. La prevalencia de agresión física aumentó levemente (de 32.8\% a 34.8\%) y este aumento se dio principalmente entre $\operatorname{los}$ grados $5^{\circ}$ y $7^{\circ}$ y en colegios privados. Frente a la agresión verbal aumentó 3 puntos (de 38\% a 41\%) y este aumento se dio principalmente para los hombres, entre los grados $5^{\circ}$ y $7^{\circ}$ y en colegios públicos. Otro aspecto que se tuvo en cuenta fue la agresión relacional traducida en la exclusión por parte de pares los resultados muestran un aumento de 3 puntos en el reporte de exclusión (de $22.0 \%$ a 25.1\%). Este aumento se dio especialmente en el reporte de hombres, en los grados $5^{\circ}$ y $6^{\circ}$, en colegios públicos y en algunas localidades como Barrios Unidos y Kennedy, aunque el aumento se dio en 16 de las 19 localidades. Por otra parte, la violencia realizada por pandillas dentro del colegio Se encontró 
un aumento de 4.5 puntos entre el 2006 y el 2011 (de 24.5\% a 29\%). El aumento se observó en el reporte de ambos sexos y especialmente entre $6^{\circ}$ y $10^{\circ}$ grado y en colegios públicos. El aumento fue marcado en las localidades de Ciudad Bolívar (10 puntos), Tunjuelito (11 puntos) y Usme (12 puntos). (Chaux, 2013).

Los datos anteriores, reflejan que en Colombia los índices de violencia escolar no se detienen, sino que por el contrario continúan. Descifrar el fenómeno de violencia escolar dentro de la escuela implica comprender todas sus vicisitudes, actuaciones y efectos; se trata de entender que no es simplemente un aspecto que aplique para determinadas escuelas o que tenga implicaciones leves en la vida de los estudiantes, es algo que va más allá y termina impregnando la manera en la que se configuran las dinámicas sociales. Superar en alguna medida las relaciones conflictivas dentro cada escuela abre un espacio esperanzador para la construcción de una Colombia en paz, con ciudadanos que comprenden su rol activo dentro de su comunidad y se arriesgan a creer que el cambio esta en sus manos.

Esta investigación problematiza el tema de la violencia escolar, pues parte de la premisa en la que es necesario reconocer el camino por el cual se quiere construir una transformación. En este caso parte de la problemática global para posteriormente abrir un espacio en el que se comprenda el impacto de la experiencia educativa que se escogió, pues en esa medida se tendrá una perspectiva más amplia de lo que se aborda a lo largo de este estudio de caso.

Es gracias a lo anteriormente expuesto, que esta investigación se enfoca en estudiar el caso de la Escuela Mediática, tomando como base el enfoque hermenéutico, pues no busca precisamente abordar una problemática específica dentro del lugar en el que se estudia, si no que se encarga de analizar, comprender y escudriñar los elementos significativos que en esta se gestan, para asi significar la realidad desde la misma práctica. Lo anterior, teniendo en cuenta que se presenta una experiencia en la que se evidencia la forma en la que el aspecto educomunicativo entra a mediar en la escuela alternativa como un constructor de convivencia escolar. Rescatar cada uno de los elementos que se presentan en ese lugar, puede abrir un camino que se necesitan explorar en otros centros educativos en los que se de la violencia escolar. Teniendo en cuenta que en esta propuesta se trabaja la unificación de distintos elementos teóricos que se confrontan en la práctica, a fín de generar una reflexión más amplia. 
"La íntima compenetración entre educación, comunicación, sociedad y convivencia constituye un entramado de interacciones, relaciones e interdependencias que precisan una reflexión y un análisis en profundidad, siendo conscientes de que donde no hay comunicación no hay sociedad" (Hernández, 2001)

El caso de la Escuela Mediática no representa la problemática de la investigación, por el contrario se convierte en la base rectora del proyecto, pues es un referente en la medida en la que este fenómeno no se presenta de forma latente como se podría llegar a presentar en una institución educativa regular.

Lo interesante de la propuesta que se lleva a cabo en la Escuela Mediática, es que su objetivo principal no es mitigar la violencia escolar, su propósito inicial es formar ciudadanos críticos que reconocen el acto comunicativo y usan las herramientas que operan en este campo para entender la realidad, comprendiendo a su vez su potencial transformador. Lo anterior es similar a la manera en la que se contempla la educomunicación "pedagogía crítica que concibe los procesos educativos, la comunicación, los medios y las tecnologías como herramientas de análisis y de acción para la comprensión y la transformación del mundo.” (Coslado, 2012). La forma en la que se relacionan las prácticas de la Mediática con lo que se propone teóricamente acerca de la educomunicación, resulta la materialización de un concepto que en principio es difícil de comprender (ya que teóricamente se sigue contruyendo) pero que se puede enlazar a las dinámicas educativas generando buenos resultados como lo dice se expone a continuación: los espacios en los que se promueve la comunicación y la educación están llevando a cabo transformación social y educativa, pues a través de sus iniciativas son potenciadoras para acabar con problemáticas sociales y educativas evidentes, aportando a la disminución de violencia escolar (Mockus, 2003). Entonces, es necesario indagar acerca de la manera en la que relacionan los principios de la educomunicación, en las prácticas que se llevan acabo dentro de esta institución educativa. Como también, descifrar la relación de aquellos elementos que de una manera implícita aportan a la construcción de convivencia y abren posibles líneas de acción frente a la problemática global de la violencia escolar.

Para que se cumpla la intencionalidad de este estudio, es necesario indagar acerca de cómo se dan las propuestas educomunicativas en la Escuela Mediática, comprendiendo la manera en la que estas están aportando a la mitigación de la violencia escolar y contribuyendo desde ese 
frente a la construcción de cultura de convivencia. Es por esto que esta investigación se pregunta:

¿De qué manera se dan los procesos educomunicativos en la "Escuela Mediática" de Bogotá y como están aportando a la cultura de convivencia?

\subsection{Objetivo general}

Analizar los procesos educomunicativos en torno a la cultura de convivencia. El caso de la Escuela Mediática de Bogotá.

\subsubsection{Objetivos específicos}

1. Identificar los procesos educomunicativos que se están desarrollando en torno a la construcción de una cultura de la convivencia en la Escuela Mediática

2. Determinar los elementos característicos de los procesos educomunicativos que se desarrollan y permiten dar cuenta del aporte a la cultura de la convivencia en la Escuela Mediática.

3. Reconocer cuáles son las líneas de acción tendientes a costrucción de cultura de convivencia a través de procesos educomunicativos que aportan a la mitigación de la violencia escolar en la Escuela Mediática de Bogotá. 


\section{Antecedentes}

En este apartado, se hará un recorrido por las investigaciones relacionadas con las temáticas planteadas. En primer lugar, se presentarán los trabajos investigativos relacionados con la violencia escolar, que permiten dar cuenta de la problemática frente a este aspecto en las instituciones educativas. En un segundo momento, se hablará acerca de las indagaciones que estén relacionadas con la cultura de convivencia y las estrategias que se han puesto en funcionamiento para poder potenciarlas. Por último, se mostrarán aquellas averiguaciones que han desarrollado propuestas educomunicativas para abordar distintas problemáticas y se centrará la importancia en las que existe un diálogo entre la relevancia de las propuestas educomunicativas para el fortalecimiento de la cultura de convivencia y la disminución de la violencia escolar.

En primer lugar, encontramos a investigadores del Centro de estudios avanzados en niñez y juventud Universidad de Manizales - CINDE, con su investigación, en donde hacen un recorrido acerca de cómo los jóvenes de un colegio conciben la violencia escolar y la convivencia pacífica. Esas narrativas posibilitan el entendimiento de la violencia estructural concebida cultural y contextualmente (Henao Ramirez \& Lopez Peralta, 2014)”. Por otra parte está Patricia Garreton, con su investigación acerca del "Estado de la convivencia escolar, conflictividad y su forma de abordarla en establecimientos educacionales de alta vulnerabilidad social de la provincia de concepción, Chile". Ella plantea de manera bastante explícita, las tipologías de la violencia escola (física, psicológica) que se reproducen en la escuela y el impacto negativo de esas dinámicas en las relaciones interpersonales de los jóvenes, permitiendo evidenciar claramente la relevancia de trabajar este tema en este contexto. Además aporta a la construcción teórica del apartado de violencia escolar y cultura de convivencia, ya que se mencionan distintos autores que nutren estas categorías (Garreton, 2014). Estas dos investigaciones, según los intereses de esta tesis, son de gran ayuda en la medida en la que permiten entender el problema de la violencia escolar (causas, consecuencias e impactos) ampliando el panorama situados desde otras perspectivas teóricas y metodológicas.

Además, se encontraron investigaciones relacionadas con la cultura de convivencia y la disminución de violencia escolar. Por ejemplo, la primera encontrada es acerca de la "Implementación de una propuesta didáctica centrada en las competencias emocionales y 
comunicativas para la solución de conflictos en el aula de clase" en donde Yormin Escalante Villegas, plantea que estrategias pedagógicas para la escucha, participación, manejo de emociones y empatía puestas en funcionamiento en esta propuesta, inciden efectivamente en el desarrollo de las competencias emocionales y comunicativas para la solución de conflictos en el aula de clase; dando herramientas de esta manera a la construcción de convivencia y resolución de conflictos desde el aula de clase (Escalante, 2011). De igual manera, en esta rama de interés, se encontró una investigación que presenta una propuesta para abordar este tema, desde el ámbito comunicativo, planteada por Marco Antonio Alfaro Ventura quien habla acerca de " $\mathrm{La}$ optimización de los resultados de la reforma educativa para enfrentar la violencia escolar mediante la utilización de la televisión". Alfaro presenta la influencia de los medios televisivos en los patrones de violencia que se reproducen en la escuela y cómo estos pueden ser usados para una reforma educativa o en contra parte pueden significar un retraso para ésta; de hecho hace una invitación para que se entienda que esos artefactos tecnológicos también tienen un contenido simbólico que esta mediado por las prácticas culturales. La reflexión que realiza este autor frente a la televisión como una herramienta que posibilita una transformación en las dinámicas violentas dentro de la escuela es supremamente importante, ya que desde otro ángulo se apoya la premisa que se desarrolla a lo largo del texto y es que los elementos comunicativos tienen la capacidad para posibilitar cambios en las realidades inmediatas. (Alfaro, 2010).

En tercer lugar, se van a exponer aquellas investigaciones en las que lo educomunicativo, la cultura de convivencia y la disminución de la violencia escolar, entran a dialogar; resaltando aquellas en las que esa relación sea más evidente. En este orden de ideas, se destaca la investigación de Patricia del Pilar García Garavito, que plantea en su investigación " $L a$ Comunicación: mediadora en la resolución de conflictos escolares en la Institución Educativa Villamar" en la cual se plantean distintas estrategias comunicativas, que puedan ayudar a construir un puente para que los estudiantes puedan solucionar conflictos por medio de la comunicación, en esta se plantean cuatro ejes fundamentales: comunicación, conflicto y mediación, alfabetización digital e impacto de las Tics, que apuntan claramente a la utilización de comunicación para la cultura de convivencia y este aspecto puede ser relevante en la medida en la que se ponga en práctica correctamente (Garcia, 2015). Por otra parte, se destaca una investigación que trata de "La comunicación educativa en el aula: una alternativa para la 
enseñanza de las Teorías de la Comunicación" realizada por Laura González Morales, quien muestra la manera adecuada para enseñar comunicación desde el aula de clase, generando así un aporte en el aspecto de cómo poner lo educomunicativo en acción, se tiene en cuenta este estudio ya que muestra desde otra perspectiva el campo que se estudia a lo largo del texto. (González, 2001). Además se encontró una investigación acerca de "Educomunicación para la sostenibilidad ambiental" a pesar de que no está relacionada directamente con la cultura de convivencia, ésta centra el diálogo en la relación de lo educomunicativo con la transformación social y hace evidentes muchos aspectos a la hora de proceder desde este enfoque para la resolución de conflictos sea efectiva, no solo personales y sociales, sino también sus alcances en el campo ambiental (Mendoza, 2011). Por último, está la investigación de Clara Janneth Santos, una de las más recientes, en donde se describe la forma en la que se implementa la cultura de paz en la Universidad Autónoma Del Caribe y además se plantea un modelo educomunicativo integral que aporta a ese propósito (Santos, 2016); esta investigación es valiosa en la medida en la que presenta cómo se genera una cultura de paz dentro del espacio educativo y universitario, por medio del elemento educomunicativo específicamente se hace referencia a la creación de un curso no presencial de cultura de paz en el aula virtual; sin embargo, a pesar de ser la más relacionada con mi eje temático, tiene una perspectiva más instrumental de la educomunicación y en esta medida no profundiza en la educomunicación como mediadora en la construcción de cultura de paz.

Ahora bien todas las investigaciones planteadas anteriormente, presentan un espectro muy amplio frente a lo que es la violencia escolar, la cultura de convivencia y educomunicación; como también, aportan de manera evidente, al marco teórico y diseño metodológico, orientando desde sus aportaciones las iniciativas que se derivan respecto a la investigación que se está construyendo. Sin embargo, al indagar la existencia del diálogo entre educomunicación y cultura de convivencia, preliminarmente se evidencia que son pocas las investigaciones en las que los elementos acá mencionados convergen. Eso da cuenta de que el aporte propuesto en esta investigación es novedoso, con respecto a lo que en el ámbito educomunicativo se puede hacer para forjar una cultura de convivencia y por tanto aportar a la disminución de la violencia escolar. 


\section{Marco teórico}

En este capítulo, se desarrollarán teóricamente aquellas categorías que van a permitir la comprensión de la problemática que se quiere investigar en este proyecto. Este aporte de saberes entre distintos autores especializados en el tema, brindará una claridad mayor acerca del fenómeno que se estudiará y además orientará la práctica de la investigación.

La primera categoría que se tendrá en cuenta es: la educomunicación, que es el eje central y transversal de la investigación. Desde este eje se tendrán en cuenta autores que se han encargado de aportar a esta apuesta, como por ejemplo: Kaplún (2002), Ismar de Oliveira Soarez (2003), Huergo (2007), Parra (2000), Prieto (2005), Bustamante (2008), Crovi (2004), Garcia (2005), Prats (2005), Freire (1991). Por otra parte, se planteará teóricamente lo que es la educación alternativa con autores que han escrito acerca del tema como por ejemplo: Quijano (2014), Díaz (2010), Mena (2013), Salazar (2007) y Aguilar (1993). Los primeros dos autores desde una mirada decolonial y el último desde una visión que contrasta y marca la diferencia entre educación innovadora y educación alternativa. Lo anterior para dar cuenta de la razón de la escogencia del concepto de educación alternativa y evidenciar cómo a través de ese planteamiento, se puede entender la educomunicación dentro de la escuela. Por último, se esbozará teóricamente, desde el eje en el que se desarrollará la investigación, la cultura de convivencia con autores como Tuvillo (2001), Ortega (2007), Mockus (2003), Illera (2005) y Aguilar (2000). En este apartado también se busca comprender la manera en la que la cultura de convivencia aporta a la mitigación de la violencia escolar y para eso se aborda a grandes rasgos este tema con autores como Olweus (1998), Mora Merchán (2007), Palacios (1978).

\subsection{Educomunicación}

El término educomunicación emerge de la relación entre la comunicación y educación; o de las distintas denominaciones que se le dieron, como por ejemplo: comunicación para la, o en educación; educación para la comunicación, entre otras (Espuñes, 2015). Es decir, que la educomunicación surge para vincular dos grandes categorías en una sola, esta en realidad es un 
diálogo entre lo que la educación puede transformar y la manera en la que la comunicación puede facilitar este proceso.

Es importante aclarar que el termino de educomunicación ha generado muchos debates pues no es fácil concretar el origen y la evolución de un campo de estudios tan heterogéneo y plural, es por esto que ha sido abordada desde diferentes concepciones teóricas con varias líneas de desarrollo en su aplicación práctica (Coslado, 2012). Como lo dice el autor anterior, al ser un tema tan amplio y con tantas visicitudes, resulta muy complicado ubicarlo en una teória estática y única. Es por eso que teóricamente el termino de "educomunicación” continua en discusión, abriendo debates, aportando elementos valiosos a la práctica educativa y permitiendo que la comunicación y los artefactos que esta aporta, tengan una validez y un peso renovador dentro cada comunidad.

Teniendo en cuenta lo anterior la información que se presentará a continuación tiene que ver con aquellas apuestas que hacen los autores desde esta categoría, no se trata solamente de la exposición teórica acerca del tema, se busca principalmente evidenciar también una postura política que se hace evidente en las prácticas de la mediática y que se sustentará con los planteamientos de distintas fuentes.

Las aplicación práctica de la educomunicación en al aula de clases es positiva y sus alcances, hacen que se convierta en un campo que se necesita explorar. Entonces, lo que se presentará a continuación sera lo que distintos autores comprenden acerca de la educomunicación y su desarrollo práctico dentro de la escuela, Huergo (2007) expone el origen de la educomunicación en América Latina:

El campo de comunicación/educación nace como estratégico en el contexto del proyecto desarrollista de fines de los años 50 y comienzos de los 60. La hipótesis del Departamento de Estado de los EE.UU, del MIT y de la Universidad de Stanford es que una de las estrategias de pasaje de las sociedades tradicionales (latinoamericanas) a una sociedad modernizada es la difusión e incorporación de medios y tecnologías. Esta "tecnificación” incrementaría la calidad de la educación; una representación que se hizo hegemónica en América Latina (p. 37).

Sumado a lo que Huergo menciona, es importante resaltar que así como él lo expone, este nuevo campo no solo se origina por la necesidad de una mejora en la educación; sino por el contrario sigue las lógicas de desarrollo que tienen auge en esa época, añadiendo a esto el 
progreso que tenían en ese período los medios como nuevas tecnologías. "A partir de allí, no sólo las políticas sino el sentido común anudaron la incorporación de medios y tecnologías con calidad de la educación" (Huergo, 2007). Lo cierto es que muchas de las transformaciones educativas, sociales, políticas e incluso económicas, están mediadas por el pensamiento hegemónico propiamente eurocéntrico, respondiendo así a modelos de dominación implícito. En este caso la relación de la educación y comunicación responde a estas dinámicas; ya que se le otorga una funcionalidad puramente técnica, sin articular realmente la comunicación más allá de los medios.

Sin embargo, a pesar de que este fue el inicio de la relación entre la comunicación y educación inicial, cabe resaltar la influencia de otros autores que lograron fragmentar esta relación puramente desarrollista, centrándose a los contextos Latinoamericanos. Uno de estos pioneros fue Paulo Freire que "no solo elaboró un pensamiento fundacional de la pedagogía popular y de liberación latinoamericana, sino que es considerado como el representante de la ruptura del campo de la comunicación, hasta ese momento dominado por el estudio de los medios de comunicación" (Huergo, 2007). El logró que la comunicación no estuviera instrumentalizada por las distintas tecnologías, sino que encontró una verdadera relación entre estos dos campos.

Paulo Freire propone una comunicación dialógica, de donde se toman algunos principios para la educomunicación: la comunicación es educación, es diálogo, en la medida en que no es transferencia de saber, sino encuentro de sujetos interlocutores, que buscan la significación de los significados (Freire, 1991). Por lo tanto, la relación entre la comunicación - educación es una convergencia que permite el encuentro de individuos que se empeñan en una transformación y liberación, negando los comunicados y generando la comunicación, ya que esta comunicación nos permite emerger de la dominación; la opresión y trabajar por la liberación (Huergo, 2007). Por lo cual esta relación se trata de un acto de liberación en sí mismo.

Después de un largo debate entre la relevancia de estos términos de comunicación/ educación y gracias al aporte de distintos autores desde sus áreas de conocimiento el término de educomunicación se consolida en el año 2000, según Ismar De Oliveira Soares pionero de la educomunicación en Latinoamérica. Este autor menciona que se podría sostener la hipótesis de 
que un nuevo campo de conocimiento -la educomunicación- ya que este concepto se había formado, conquistado su autonomía y se encontraba en franco proceso de consolidación. Pasados ocho años, se podría aseverar por lo que ocurre en Brasil, que las prácticas educomunicativas, aunque inicialmente concebidas como alternativas ya empiezan a movilizar grandes estructuras, buscando convertirse en programas de políticas públicas (Soares, 2005).

De esta manera la educomunicación pasó de ser la relación entre dos categorías a ser una posibilidad aplicable a entornos reales como la escuela, desde una perspectiva diferente y liberadora. Se convierte ahora no solo en una alternativa diferente a la hora de educar, sino que ha alcanzado lugares de impacto como las políticas públicas, en donde se pueden empezar a transformar las prácticas de educación, desde otras esferas de poder. Es esta relación entre la comunicación-educación en la que la educomunicación se convierte en un acto netamente pedagógico en el cual "Solamente el diálogo, que implica el pensar crítico, es capaz de generarlo. Sin él no hay comunicación y sin ésta no hay verdadera educación" (Freire, 1970). La educomunicación trasciende lo teórico y converge en la práctica de manera constante. No es un conocimiento estático, ni reduccionista, es por el contrario, dinámico en la medida en la que posibilita nuevas relaciones, comprensiones y transformaciones en el espacio en el que se escuentra.

Teniendo en cuenta lo planteado anteriormente por Freire (1970), acerca de lo que posibilita la educomunicación dentro del aula de clase, encontramos a Prieto (2005) refiriendose a la educomunicación como un campo del conocimiento ya conformado, que plantea cómo el interaprendizaje se vuelve clave en el proceso educomunicativo y hace aportes que abren nuevas perspectivas al respecto. "La educación y comunicación están a la base de nuestra humanización. Es ése el alcance del término educomunicación. Aprendemos del otro y con el otro. Lo hacemos, entonces, en común unión, en com-unión” (Prieto, 2005). Este plantamiento situa a la educomunicación en una postura diferente a la instrumental y la pone en la linea que trabaja Freire, donde se ve la escuela como un espacio propicio para crear comunidad, término en el que profundiza Prieto (2005) "Supongamos la posible comunidad de un aula en la cual se comparten cuatro a cinco horas diarias. Treinta seres, por ejemplo. iCuánto para aprender de los demás! iCuánto para interactuar, para regocijarse con la palabra y la experiencia de todos!” (Prieto, 2005). 
Adicionalmente, Parra (2000) busca conformar epistemológicamente este término dentro del campo de las ciencias sociales y habla de la educomunicación como "la pedagogía que orienta y enseña cómo desarrollar aprendizajes significativos, y a la vez, cómo consumir productivamente los mensajes que nos vienen de los mass media y del intercambio de pensamientos que se producen en la convivencia social" (Parra, 2000). La mirada en este caso evoluciona y abre campo a otra manera de ver el poder transformador de la educomunicación, ya que habla de ésta como aquella que permite conformar un pensamiento crítico frente a lo que se consume, dando insumos para aprender a decodificar esos mensajes que en los medios moldean la realidad.

Una lectura crítica de mensajes presupone en los preceptores el manejo de intrumentos del conocimiento y el desarrollo de operaciones intelectuales. Con este instrumental conceptual se podrá acceder con libertad, creatividad y productividad a desentrañar las polifacéticas manifestaciones de la realidad social. Se podrá decodificar los sistemas linguísticos. Se podrá penetrar y analizar la sintaxis de los mensajes icónicos. Niños, niñas, adolecentes y jovenes estarán armados para enfrentar la tiranía o avasalladora seducción de los medios. (Parra, 2000, p. 147).

El recorrido anterior da cuenta del sendero de la educomunicación y muestra desde su origen, hasta su desarrollo, apoyado desde la visión de Huergo que en primera medida explica que este nuevo término nace de la relación entre dos términos que tienen una relación directa todo el tiempo, que son la comunicación y educación. Este autor plantea además, que esto sucede a inicios de los años 60 gracias al concepto de desarrollo que empieza a permear todas las prácticas del mundo, teniendo en cuenta el momento coyuntural en el que se encontraban las nuevas tecnologías, y para América Latina como consecuencia del poder hegemónico de los países pertenecientes al mundo "desarrollado", termina reproduciendo estos patrones de tecnificación igual calidad; para el caso de la comunicación y educación las nuevas tecnologías inmersas en el aula de clase significaban la mejora de la educación. Sin embargo, pensar de esta manera el inicio de la educomunicación limitaría su posibilidad de transformar las dinámicas educativas, pues únicamente cumpliría con una función utilitarista.

En vista de lo anterior es válido resaltar que los autores anteriores se encargan de resignificar este término, como también de hacer que la educación y comunicación cobre un sentido 
diferente. Por ejemplo, Freire y Prieto desde su apuesta por una educación liberadora buscan la manera de hacer que por medio de la comunicación se den procesos de reflexión y comprensión de la realidad desde el conocimiento del otro. Estas apuestas planteadas pensandas en el aula como un escenario perfecto para poder llegar a un verdadero cambio es pertinente, pues esa relación entre la comunicación y educación antes concebida de una manera utilitarista se transforma y abre campo a otros tipos de práctica, el cual es más importante para un proceso de cambio dentro de la escuela es el mismo estudiante. Creo que ninguna de las teorías entra a chocar con la otra, sino que por el contrario permiten la comprensión de esta area del conocimiento que continua en contrucción.

Ahora bien, Ismar de Oliveira uno de los pioneros en la educomunicación, llega a la misma conclusión que Huergo, ya que los dos rescatan que, ésta nace de la relación entre dos campos inmensos la educación / comunicación. La apuesta de Oliveira es más actual y se proyecta a grandes rasgos en campos de más impacto, como políticas públicas relacionadas con esta nueva rama del conocimiento, el cual considera a la educomunicación como necesaria en los procesos educativos, teniéndolo en cuenta como potenciadora de otros elementos que se verán a continuación. En este campo entra Parra que apoya y aporta dando los insumos epistemológicos de la educomunicación, valiosos para comprender esta como un todo dentro de la escuela y su importancia a la hora de pensar en una verdader comunidad educativa.

\subsubsection{Educomunicación y medios}

Partiendo de la premisa anterior, acerca de la educomunicación como campo que está orientado a "relacionar la escuela con los procesos de la comunicación, a enseñar la naturaleza de los medios, a recontruirlos en funcion de los mensajes, a leerlos en sus lecturas profundas, en sus "entre lineas", a develar los senntidos realles, a decodificar certeramente sus mensajes que vienen, como sabemos, almibarados en gráficos, colores y formas, para depositarse especianmente en las mentes menos prevenidas" (Villarruel, 2011). No se puede olvidar el desafío que ésta enfrenta, en la medida en la que asume el reto de aparecer en la escuela como mediadora en el proceso de aprendizaje, pero además busca principalmente incentivar procesos críticos frente a los consumos mediáticos de los estudiantes. Es por esto que la escuela no puede desconocer que la realidad hoy en día esta mediada por los distintos dispositivos informativos, 
tecnológicos y comunicacionales, como lo dice Kaplún es necesaria una modernización educativa, "La educación necesita actualizarse, adoptar las nuevas tecnologías, valerse de los modernos medios de comunicación: la radio, la televisión, el video, incluso tal vez las computadoras" Kaplun (2002, P. 16) Desde esta perspectiva, plantea lo relevante que se hace en este momento tener en cuenta las nuevas tecnologías inmersas en el aula, como un recurso necesario.

Este postulado no busca darle todo el protagonismo a los medios en la escuela, ya que "no es sino una consecuencia de esa visualización instrumentalista y reductora” (Kaplún, 2002) por el contrario, se trata de una apuesta dialógica en la cual se tenga en cuenta un verdadero proceso comunicativo donde dos o más seres humanos intercambian y comparten experiencias, conocimientos, sentimientos aunque sea a distancia a través de medios artificiales (Kaplún, 2002). Entonces la educomunicación se refiere claramente a la manera en la que se da ese proceso comunicativo, sin importar el medio por el que se dé. Como Kaplún (2002) lo plantea “educarse es involucrarse en un proceso de múltiples interacciones comunicativas, un sistema será más educativo en la medida en la que sea más rica la trama de flujos de comunicación que sepa abrir y poner a disposición de los educandos". Así la educomunicación desde esta perspectiva plantea la separación de distintos esquemas de dominación y en la práctica empodera a los sujetos para que sean ellos los que construyan cambios por medio de lo que se comunica y cómo se comunica.

Ismar de Oliveira Soares, uno de los pioneros en trabajar para que educomunicación se convirtiera en una rama del conocimiento con impacto en lo educativo y social, plantea que ésta tiene como objetivo la "planificación, creación y desarrollo de ecosistemas comunicativos mediados por el uso de las tecnologías de la información y de los procesos de comunicación" (Soares, 2003). Es decir, que ésta apuesta teórica tiene una orientación hacia la utilización de los medios, no solo como una tecnología, sino las que tiene en cuenta como potenciadoras de otro proceso más grande y es el comunicativo. Soares (2003):

"busca también facilitar la producción y difusión de la información, promueve la interactividad en los procesos de enseñanza-aprendizaje y ofrece los referentes teóricos y 
metodológicos necesarios para el análisis de la producción cultural efecto de una adecuada formación en la relación con el sistema masivo de medios de información.” (p. 138)

Ahora bien cuando se habla de medios, se hace referencia no solo a lo televisivo, escrito y radial, sino que también se hace referencia a lo digital, es decir, la web 2.0 una evolución de la internet donde los usuarios pueden a través del uso de aplicaciones expresarse, generar colaboraciones y servicios originales, compartiendo e interactuando con otros, por eso se ha convertido un lugar donde se establecen redes sociales (Crovi, 2004). El uso de estas dentro de procesos educativos responde a la necesidad de nuevos espacios de aprendizaje, donde se pueda transformar desde distintos puntos la sociedad. Estas nuevas formas de relaciones en las redes, pueden llegar a facilitar el aprendizaje educativo social y como lo dice Crovi (2004) "Se trata de crear una situación educativa en la cual el alumno desarrolle su pensamiento crítico, a través de mecanismos de autoaprendizaje y trabajo en equipo, auxiliado por tecnologías y orientado por su maestro, guía y tutor del proceso" Son esas nuevas redes de interacción, las que permiten otros tipos de aprendizajes, más independientes del contenido y colectivas entre pares.

Los nuevos conocimientos que se encuentran en los distintos medios, ya sean digitales, informáticos o de comunicación, dan paso a la creación de conocimiento, nuevos tipos de lenguajes y otras interacciones. Estos dentro de la escuela no se deben ignorar, por el contrario es de aprovechar (Crovi, 2004). La educomunicación supone la utilización de estas herramientas en el sistema escolar, para que desde éste se de paso a procesos comunicativos y participativos, que conlleven a la crítica de la realidad, desde distintas ópticas, teniendo en cuenta el mundo en el que nos encontramos

Por último, para lograr terminar de vincular la relación de la educomunicación con los medios, se hace necesario hablar de las redes virtuales en las que se está inmerso hoy en día, para la comprensión de este aspecto Crovi logra dar cuenta de esto proceso. Él plantea lo necesario que se hace en estos tiempos, en los cuales las tecnologías están inmersas en todas las prácticas, el uso de las mismas dentro del aula "a través de la mediación de los medios y las nuevas tecnologías, los saberes que circulan en la escuela entran en diálogo con los saberes de la vida cotidiana" (Valderrama, 2007). Pues son estas nuevas redes de interaccion cotidianas en las que se pueden llegar a comprender de mejor manera las nuevas realidades y relaciones sociales que se tejen dentro de estas redes. Al mismo tiempo facilitan la creación de nuevos conocimientos y 
la retroalimentación de los mismos, haciendo que el trabajo en equipo y la creación de nuevos contenidos se haga realidad en estos tiempos. Este punto de vista por parte de Crovi se hace sumamente relevante, pues logra exponer la manera en la que la utilización de los medios crea la posibilidad de nuevos tipos de interacciones, que a su vez aportan de maneras distintas a las sociedades y cómo estas se configuran en la cultura.

Los tres puntos de vista por parte de los autores anteriormente mencionados, permiten aclarar la forma en la que los nuevos medios tecnológicos y de comunicación forman parte de cualquier proceso educativo y dejan entre ver la forma de aprovechar estos recursos en el aula. Las visiones de estos teóricos son claras en la medida en la que en sus intervenciones, se puede entender el porqué del uso de las nuevas tecnologías y medios deben estar en constante diálogo.

\subsubsection{Educomunicación para la participación y ciudadanía}

Los alcances de la educomunicación no solo se limitan a sus efectos inminentes dentro del aula de clase, esta también tiene un efecto directo en la manera en la que cada estudiante involucrado en este ecosistema concibe la ciudadanía y su participación dentro de ella, se trata de un ejercicio en doble vía, donde los mensajes que cada sujeto recibe, son confrontados desde una perspectiva crítica, transformados en cada contexto cotidiano a través de la argumentación y acción, ese es alcance y el fin mismo de la educomunicación, al no ser un saber más, se convierte en un elemento clave para aportar a la formación ciudadana.

Es en ese punto en el que las nuevas tecnologías se convierten en canales que ayudan a potenciar la retroalimentación, participación y cierto tipo de interacción entre los agentes para compartir y construir conocimiento. Por lo tanto no constituyen la esencia del proceso educomunicativo. Por esa razón para Bustamante (2008) la educomunicación es una vía para construir procesos simbólicos que conducen a la consolidación de formas culturales auténticas y libres donde hay mayor espacio para la participación, la interacción y la construcción simbólica de nuestros pueblos y nuestra gente. He aquí el surgimiento de nuevas comunidades, físicas, virtuales pero reales. Comunidades comunicativas, desde una positura ético - política.

Estos procesos educomunicativos permiten una nueva manera de construir ciudadanía de una forma menos sesgada por la indiferencia y vías auténticas que permitan la verdadera 
participación por medio de distintos canales. Se trata de nuevas comunidades que se construyen a sí mismas por medio de otros espacios, como los denomina Bustamante comunidades comunicativas, en donde los medios son una manera de comprender la realidad desde otras perspectivas. En este orden de ideas la educomunicación es más que una estrategia y se convierte en un paradigma, es decir, un estilo de ver, percibir y sentir (Bustamante, 2008).

Por otra parte, Joan Ferrés i Prats (2005) expresa la manera en la que por medio de la interactividad tecnológica se promociona la participación, son esas nuevas herramientas interactivas las que facilitan el empoderamiento que se pretende con la educomunicación. Estos nuevos códigos de lenguaje, permiten que cada sujeto inmerso en alguna red de comunicación tenga la oportunidad de hacer que estas realidades virtuales se conviertan en espacios que se pongan al servicio del orden social, político y cultural. Ya que desde lo que el postula se crean posibles movilizaciones sociales que evidentemente se traducen en la transformación del entorno de la persona involucrada. (Prats, 2005).

Cuando se habla de educomunicación y participación ciudadana Bustamante y Prats, encuentran la manera de exponer cómo se construyen nuevos lenguajes por medio de las nuevas formas de comunicación. Bustamante se centra específicamente en que los medios tecnológicos y de comunicación están construyendo procesos de participación ciudadana desde la visibilización y reconocimiento de distintas realidades. De hecho, desde la perspectiva de Bustamante se puede entender también la educomunicación y el uso de los medios como una forma de encuentro multicultural, en donde se establecen vínculos simbólicos de nuevas comunidades comunicativas. Por otra parte lo que Prats plantea es una nueva forma de participación en la cual se construye de manera palpable ciudadanía, entendiendo las nuevas redes que nos conciernen en la época actual. Buscando no excluir estos nuevos lenguajes y herramientas del proceso educativo, sino teniéndolas en cuenta como otra manera de comunicar y construir ciudadanía. Estos dos autores encuentran la manera de hacer que sus teorías dialoguen en la medida en la que se complementan y aportan desde distintos saberes, en suma, Bustamante desde la participación y la aparición de nuevas comunidades comunicativas y Prats desde las nuevas redes sociales que se construyen, en razón a estos medios.

En conclusión estan emergiendo otras formas de pensamiento y ciudadanía, que hablan de la realidad de una manera más amplia, por esto no se deben desvincular de los procesos 
educomunicativos de los cotidianos. Se trata de la comprensión de otros espacios, otros tiempos y por tanto otros medios para cumplir objetivos de transformación social y educativa, en donde se encuentre la manera de hacer que estas dialoguen con los contextos cercanos. "Pensar en la educación del ciudadano significa también pensar en el desarrollo de competencias comunicativas acordes con el entorno comunicativo e infocomunicacional de la sociedad contemporánea" (Valderrama, 2007, p. 189). Es por esto que la educomunicación no se trata únicamente de la integración de los medios en la escuela, sus alcances y su propósito principal esta ligado a la formación de sujeto politicos que aportan a la construcción de ciudadania a través de dichos medios y canales, esta es intencional pues su preocupación fundamental es potenciar la creatividad en los procesos de aprendizaje, valiéndose principalmente del

desarrollo de la lectura crítica de mensajes (...) de esta forma se podran desentrañar las polifacéticas manifestaciones de la realidad social. Los jovenes estarán armados para enfrentar la tiranía o avasalladora seducción de los medios (Parra, 2000). Se trata entonces de la formación de ciudadanos preocupados y comprometidos con su realidad social.

\subsection{Educación alternativa}

La educación se ha transformado con el paso del tiempo, teniendo en cuenta que el modelo tradicional de educación no convierte a la educación en una práctica propiamente liberadora o novedosa. Por esa razón se da un giro a la manera en la que se ve la educación y se empieza a hablar a mediados del siglo XX de una pedagogía liberadora, emancipadora y transformadora. Sin embargo, para hablar de transformación es necesario dar una mirada a la historia de la educación. Por lo tanto, se hace a continuación un breve recorrido por lo que se concibe como escuela tradicional, para luego abordar lo que se considera educación alternativa.

"La pedagogía tradicional comienza a gestarse en el siglo XVIII con el surgimiento de la escuela como institución y alcanza su apogeo con el advenimiento de la pedagogía como ciencia en el siglo XIX" (Cavazos, 2013). Este inicio de la pedagogía tradicional y la escuela en general, se debe al avance de las sociedades en busca de un sistema homogeneizador de las sociedades, un ejemplo de esto son las escuelas prusianas que nacen como la primera opción de 
educación pública y obligatoria. La vía prusiana, es la respuesta a un modelo autoritario de poder político, que se desenvolvió a través de todo el siglo XVIII, dando lugar al sistema de educación estatal obligatoria más acabado (Cuesta, 2009). Este modelo militar se introduce y es pionero en esquemas educacionales que se siguen reproduciendo hasta el día de hoy, con elementos característicos como por ejemplo: el uso de uniforme, la organización del aula de clase y el modelo de autoritarismo por parte de los docentes a los estudiantes, entre otros elementos.

Los países Latinoamericanos con tradición reproductora de distintos modelos educativos extranjeros, se vuelven herederos de lo que es llamado educación tradicional, apoyados por la iglesia y el Estado. Esta relación de dependencia como lo menciona Quijano se debe básicamente a "las sociedades nacionales latinoamericanas son constitutivamente dependientes y, en consecuencia, su legalidad histórica es dependiente; o, en otras palabras, la racionalidad de sus procesos históricos de cambio no puede ser establecida al margen de la dependencia" (Quijano, 2014). Es decir, esta relación de dominación a pesar de haber superado la época de la colonia, queda inmersa en las prácticas culturales e incluso intelectuales de los países latinoamericanos, incluyendo así a la educación dentro de estas dinámicas.

Colombia específicamente, “fue uno de los países más atrasados del mundo en materia Educativa, respecto a los otros países Latinoamericanos” (Salazar \& Ramírez, 2007). Esto básicamente por la dificultad de que el sistema de educación se expandiera, fundamentalmente, como resultado de factores económicos y sociales característicos de una nación inmersa en el conflicto. Sin embargo, en Colombia se han ejecutado algunos avances en educación que nacen de la inconformidad con el modelo autoritario de la educación tradicional que se caracteriza según Mena (2013) por:

La autoridad incuestionable como característica definitoria del rol del maestro, el dogmatismo como manifestación de la autoridad en el terreno pedagógico, la disciplina como uno de los pilares del funcionamiento de la institución educativa, y como instrumento para garantizar la forma de homogeneizar y normalizar, el cuerpo como el principal objeto de control, la definición estricta de espacios, tiempos y funciones (p. 344) 
Lo antes mencionado deja ver la manera en la que los fines educativos han estado ligados a intereses aún mayores, un ejemplo de esto son las escuelas prusianas, que respondían a las utilidades de los Estados del momento. La relación de dominación ejecutada por parte del docente al estudiante hace claro que los modelos militares y de autoritarismo estaban presentes en la escuela tradicional como lo plantea (Cuesta, 2009) en su caracterización de la misma. La reproducción de estos modelos traídos de otros lugares del mundo aparentemente más avanzados generan una ola de escuelas tradicionales en Latinoamérica y como Quijano (2014) lo menciona, es evidente que la dominación superó las épocas de la colonia y se reproduce en distintos campos, en este caso dentro de la misma escuela. Mena (2013) también logra evidenciar las prácticas dentro de las escuelas de este corte y por ello se comprende la necesidad de hablar de tipos de educación alternativos, que se salen de estas dinámicas. Es por esto que se necesita una transformación educativa, en donde los esquemas tradicionales, le abran un espacio a nuevas apuestas pedagógicas. Este primer recorrido, se realiza con el fin de reeinvindicar la necesidad de nuevos elementos en la educación.

\subsubsection{Educación como práctica emancipadora}

Se hace urgente hablar de una transformación en la educación, donde el centro sea el estudiante y el diálogo construya conocimiento a través de la práctica de compartir con el otro (Freire, 1991); donde el educador no se convierta en un general que se limita a dar instrucciones, sino que por el contrario provoca deseo por aprender. La escuela debe ser el lugar en el que los individuos edifiquen su ciudadanía y pongan en práctica su libertad.

Paulo Freire es uno de los autores y pedagogos que hizo una fuerte crítica respecto a los modelos autoritarios de educación. En los años 60 aproximadamente plantea el concepto de una educación liberadora, que suponía la ruptura de lo que se entendía como educación opresora. Definida como la Pedagogía de la Respuesta (educación bancaria), donde la adaptación es la manera más sencilla de afrontar el ámbito educativo; no existían los riesgos, el asombro, las preguntas y el profesor autoritario teme más a las respuestas que a las preguntas. Él por el contrario propone la educación liberadora que se nutre de la pregunta, como un desafío 
constante a la creatividad y al riesgo del descubrimiento. La educación liberadora es, por lo tanto, la Pedagogía de la Pregunta (Guerrero, 1990).

Ahora bien, para hablar de una educación emancipadora, es necesario reconocer que en las prácticas educativas, la mentalidad colonizadora permeó fuertemente la escuela, por que como se exponía anteriormente, el origen de la escuela pública se da desde un pensamiento desarrollista y netamente eurocéntrico; por lo anterior es ineludible reconocer la necesidad de desligar dentro de las prácticas educativas el modelo colonial, para esto se debe aclarar lo que menciona Quijano (2014) es necesaria una pedagogía en clave decolonial que se convierta en un esfuerzo sostenido para dejar de reproducir modelos de pensamiento hegemónicos, en la perspectiva de una reflexión crítica en torno a lo educativo y a sus conceptos asociados (Díaz, 2010).

Una pedagogía en clave decolonial, es concebida como una transformación social dentro y desde la escuela, donde la apertura constante a la generación de nuevas prácticas educativas forme a los estudiantes en la conciencia histórica que permean los escenarios de la escuela actual, creando espacios donde la mirada crítica se constituya en ángulo epistémico capaz de producir nuevos significados sobre sí y la realidad constituida (Díaz, 2010). Después de todo, la educación es una práctica con la que el ser humano debe tener la oportunidad de observar el mundo a través de un lente crítico e histórico desde el principio de la historia y desafiar estos modelos, por medio de la creación de nuevos conocimientos que nacen desde y para el otro. Teniendo en cuenta la ruptura de un modelo tradicional y avanzando hacía otra manera de ver la educación desde una óptica alternativa.

La educación alternativa no supone un cambio superficial desde la estructura de educación actualmente concebida. Por el contrario, las alternativas pedagógicas son todas aquellas experiencias educativas que se diferencian de y se oponen a la práctica pedagógica tradicional, pero que acogen los procesos de innovación educativa, ya que no pretenden el mejoramiento del sistema educativo por la vía de la modernización, sino que buscan contribuir al logro de una nueva hegemonía política y cultural para las clases subalternas (Aguilar, 1993). Por consiguiente, se puede comprender que el hecho de considerar una educación o pedagogía alternativa, responde a la necesidad de reconocer el problema educativo desde la raíz, buscando 
una transformación no solo en lo institucional, sino por el contrario, apostando desde lo cultural.

Las alternativas pedagógicas buscan desligarse de algunas de las lógicas de educación tradicional, en las cuales el maestro es el centro y se encarga de introducir conocimiento en los estudiantes por medio de la autoridad. Los postulados de la educación alternativa están orientados a una reforma en la práctica educativa, ya que propone un proceso de aprendizaje dialógico como lo llamaba Freire, en el cual el conocimiento proviene de las experiencias del entorno mismo de los estudiantes y el salón de clases sea un espacio de encuentro de saberes. La finalidad de esta clase de educación debe ser el aumento de las capacidades para adaptarse al cambio continuo, que permita profundizar en la individualización del proceso formativo, adquiriendo capacidades que le permitan de manera fluida y variable el manejo de sus conocimientos en la sociedad (Aguilar, 1998).

Por otra parte, pensando la educación como una posibilidad de emancipación de los individuos, se encuentran los aportes de Díaz (2010) y Quijano (2014) que hablan desde la descolonialización de la educación. En primera instancia Díaz rescata lo que se concibe como pedagogía en clave de-colonial, donde su principal apuesta es por medio del conocimiento histórico y reflexivo, para la creación de nuevas críticas educativas y a la vez constructivas. Para Díaz la educación es la oportunidad perfecta para salir de la minoría de edad en términos Kantianos, generar nuevo conocimiento y transformar la sociedad, a través de la cotidianidad. Por otra parte, Quijano habla de lo necesario que es desligarse de los modelos tradicionales y propiamente hegemónicos, creando oportunidades para otra clase de educación. Desde estas dos perspectivas enfocadas en la des-colonización de la educación se encuentra una convergencia bastante pertinente con lo que se espera de esta investigación, es rescatar esos procesos que se salen de las lógicas convencionales y dan paso a las alternativas que son aquellas que agitan el mar de las certezas y generan incertidumbres, allí donde la tradición anclaba sus principios (Aguilar, 1998).

Por último, el aporte de Aguilar hace refencia a la manera en la que la educación alternativa entra a mediar en los procesos educativos y los transforma oponiéndose por completo a 
las dinámicas tradicionales, se trata de una manera de resignificar la educación desde el inicio, es decir, no se trata de intentar cambiar la educación desde una sola iniciativa o innovación, en realidad estas alternativas lo que buscan es hacer que toda la educación desde su concepción se renueve, que las bases sean diferentes y que el fundamento real de estas nuevas alternativas sea la transformación. Esta perspectiva desde lo alternativo es necesaria en esta investigación ya que desde ésta se entran a analizar elementos de la misma y facilitan la comprensión de dinámicas diferenciadoras de las otras experiencias educativas.

El recorrido con distintos autores permite evidenciar la forma en la que la educación se debe considerar como una práctica emancipadora, que da cuenta de cómo las nuevas experiencias de educación alternativa, abren un espacio para que estas generen una transformación desde la base. La educación alternativa en general es la manera en la que se busca cambiar la forma tradicional de ver la educación, se trata de resignificar la educación.

\subsection{Cultura de convivencia.}

Comprender lo que significa convivencia puede dar luces acerca de lo que se espera de una cultura en esta vía. Como lo menciona Illera (2005) Convivencia, etimológicamente, proviene de conviviré, que significa 'vivir en compañía de otros, cohabitar'. Relacionarse y compartir con el otro.

El concepto de convivencia da cuenta de un fenómeno propio aunque no exclusivo de lo humano, el cual es el convivir, el vivir con. La existencia humana se lleva a cabo inevitable e inexorablemente en un contexto de convivencia. Entonces la cultura de convivencia se hace cada vez más fácil de comprender ya que pretende en gran medida es en primera instancia, generar una red de relaciones en donde se pueda vivir con el otro. (Condori, 2014)

La cultura de convivencia en general no solo hace referencia a aquella educación para vivir con el otro; también busca formar ciudadanos realmente interesados en su sociedad y en el otro. Es por esto que las instituciones de educación procuran hacer énfasis en la convivencia dentro de la escuela, ya que es desde ésta, que cada sujeto aprende a relacionarse con el otro y son estos patrones de convivencia los que marcan pautas en el relacionamiento futuro de cada uno. Estas 
pautas de convivencia deben estar articuladas desde el salón de clases con actividades y distintos encuentros que permitan al "estudiante tomar conciencia sobre la necesidad de construir un sistema de relaciones personales más justo y democrático" (Ortega, 2000). Es decir que la convivencia surge desde la reflexión del estudiante frente a sus pares, es en esa introspección que el estudiante puede comprender que relacionarse con el otro requiere de ciertos acuerdos equitativos de respeto y tolerancia.

Según Ortega (2000) la convivencia tiene que ver con "ceñirse a unas pautas de conducta que permiten la libertad individual al tiempo que salvaguardan el respeto y la aceptación de los otros" (p. 177). Es decir que la convivencia es comprender que dentro de cualquier ámbito social, existen unos mínimos de respeto hacia los otros que se deben respetar, para que de esta manera la práctica de la convivencia sea efectiva. Ahora bien, la convivencia escolar supone el respeto de distintas normas establecidas socialmente, que procuran el desenvolvimiento de la actividad educativa en un ambiente de armonía (Ortega, 2000).

Es válido aclarar que la convivencia escolar a pesar de buscar un ambiente de cordialidad no ignora los problemas de violencia y tampoco pretende acabarlos, ya que su tarea principal es lograr "relaciones interpersonales y grupales satisfactorias que contribuyan a un clima de confianza, respeto y apoyo mutuo en la institución escolar, potenciando así mismo el funcionamiento democrático de la escuela, lo que, a su vez, favorecerá también la existencia de relaciones positivas entre los miembros de la comunidad escolar" (Ortega, 2000). Es decir que en la medida en la que se fortalece un ambiente en la escuela favorable y de apoyo entre pares, la resolución de conflictos se dará de manera más natural y los problemas de violencia escolar disminuirán evidentemente.

Añadiendo a lo anterior, es relevante aclarar que no se debe solo coexistir y negar el conflicto que está impregnado en toda comunidad, sino que se trata de ser partícipe y reconocer que los que comparten en este medio deben intentar cooperar con un sistema de convenciones y normas que den orden y permitan que la vida en comunidad sea lo mejor posible. Por tanto, se hace necesario que cada cual controle sus propios intereses y comprenda los intereses de los demás (Ortega, 2000). Comprender la convivencia dentro del ambito escolar es entender un esquema 
de relaciones que requieren de sujetos que se deben adaptar a ciertos contextos y dentro de estos hacer lo posible por convivir o coexistir en paz (Illera, 2005). Se trata de un orden social que le da sentido a las relaciones sociales enmarcadas en la cordialidad y el buen trato.

Las reflexiones que realizan Ortega e Illera frente a la manera en la que se concibe la convivencia escolar es bastante amplia, ya que no la plantean como un término estático, sino que la posiciona como una estructura de organización social, en donde las distintas dinámicas sociales se desenvuelven teniendo en cuenta otros actores diferentes, con una visión incluyente y creadora. Se trata de una contrucción de ciudadania en espacios más pequeños, que va a afectar de manera positiva el resto de prácticas del sujeto dentro de otros macro contextos.

De hecho, entender la convivencia como una fortalecedora de organización social resulta bastante esperanzador teniendo en cuenta los conflictos que como nación atravesamos, la meta de esta investigación es poder demostrar que la convivencia es posible y se puede potenciar de distintas maneras usando las herramientas que tenemos a la mano y creyendo en la educación como potenciadora de transformación social. Se trata de una apuesta no solo por la paz en los centros educativos, se trata de una construcción de ciudadanía desde micro contextos como la escuela y que tenga impacto en otros ambientes.

\subsubsection{Importancia de la cultura dentro de la escuela}

Pensar en la convivencia y formas de fomentarla dentro de la escuela requiere de la comprensión de la cultura dentro de la misma, ya que ésta señala las interacciones y expresiones propias de los sujetos en sus distintas vivencias, códigos, relatos, discursos; como también sus posiciones, valores y formas de actuar (Aguilar \& Betancourt, 2000). Es decir que todos estos aspectos aprendidos por el entorno y la construcción de estos ideales terminan constituyendo una cultura que se pone a prueba en escenarios como la escuela. Por lo tanto, pensar en la escuela y en la convivencia por separado resulta imposible y menos sin mencionar el puente que construye la cultura en esta operación, pues es el lugar en el que se facilitan procesos de socialización. 
Reflexionar acerca de la carga cultural de cada estudiante dentro de un sistema rígido en su mayoría, evidencia la forma en la que los dispositivos pedagógicos de selección social, privilegian a los portadores de códigos elaborados y ponen en una situación de desventaja a aquellos de códigos restringidos (Aguilar \& Betancourt, 2000). La escuela vista como aquella que permite el desarrollo de una cultura de convivencia se convierte en el lugar preciso para que se de la contrucción de esos codigos personales o grupales, en ese sentido en algunas ocasiones entran en disputa pues es un proceso de mediación e intercambio.

Es por esto que definir la cultura escolar es el primer paso para poder consolidar una cultura de convivencia que aporte a la disminución de problemáticas escolares de violencia. Referente a la cultura escolar Gómez (1995) la define como el conjunto de significados y comportamientos que genera la escuela como institución social. Las tradiciones, costumbres, rutinas e inercias que la escuela estimula y se esfuerza en conservar y reproducir, las que claramente condicionan el tipo de vida que en ella se desarrolla y refuerza la vigencia de valores, creencias y expectativas ligadas a la vida social de los grupos que constituyen la institución social. Identificar este aspecto permite re definir propias formas de ser y de hacer, en sus símbolos y rituales, en sus normas y valores, en los roles y funciones, en la estructura y relaciones de poder; como también en sus códigos de comunicación (Aguilar \& Betancour, 2000). Cuando estos aspectos se tienen en cuenta, es posible que se regulen aquellos comportamientos que se desean en los estudiantes desde su individualidad y a partir de este momento se empieza un proceso real a favor de una cultura de convivencia.

Entender la manera en la que se construye la cultura dentro de la escuela requiere de la comprensión de distintos elementos que rondan los pasillos, patios, salones de clases; uno de esos es la comunicación, la manera en la que se comunica y con qué objetivo. Pensar en los códigos de comunicación abre un espacio para intuir de qué manera se gestiona la convivencia o el conflicto. Así como Rocha (2000) lo expone a continuación:

La escuela tiene ante sí varios retos, pero el principal de ellos es aprender a gestionar de manera pedagógica los conflictos. Hablamos de generar comunicación entre los docentes, entre los estudiantes y entre los docentes y los padres. Muchas de estas relaciones poseen un carácter administrativo - disciplinario. Es lo que podríamos llamar la comunicación del conducto regular, es una comunicación normalizada y por tanto es una comunicación que produce múltiples conflictos. De hecho, buena parte de los conflictos se gestionan de esta manera, 
dependiendo de lo que diga el manual de convivencia o de lo que esté institucionalmente concebido (Rocha, 2000).

Lo expuesto por Rocha (2000) nos habla del principal reto de la escuela y es la comunicación dentro del sistema educativo y la forma en la que puede aportar a la gestión de conflictos. Lo anterior, depende en gran medida de los espacios simbólicos de comunicación que se lleven a cabo dentro de la escuela, como por ejemplo el manual de convivencia, que hace parte del conducto regular, pero que en realidad no termina de solucionar todos los retos que afronta la construcción de convivencia. Entonces se trata de crear puntos de encuentro y estrategias para que la gestión de conflictos se construya basada en códigos comunes por parte de los estudiantes y directivos. Es en este punto en el que entra la importancia de la comunicación dentro de la escuela, pues es a través del diálogo, del compartir, del convivir y cohabitar con el otro; en el que se trasforman las dinámicas conflictivas.

\subsubsection{Contrucción de cultura de convivencia, un camino hacia la mitigación de la violencia escolar}

Ahora bien, para terminar de comprender la manera en la que actúa la convivencia dentro de la escuela, es importante entender la contra parte de esta y es la violencia escolar, ya que desde esta perspectiva se entenderá de una forma más profunda la importancia de espacios que fortalezcan la construcción de ambientes enmarcados en el respeto por el otro. Abordar a grandes rasgos y hacer la tarea de comprender las manifestaciones, causas y posibles soluciones se hace relevante para de esta forma tener clara una forma de actuación frente a esta problemática social y educacional.

Nuestra historia como país está atravesada por el conflicto y la violencia en general que está impregnada en casi todas las instituciones e incluso prácticas sociales en las que cualquier individuo se desenvuelve en la cotidianidad. La normalización de la violencia en general se evidencia en nuestra sociedad en los modelos de desarrollo neoliberales, que aportan a la competencia, individualismo y consumo desmedido. La violencia escolar está en aumento, como se planteaba en la problemática de esta investigación. Lo preocupante de estas prácticas de violencia escolar es que su normalización ha generado relaciones caracterizadas por la crueldad y el atropello, entre iguales. De hecho la violencia escolar ha estado en la escuela 
durante mucho tiempo, debido a la normalización de prácticas violentas en el relacionamiento con el otro. "Estos fenómenos de violencia deben ser interpretados como el resultado de la participación en procesos interpersonales que incluyen distintos grados de la misma violencia estructural de la sociedad y se hacen presentes en las actitudes y actividades que se desarrollan dentro del aula" (Ortega \& Mora-Merchán, 2007).

Es decir que, así como plantean estos autores, la violencia escolar es simplemente la reproducción de patrones violentos que cada individuo ha tenido que interiorizar a lo largo de la vida y se desencadenan en los contextos próximos a estos, como por ejemplo la escuela y el salón de clases. Es en estos micro- contextos que son cercanos a cada individuo donde se da cuenta de aquellos macro-sistemas que permean la cotidianidad de cada sujeto y aquellos sistemas de valores que conforman una sociedad.

Es muy importante entender también la forma en la que de manera inconsciente los mensajes estructurales de violencia se encuentran en los medios de comunicación y tecnológicos, generando de esta manera diversas formas de actuaciones que responden a estas utilidades. Por lo tanto es relevante abordar estas perspectivas y comprender que la tarea de la educomunicación es construir un puente con otras maneras de concebir la relación con el otro y llevar a cabo por medio de las herramientas que ésta facilita, y otras maneras de consolidar las relaciones dentro del ámbito escolar. Cuervo (2003) caracteriza de manera específica lo que sucede en estos ambientes educativos:

Generalmente la violencia escolar, se ejerce mediante amenazas de violencia, asignación de apodos o sobrenombres, exigencia de dinero o de bienes materiales, utilización de lenguaje sexualmente ofensivo, ridiculización y humillación, forman parte del acoso psicológico. Este tipo de acoso se manifiesta también a través de exclusión y aislamiento en las actividades escolares como trabajo en grupo, actividades recreativas y/o deportivas o, por ejemplo, no invitándolo a las fiestas que se organizan. También forman parte del acoso psicológico la expansión de rumores tendientes a generar malestar a los estudiantes acosados (p. 23) 
Es decir, la violencia escolar, como se ha planteado, trae consigo distintas clases de manifestaciones, unas más evidentes, como también otras que pueden llegar a ser normalizadas, pero de igual manera son relevantes para poder comprender la extensión de este fenómeno. Tal como lo exponen Palomero \& Fernández (2001) se puede entender como violencia escolar todo acto o conducta de persecución y agresión física, psicológica o moral que realiza a un alumno o grupo de alumnos sobre otro, con desequilibrio de poder y de manera reiterada.

Entonces la violencia escolar, es cualquier forma de represión no solo dentro de lo físico, sino también lo simbólico, es decir se manifiesta de distintas maneras en lo material y psicológico (por parte de cualquier miembro de la institución educativa, ya sea el y la docente, cualquier estudiante o la misma institución). Por lo tanto es válido aclarar que el tipo de violencia escolar se presenta de distintas formas dependiendo de los grupos de agredidos o agresores y el contexto en el que se encuentran. La violencia dentro de la escuela también está caracterizada como bullying que hace referencia a un comportamiento repetitivo de hostigamiento e intimidación, cuyas consecuencias suelen ser el aislamiento y la exclusión social de la víctima (Sarmiento, 2005).

Uno de los pioneros en estudiar este término e investigador de la violencia escolar, menciona que el bullying se refiere a un alumno que está siendo maltratado o victimizado, siendo expuesto repetidamente y a lo largo del tiempo a acciones negativas de otro o un grupo de estudiantes (Olweus, 1998). Según este autor es importante tener en cuenta ya sea a los agresores o agredidos y menciona tres elementos que hablan acerca de la magnitud de la violencia ejecutada, estos son: la intencionalidad, la persistencia en el tiempo y el abuso de poder, según su teoría, dependiendo de éstas, se puede determinar qué tipo de violencia está sufriendo y si es un episodio o una conducta repetitiva y perjudicial.

De hecho la violencia escolar tiene implicaciones serias en los comportamientos de los estudiantes ya sean acosadores o víctimas, ya que no solamente afecta su rendimiento escolar sino que también perjudica su relación consigo mismo y su entorno, como lo expone Cuervo (2003):

"Los adolescentes que son acosadores o víctimas tienen una experiencia social y un bienestar emocional reducido y participan en comportamientos riesgosos para la salud, en general, reportan 
mayores tasas de consumo de alcohol y drogas, de peleas y de porte de armas, que los estudiantes que no son víctimas. Así mismo, los estudiantes que son víctimas de acoso escolar a menudo experimentan una mala adaptación social y emocional, baja autoestima, y mayores niveles de soledad, ansiedad, depresión e ideas suicidas, que los que no participan en la intimidación” (p. 24)

En razón de lo anterior se puede decir que las consecuencias tanto para aquellos que son acosadores y acosados son en cierto grado igual de negativas, ya que por su parte aquel que esta en la posición de generar daño hacia el otro se mueve por distintos impulsos negativos, a un manejo desordenado y poco controlado de su vida. Por otra parte aquel que es maltratado o acosado, no se queda atrás, las consecuencias para este individuo se traducen en problemas emocionales serios que pueden llegar a poner en riesgo no solo su adaptación social, sino también su misma vida. En esta vía y comprendiendo las consecuencias desde ambos actores del conflicto, no se puede determinar quien es más o menos perjudicado, pero se puede rescatar que ninguno de los dos es beneficiado de la situación.

Las problemáticas de violencia escolar en la que los estudiantes se encuentran inmersos surgen a través de distintos conflictos que pueden ser manejados, antes de que desencadenen en manifestaciones de violencia ya sea física o psicológica. Los conflictos de hecho hacen parte del desarrollo natural de cualquier sociedad, ya que como en toda relación el ejercicio de mediación de gustos, opiniones y visiones de vida hace parte fundamental de su desarrollo.

Hoy en día, sin embargo, consideramos que el conflicto es un rasgo inevitable de las relaciones sociales. El problema estriba en que toco conflicto puede adoptar un curso constructivo o destructivo y por lo tanto la cuestión no es tanto eliminar o prevenir el conflicto sino saber asumir dichas situaciones conflictivas y enfrentar a ellas con los recursos suficientes para que todos los implicados en dichas situaciones salgamos enriquecidos de ellas. (Alzate, 2007)

Partiendo de esta concepción que plantea el autor, los conflictos tienen dos vias de desarrollo, en primera medida una que construye teniendo como resultado nuevas comprensiones acerca del tema que se discute; otra en la que el final queda inconcluso y el efecto es negativo, ya que 
desencadena comportamientos de violencia escolar como los que se exponen anteriormente. De hecho, la escuela es uno de los lugares en los que se pueden llevar a cabo estas experiencias, pues es donde

Se tejen una serie de subsistemas de relaciones interpersonales que influyan directamente en el devenir de la convivencia, que están estampados de conflictos y que pueden, si no aprendemos a comprenderlos, llegar a cuajarse de problemas sociales (...) Entre el subsistema de iguales acontecen con bastante frecuencia episodios conflictivos puntuales provocados por malentendidos, desacuerdos, motivaciones encontradas, por la poca práctica o conocimiento acerca de cómo se gestionan y resuelven los problemas de relación interpersonal, etcétera. Son conflictos que deben analizarse de forma positiva puesto que proporcionan al alumnado una fuente de aprendizaje real y de oportunidad de cambio. Sin embargo, no todos los conflictos se resuelven de forma dialogada y satisfactoria; especialmente porque hay escasa cultura de aceptacion de la potencialidad transformadora del conflicto (Ortega, 2001).

Lo que plantea el autor en este punto, responde básicamente al reconocimiento del conflicto como una oportunidad creadora de nuevas posibilidades, esta investigación busca que se comprenda el conflicto como una facultad necesaria en las relaciones humanas. Si bien, esta premisa es importante, se hace aún más relevante buscar una manera para que se aproveche este potencial positivo del conflicto. Es teniendo esta conciencia en donde entra a mediar la cultura de convivencia, si dentro de la institución se tienen bases de comunicación acertiva y un buen plan de acción basado en el diálogo, el resultado va a ser prometedor pues gestionar las dificultades va a ser más sencillo; más si por el contrario, la escuela no es ese lugar en el cual se tiene una ruta frente a las complicaciones que pueden existir, se van a terminar perpetuando ciclos de violencia prolongados.

Es por eso que se hace necesario consolidar otras maneras en las cuales se pueda gestionar el conflicto, para que de esta forma se quiebren las brechas relacionales dentro del ambiente escolar. Es necesario pensar en alternativas que aporten a la contrucción de cultura de convivencia escolar, con el fin principal de alcanzar el potencial formador del conflicto y cerrando de esta manera los ciclos de violencia que se han perpetuado a lo largo de los años. 


\subsection{Algunas conclusiones preliminares}

A modo de conclusión de este capítulo de marco teórico, se puede afirmar en primer lugar que la relación que se encuentra en dos categorías, educomunicación y educación alternativa, ya una permite el ejercicio de la otra, es decir, no se puede hablar de educomunicación si no se concibe la educación alternativa dentro de sus prácticas, debido a que desde la educomunicación, se hace una apuesta por otra clase de experiencia educativa donde el diálogo de saberes sin importar el medio por el cual se de, construya conocimiento y haga participe a los estudiantes de la creación de nuevos elementos conceptuales y vivenciales. Lo anterior de cierta forma hace referencia a una ruptura del sistema tradicional en aquellos lugares que están orientándose por apuestas de este tipo y abren una mirada desde lo alternativo que también busca realizar una transformación a la manera estática en la que se concibe la educación en ocasiones. De hecho, estas dos buscan como objetivo principal hacer que la persona que está involucrada en cualquiera de los dos procesos busque su emancipación por medio del conocimiento y gracias a la construcción de nuevos elementos de participación colectiva.

En segundo lugar, como se expuso anteriormente, la relación de la violencia escolar y cultura de convivencia es explícita pues las dos coexisten, Sería imposible hablar de violencia escolar, si esta no se desencadenará de un conflicto que tiene un potencial positivo o negativo en la medida en la que se sepa gestionar de manera eficaz a través de lo que posibilita la cultura de convivencia.

En tercer lugar la educación alternativa abre paso a propuestas como las educomunicativas, que contribuyen a la cultura de convivencia, en la medida en la que se rompen estructuras educativas que estan impregnadas de una u otra forma de la violencia que se ha naturalizado en las distintas sociedades. Es decir, al cambiar las dinámicas educativas desde la base, teniendo como pilar fundamental la comunicación, se está construyendo una ciudadania basada en la tolerancia y respeto por el otro. 
Hay que afirmar que en las dos o tres últimas décadas se ha avanzado en un creciente proceso de sistematización de los conocimientos, de las experiencias, de los métodos, prácticas y procedimientos, de las estrategias y de las perspectivas del desarrollo de la Educomunicación. Indudablemente que estos desarrollos han tenido una fuerza especial en América Latina, puesto que nuestros pueblos y naciones viven un momento trascendental de su autoafirmación y de la busqueda de su liberación; es decir, se encuentran en el camino de su maduración histórica. (Parra, 2000)

Se trata entonces, de una perspectiva que le da fuerza a este nuevo momento de maduración histórica como lo plantea Parra (2000). En el cual se busca construir modelos alternativos que direccionen a una transformación social, teniendo en cuenta a los seres humanos como potenciadores de estos cambios.

\section{Metodología de Investigación}

En este apartado, se hará evidente el diseño metodológico que se llevó a cabo, para el desarrollo y cumplimiento de los objetivos previamente previstos. De igual manera se presentan aspectos relevantes como el enfoque epistemológico, la metodología, el método, y las técnicas de investigación que se utilizaron.

\subsection{Población}

La investigación se realizó en el CEL (Centro Educativo Libertad), específicamente en la Escuela Mediática que comprende los grados $10^{\circ}$ y $11^{\circ}$, cada curso apróximadamente de 24 a 30 estudientes y un promedio similar en la cantidad de hombres y mujeres. Se conto también con el apoyo de la directora del colegio, algunos docentes, estudiantes, administrativos y padres de familia.

\subsection{Enfoque epistemológico}


La postura en la que se mueve esta investigación es hermenéutico ya que "este enfoque abarca un conjunto de corrientes y tendencias humanístico interpretativas, cuyo interés se centra en el estudio de los símbolos, interpretaciones, sentidos y significados de las acciones humanas y de la vida social" (Ortiz, 2015). Teniendo en cuenta lo que implica este tipo de investigación, se puede decir que va acorde a los objetivos planteados, ya que posibilita la comprensión de una realidad específica dotando de sentido las experiencias que se consideran significativas, pues gracias a esto se puede "considerar un acontecimiento desde una doble perspectiva; no solo como acontecimiento objetivo y material, sino como un evento que puede comprenderse e interpretarse" (Ortiz, 2015). Entonces el ideal del que parte es el del análisis profundo, en el que se identifican los factores más relevantes, teniendo como punto de partida las relaciones humanas y toda la riqueza que se pueden extraer de ellas.

"La hermenéutica involucra un intento de describir y estudiar fenómenos humanos significativos de manera cuidadosa y detallada, tan libre como sea posible de supuestos teóricos previos, basada en cambio en la comprensión práctica." (Packer, 1985). Esta investigación comprende la realidad como praxis a partir de un ejercicio de análisis y es por eso por lo que se encarga de entender las dinámicas del sitio que se estudia. En esa medida este enfoque posibilita la comprensión del modelo educomunicativo que se desarrolla en la Escuela Mediática y abre un camino por el cual es posible identificar esos factores educomunicativos entorno a la cultura de convivencia que se gestan desde la práctica y a partir de eso tener una perspectiva amplia de lo que posibilitan las escuelas de educación alternativa, no desde una teoría que lo exprese, más bien, manifestado en su entorno.

Al ser un proyecto hermenéutico, no se hace una intervención directa dentro de la comunidad buscando una transformación de una realidad especifica. Más bien, se trabaja con ella para comprender las prácticas que se desarrollan y permiten llegar a una comprensión amplia de lo que ocurre al interior, con la principal intención de resaltar lo que ocurre allí. Por medio de las realidades expuestas y los individuos que en ellas habitan, se encuentra una riqueza inconmensurable que permite nuevas maneras de ver la realidad en sí misma. Son estos 
encuentros los que se buscan en esta investigación, experiencias que transformen futuras realidades.

\subsection{Enfoque metodológico}

El enfoque metodológico de esta investigación es de tipo cualitativo, según Sampieri (2010) "utiliza la recolección de datos sin medición numérica para descubrir o afinar preguntas de investigación en el proceso de interpretación". Ya que su objetivo es el entendimiento del entorno, siendo centrada en la indagación de los hechos y pretende, la comprensión de las complejas interrelaciones que se dan en la realidad y dentro de un contexto específico.

El tipo de investigación cualitativa plantea unas características que son pertinentes en la investigación propuesta: es expansiva y paulatinamente se enfoca en conceptos relevantes de acuerdo con la evolución del estudio, permite el entendimiento del fenómeno internamente y externamente, pasadas y presentes (Arellano, 2012). Básicamente, lo que posibilitan estas características es que permiten estudiar a fondo una situación específica, comprenderla, estudiarla y eso resulta pertinente con los objetivos presupuestados.

Es importante aclarar que la investigación cualitativa se ha elegido como metodología de la investigación ya que esta es la que permite un mejor desarrollo de la metodología de estudio de caso, que como menciona Galeano (2009) se ha ido afianzado gracias a distintas disciplinas de ciencias sociales, lo que ha aportado a la consolidación de este como un método cualitativo de investigación social.

\subsection{Método}

Para esta investigación que está ligada entre lo comunicativo y educativo se tendrá en cuenta el método de estudio de caso, ya que esta posibilita estudiar a fondo la realidad dentro del contexto educativo escogido como dice Galeano (2009): "la historia del estudio de caso muestra su origen interdisciplinario, y su uso presenta una larga tradición en la educación" es por esto también que se convierte en una metodología pertinente, ya que esta ha desarrollado en el ámbito educativo, analizando la manera en la que las propuestas educomunicativas se llevan a cabo en instituciones de educación alternativa. El estudio de caso se escoge ya que responde a 
la elección del objeto / sujeto de investigación (Galeano, 2009) que en este caso sería la institución educativa Escuela Mediática.

El estudio de caso tiene como finalidad lograr una mejor comprensión de la realidad, no por qué este sea el más representativo entre otros, sino porque en su particularidad es de interés en sí mismo, en realidad no busca generar una teoría, ni encontrar una verdad específica, por el contrario, buscan analizar su valor intrínseco (Ocaña, 2015) El elemento que se debe resaltar en este proyecto está directamente relacionado con visibilizar lo que posibilita una educación alternativa al subvertir el orden establecido y apostar por propuestas en donde se tiene en cuenta la comunicación como pilar fundamental, apoyando de esta forma el desarrollo de procesos dialógicos dentro de la escuela y cambiando las formas en las que se estructuran las dinámicas escolares.

\subsection{Técnicas de investigación}

Las técnicas de investigación que se presentan a continuación, responden a la manera en la que se desarrolló la investigación y dan cuenta de la forma en la que se realizó la intervención. A través de estas se podrá facilitar la comprensión del cumplimiento de los objetivos establecidos.

\subsubsection{Observación participante}

La observación se entiende como la recogida de información por medio del análisis detenido que se realiza en un contexto con un sujeto establecido. Según Anguera (1981) en su libro Observación en la Escuela afirma que:

La observación es una estrategia de investigación cualitativa para la construcción de conocimiento acerca de la realidad física, social y cultural. Su evolución ha llevado a pasar de una perspectiva externalista, donde la realidad se mira solamente en su dimensión fenoménica o de apariencia, hacia un plano analítico y comprensivo, que en el espacio de la realidad social y cultural implica desenmarañar la red oculta de relaciones que subyacen a las acciones y situaciones humanas. (p. 207) 
Dentro de este marco se puede verificar por medio de una observación directa el desarrollo de las propuestas educomunicativas y además se puede evidenciar desde la práctica la manera en la que estos aportan a la cultura de convivencia de manera representativa, aportando de esta manera a la disminución de la violencia escolar y esto se puede discernir en las distintas dinámicas a lo largo de las jornadas escolares.

Existen varios tipos de observación, específicamente en esta investigación se utilizara la observación participante ya que es: "una técnica cualitativa con la cual el investigador recoge datos de naturaleza especialmente descriptiva, participando en la vida cotidiana del grupo, de la organización, de la persona que desea estudiar” (Estupiñán, 2004).

Es importante aclarar que esta técnica de investigación se lleva a cabo en todo el proceso de investigación, pues es desde esta que se puede realizar un análisis y permite el cumplimiento de los otros objetivos, como el de determinar los elementos característicos de los procesos educomunicativos entorno a cultura de convivencia, lo que a grandes rasgos facilita el tercero de los objetivos en el que se evidencian estos procesos. Sin embargo, es en el primer objetivo en el que se lleva a cabo de una manera más detenida y en el que esta técnica se necesita de forma más evidente. Pues se identifican elementos que se necesitan para el cumplimiento de los otros objetivos.

El proceso de observación inició desde el momento en el que se realizó la primera visita al colegio y a lo largo de toda la investigación, los periodos de observación oscilaron entre marzo del año 2016 y Septiembre del mismo, ciclo en donde se efectuaron aproximadamente 10 visitas, en los cuales se pusieron en funcionamiento las técnicas investigativas plasmadas en este capítulo. Los diarios de campo, permitieron que la observación se registrara estos son "Los que permiten al investigador un monitoreo permanente del proceso de investigación (...) Un buen diario de campo es un recurso insustituible para captar la lógica subyacente a los datos." (Bonilla, 1995) También estos son los que permiten llevar un registro de las cosas que suceden a diario en medio del proceso de investigación, en este se anotan cosas importantes que llevaran a incidir mejor en el medio, por lo que se tiene que hacer una observación constante de lo que sucede, esto permitirá identificar distintos momentos que serán de vital importancia en el desarrollo de la misma. 
En el proyecto de investigación es totalmente necesario llevar a cabo este tipo de diarios de campo, ya que se precisa no solo de constante observación sino también se necesita de un registro que permita la identificación de factores importantes en la misma, para que de esta forma se consiga condensar todo con hechos reales y de esa manera identificar la incidencia del proyecto en la cotidianidad.

El diario de campo se ha usado durante todas las fases de la investigación, facilitando el cumplimiento de todos los objetivos, pues ha brindado las características de las propuestas educomunicativas, el progreso y los elementos que se quieren rescatar de esta apuesta educomunicativa en torno a la cultura de convivencia. La recopilación de toda la información desde distintos puntos de vista y miradas ha proporcionado el desarrollo en gran medida del tercer objetivo, ya que lo que se ha recogido a través de esta técnica ha facilitado, la manera en la que se van a evidenciar los procesos educomunicativos entorno a cultura de convivencia y cómo estos aportan de manera significativa a la disminución de violencia escolar.

\subsubsection{Entrevista}

Esta hace énfasis en "La interacción limitada y especializada, conducida con un fin específico y centrada sobre un tema particular" (Estupiñán, 2004). Se ha utilizado esta técnica ya que lo que busca es conocer las experiencias educomunicativas dentro de la institución educativa, intentando abordar la experiencia de las personas que están involucradas y aquellos que forman parte de la institución como docentes, estudiantes, personal administrativo, egresados y padres de familia; ya que a través de sus apreciaciones identificaron aspectos que dan cuenta de los aspectos que se analizaron en la investigación.

Ahora bien, existen varias clases de entrevistas, sin embargo, la que se ha usado en este caso es la entrevista semiestructurada. Según (Díaz-Bravo, Torruco, \& Martínez, 2013): "presentan un grado mayor de flexibilidad que las estructuradas, debido a que parten de preguntas planeadas, que pueden ajustarse a los entrevistados. Su ventaja es la posibilidad de adaptarse a los sujetos con enormes posibilidades para motivar al interlocutor, aclarar términos, identificar ambigüedades y reducir formalismos". Esta clase de entrevista permite una flexibilidad característica que le permite al entrevistador orientar las preguntas a los puntos clave que le interesa conocer, este aspecto es muy importante a la hora de comprender la manera en la que la 
relación de la educomunicación está ligada a la violencia escolar y cultura de convivencia, pues posibilita espacios en donde se encuentran y relacionan. Es decir, que está básicamente, nace del compartir con el otro y comprender la manera en la que este ha vivido dicha experiencia.

Las entrevistas se realizaron a lo largo del periodo de investigación en dos visitas en total se efectuaron 8; la primera sesión de entrevistas se realizó el 25 de Mayo a la rectora Hilda Forero, a la docente Margarita Olaya docente de deportes, directora del grado $11^{\circ}$ y madre de familia; como también a los estudiantes Giorgio y Sofia estudiantes del grado $11^{\circ}$, el segundo encuentro para realizar entrevistas fue el 3 de Agosto, en donde se contó con el docente Sebastián Sabogal encargado de la materia de taller de texto, la estudiante Saray Martinez de grado $10^{\circ}$, la directora administradora Mercedes Gómez y la secretaria académica Veronica Bejarano. Se escogieron estas personas para la realización de las entrevistas ya que el propósito inicial era escuchar las distintas opiniones de los miembros del plantel educativo y comprender la manera en la que estas personas entienden las dinámicas internas, juntamente con la intención de encontrar la lógica entre lo que dicen los diferentes integrantes de la misma. Las entrevistas a los distintos participantes en este proceso también se hacen con la finalidad de encontrar en su discurso, los elementos que le dan cumplimiento a los distintos objetivos planteados inicialmente.

La entrevista facilitó el cumplimiento del primer, segundo y tercer objetivo, ya que por medio de este se identificaron las características específicas de los procesos educomunicativos entorno a la cultura de convivencia que permitirán la comprensión de lo que entiende la comunidad educativa en la cotidianidad con este tipo de propuestas e iniciativas. (ANEXO 2)

\subsubsection{Grupo focal}

Un grupo focal facilita la recolección de información de una manera más detallada y enfocada, ya que es una forma de escuchar lo que dice la gente y aprender a partir del análisis de lo que dijeron. En esta perspectiva los grupos focales son aquellos que crean líneas de comunicación, donde el primer canal de comunicación se establece al interior del grupo, con un propósito comunicativo entre el moderador y los participantes, así como entre los participantes mismos (Mella, 2000). 
Lo que esto facilita es profundizar en aquellos elementos que después de la entrevista resultan importantes, aportando de la misma manera al cumplimiento de los tres objetivos específicos y por lo tanto al cumplimiento del general, ya que en primera medida permite identificar los procesos educomunicativos que se llevan a cabo, a través del diálogo se llega a la comprensión de esos elementos característicos que aportan a la cultura de convivencia y adicional a eso ayuda reconocer cuales son las líneas tendientes a la mitigación de la violencia escolar. Ya que con los estudiantes haciendo se parte de estas dinámicas se pueden descubrir elementos fundamentales.

El grupo focal se realizó el 21 de Septiembre con 3 estudiantes del grado $10^{\circ}$ (Saray Martinez, Federica Quiroga, Paula Saganome) y 3 estudiantes del grado $11^{\circ}$ (Ana Maria Velez, Giorgio Lizcano y Sofia Cordoba), ellos fueron seleccionados por la rectora para la realización del grupo focal, son unos de los estudiantes que se destacan en estos procesos. (ANEXO 3)

\subsubsection{Revisión documental}

Se utilizo este elemento para lograr comprender las dinámicas de la institución educativa, observar, leer y tener un acercamiento con los documentos que rigen la estructura de la Escuela Mediática, lo que permitió entender en profundidad su propósito original, la visión y finalidad que tendrá

En este orden de ideas, se hace relevante esta revisión pues ayuda a identificar y caracterizar los elementos educomunicativos que se encuentran presentes y la forma en la que estos aportan a la cultura de convivencia. Como también permiten reconocer la manera en la que esta institución propone lineas de acción tendientes a la disminución de la violencia escolar.

En esta etapa se revisaron los aportes que se hace desde tres distintos documentos institucionales de la Escuela Mediática, el primero es el PEI que esta condensado en una investigación: “Educación media bivalente con énfasis en la producción y recepción critica de medios y nuevas tecnologías comunicacionales" En este documento se presenta la propuesta pedagógica que se desarrolla en los grados décimo y once, entonces se encuentran sus principios y los autores con los cuales sustentan su propuesta. El segundo es el “documento de la regulación de la convivencia” en este se encuentran los 
pactos construidos colectivamente con los estudiantes, docentes y directivos. El último por su parte es una investigación que presenta el trabajo por proyectos que se realiza en el CEL "Caracterización de la práctica pedagógica de la relación con el conocimiento y de la interacción social, que se dan en el trabajo por proyectos, eje de la innovación educativa en el centro educativo cel."

\subsubsection{Análisis de datos:}

Los datos recopilados a partir de las técnicas ejecutadas y explicadas anteriormente, se sistematizaron inicialmente y posteriormente se organizaron en una matriz de análisis realizada teniendo en cuenta el campo práctico y teórico, teniendo como eje las categorías escogidas estratégicamente. Lo que posibilito la matriz fue una comprensión general de los elementos significativos de la experiencia dentro de la Mediática, ya que se pudo evidenciar el diálogo existente entre lo que se encontró gracias a los distintos autores y como la praxis era el reflejo de esas teorías materializadas en una experiencia. En esta matriz arrojaron unas reflexiones iniciales, que se convirtieron en el punto de partida a la hora de sintetizar los elementos rastreados. (ANEXO 6)

\subsection{Cronograma}

En este apartado se muestra la manera en la que se llevó a cabo el diseño metodológico por meses y actividades realizadas. En el cronograma, se evidencia la continuidad de la investigación, como también las actividades que se desarrollaron para dar cumplimiento a los objetivos establecidos en la investigación. Los instrumentos de investigación que se usaron y las actividades que se desarrollaron se exponen más adelante. (ANEXO 5) 


\section{Resultados y discusión}

Este capítulo se centra principalmente en dar a conocer lo que se trabajó dentro del centro educativo CEL (Centro Educativo Libertad) específicamente en la escuela mediática. La información presentada a continuación permitirá llegar al cumplimiento de los objetivos planteados anteriormente. Para la realización de esta tarea, se hace un énfasis importante en lo que se encontró en el trabajo de campo, esto con el fin de definir y delimitar aquellos ítems característicos que aportan a la construcción una cultura de convivencia. (ANEXO 5)

Para tener una comprensión completa de lo que ocurre en la Escuela Mediática y por qué se escoge para este estudio de caso, se van a resaltar los distintos hallazgos importantes separados por categorías teóricas y lo que arrojo el trabajo de campo en cada una de ellas, inicialmente se presenta lo que se recolecto en las entrevistas y los descubrimientos más importantes encontrados en estas. Posteriormente, se expone y explica el trabajo que se realizó en el grupo focal y los aspectos que se desean resaltar de esta experiencia. Además, se hace un despliegue de la información más relevante que se consigue de los documentos institucionales, esto para comprobar la manera en la que lo que está estipulado en estos documentos da cuenta de lo que pasa en realidad. Por último, se tiene en cuenta lo que se vio gracias a la observación participante y se confrontará con lo que se encontró gracias a las otras técnicas. La finalidad primaria es alcanzar una comprensión más profunda de lo que se ha expuesto anticipadamente y hacer un análisis acentuado en las categorías que se plantean, confrontando los elementos que se exponen en el campo teórico y práctico.

Posteriormente y teniendo en cuenta los aportes realizados en el trabajo de campo, conviene hacer un barrido de esa información y retomar aquellos elementos que dan luces acerca de los elementos educomunicativos que aportan a la construcción de cultura de convivencia dentro de la Escuela Mediática, que están relacionados con la disminución de violencia dentro de esta institución, esto con el fin de dar cumplimiento a los objetivos planteados inicialmente. 


\subsection{Educomunicación}

Gracias al trabajo de campo se logró llegar a distintas clases de concepciones, el primer elemento en el que se ahondo fue en el de la educomunicación y en este se encontró que son diversos los rasgos que relacionan la experiencia de la Escuela Mediática con los principios de la educomunicación. En este aspecto se profundiza acerca de las opiniones que tienen los agentes involucrados dentro de la institución frente al tema de la educomunicación, ahora bien es válido aclarar que no se reconoce como educomunicativo propiamente, si embargo, se comprenden las relaciones intrínsecas entre la educación y la comunicación, por eso se habla de que tiene en cuenta el enfoque educomunicativo en la medida en la que sus aportes prácticos dentro del establecimiento responden a los principios de está. A continuación se presentan los elementos que se consideran claves y que hablan del modelo que se lleva a cabo en la institución.

Lo primero que se revisó fue lo que se encontró en las entrevistas, comprender las opiniones de las personas que están involucradas en la institución es de suma importancia para entender las dinámicas dentro de la misma. Las entrevistas semi-estructuradas se realizaron a la directora del colegio Hilda Forero, 2 estudiantes del grado décimo, 2 del grado once, dos profesores, dos administrativos y dos madres de familia. Las preguntas se orientaron a las tres categorías de análisis relevantes en esta investigación y una subcategoría (educomunicación, educación alternativa, cultura de convivencia y la de violencia escolar). Se retomaron en este capítulo los elementos más importantes, los hallazgos más significativos y específicos por categorías.

Al preguntarle a Hilda Forero cual es el enfoque de la Escuela Mediática y el por qué su respuesta hace referencia a los ejes que se manejan que son "el uso, recepción y crítica de medios y nuevas tecnologías, idiomas (inglés y francés) y las artes" y menciona el por qué y cómo se integran estos tres ejes a las dinámicas cotidianas.

"Es una propuesta pedagógica integradora, con un enfoque holístico, especialmente se integra el contenido por medio de las áreas, con un eje transversal o un nodo que atraviesa todas las áreas que son sus énfasis, quiere decir que entonces no solo utilizan el PageMaker para hacer sus revistas literarias que son entre otras cosas de muy buena calidad, sino que si en química 
quieren hacer también revista literaria la hacen, que si quieren hacer emisión radial en sociales lo hacen" (Forero 2017, entrevista).

Este primer comentario parece apuntar a la visión que se tiene reduccionista de la educomunicación, sin embargo, en la medida en la que se desarrolla la entrevista, se comprende cada elemento a profundidad. El primer tema sobre el que se indaga es su primer eje de acción “el uso, recepción y crítica de medios y nuevas tecnologías” y menciona los medios en los que trabaja cada curso.

"Los de décimo aprenden teoría y práctica radial e impresos y en once sin desconectar lo anterior se trabaja en cine y televisión, en video, en fotografía, entonces en décimo el proyecto es por ejemplo la revista literaria, que tiene un nombre institucional que es ciudad de piedra (...) Por ejemplo, en $11^{\circ}$ con el profesor con el que trabajan es un realizador de cine y televisión, entonces hacen unos video clips, cortometrajes, documentales (...) los chicos escogen un tema de su interés como joven y lo trabajan en compañía de su maestro de comunicación y conmigo también en la pre-producción, en la los producción, esos documentales, o video clips o documentales hacen cantidad de cosas interesantes" (Forero 2017, entrevista).

Lo que se puede ver acá es que la intención inicial de la institución es equipar a los estudiantes con el propósito de que puedan y estén en la capacidad de entender la manera en la que funcionan los distintos medios, los distintos lenguajes comunicativos que circulan en la sociedad y en esa medida se logra entender su actuación en la misma, Hilda hace referencia a cada acercamiento con estos elementos comunicativos.

En este punto se entiende lo que seria la primera relación que tiene la propuesta pedagógica de la institución con el primer postulado de Kaplún (2002), que consiste en la necesidad de modernizar el aula y agregar dinamizadores a ésta para que la escuela así como la realidad siga su curso y evolucionen a la par. Cabe resaltar que el plan inicial no es instrumentalizar el aula de clases como lo menciona Huergo (2007), por el contrario, es algo que se incorpora en la escuela y se moviliza dentro de ella para facilitar y permitir que el proceso de enseñanza aprendizaje sea estimulante. 
Este asunto es de suma importancia, púes es en este en donde se comprende el fin real de estas nuevas formas de configurar la educación, pues se valen de distintos recursos para cumplir con la finalidad de preparar integralmente a los estudiantes. Lo que busca la Mediática, es básicamente por medio de los distintos dispositivos electrónicos en los cuales diseñan los distintos impresos y documentales, darle dinamismo a el proceso de aprendizaje, haciendo que los estudiantes los hagan parte de su conocimiento usando estas herramientas.

Otro aspecto importante de los productos que se realizan dentro de la Escuela Mediática es que estos no son el fin, si no más bien el punto de partida, por eso inicialmente se expone lo que se realiza, para luego comprender la manera en la que se consolida y los efectos que esto tiene en los estudiante. Uno de los aspectos que se debe resaltar dentro del proceso de creación, son las habilidades que se desarrollan gracias a estos. Como por ejemplo:

"La crítica de la comunicación y los medios que está inmersa en el proceso, porque los estudiantes son receptores de medios, pero a la vez son productores de medios, entonces cuando uno es el que recibe información y al mismo tiempo la transmite, las cosas son diferentes ósea no es esa concepción de comunicación tradicional en el show, sino que eso es un circulo, un ciclo, entonces además de que son receptores críticos de medios, son productores también (...) los chicos lo que están recibiendo lo ponen en juego. Y te vas a dar cuenta que los chicos son críticos, a veces hipercríticos (risas jajaja), pero eso está bien, porque les posibilita pues mayor descentración, mayor cantidad de cosas, entonces son chicos muy críticos y muy pilos" (Forero 2017, entrevista).

Referente a lo que dice Hilda, acá se hace referencia a que esta educación le apunta a principios epistemológicos básicos como los que menciona Parra (2000) que habla de la educomunicación como aquella que se encarga de orientar y enseñar a los estudiantes a consumir productivamente los mensajes que están en los medios. La apuesta de la mediática en este sentido le apuesta precisamente a lo que se expone a continuación:

"Se trata de llevar a la práctica una pedagogía crítica de la representación, para que este contrarreste el poder de los medios de difusión generando un conocimiento emancipatorio para las audiencias y fortalezca un intercambio más equitativo entre los diversos sectores sociales" (Forero, 1999). 
Además, lo mencionado anteriormente tiene mucho que ver con el aporte de Villarroel (2011) que contempla la educomunicación como esa que brinda las herramientas para reconstruir los mensajes que se reciben, entender su significado real y aportar de alguna forma a estos desde la postura personal y ese es precisamente uno de los alcances de la educomunicación: una comprensión distinta del mundo en el que se encuentra. Lo que se expone anteriormente responde a lo que se hace en la Mediática y es que cada producto que ellos presentan es simplemente una excusa para poder significar la realidad de una manera diferente a la que se contempla tradicionalmente. Los dos puntos anteriores abordan el eje inicial de la Mediática y es el uso, recepción y crítica de medios, que responde al principio básico del modelo educomunicativo. Un ejemplo de esto son los documentales que realizan, en los cuales proponen temas de su interés y los abordan desde distintas miradas, entendiendo sus problemáticas, aristas; escuchando también diversas opiniones y construyendo a partir de ese rastreo inicial su propia opinión acerca del tema.

Entonces, lo explicado preliminarmente permite entender que como explica Parra (2000) estas apuestas se entrelacen de manera perfecta con el que hacer pedagógico dentro de la mediática, por que al ser productores de medios hacen una operación intelectual y por lo tanto acceden productivamente a la polifacética realidad social, se trata de "enfrentar la tiranía avallasadora de los medios de comunicación" decodificando lo que consumen, desarmando los mensajes, reconstruyendo su significado y leyendo entre líneas su verdadero significado y de esta manera formando sus propios conceptos, haciendo del acto educativo una experiencia liberadora y no opresora como dice Freire (1970).

Ahora bien, la perspectiva de los docentes frente a lo que se contempla en la parte educomunicativa es muy valiosa, porque eso habla de las prácticas en las que se desarrolla el proceso de aprendizaje, la docente Margarita Olaya directora del grado $11^{\circ}$ y docente de la materia de deportes hace el siguiente aporte:

“Acá se llevan los procesos como el mismo nombre de la mediación como llegar a donde queremos llegar de una manera mucho más fraterna, más bonita, y que realmente garanticemos los procesos de educación que se dan acá. Ósea, hay garantía, no hay un proceso, de que tienen que cumplir así, tienen que todos ser así, sino que, hay la garantía de que 
realmente se aprende, entonces por todos los medios la forma pedagógica que se maneja el enfoque que tiene le damos, estamos formando chicos para enfrentarse a la vida y a una sociedad y que sean capaces, chicos capaces, todo, no solo en la parte emocional, física , mental, en todo, íntegros" (Olaya, 2017, entrevista).

Reconocer entonces, los alcances de la educomunicación dentro de la escuela es supremamente valioso, pues aporta al desarrollo intelectual y crítico de los estudiantes. Sin embargo, ese no es el único efecto, se encontró además que otro de los resultados de lo que se contempla por mediación, no hace referencia únicamente a los medios como actor fundamental, sino aportando a la manera en la que esta entra a jugar un papel importante en las relaciones humanas. Es similar a lo que habla Freire (1991) acerca de la comunicación dialógica y su potencial creador, en donde menciona que es imposible pensar una educación sin comunicación, tal como lo menciona la docente Margarita Olaya, la mediación le permite a los estudiantes formarse de manera integral, no solo en cuanto a contendidos, también frente a la vida.

Por otra parte el docente Sebastián Sabogal, docente de taller de texto de los grados $10^{\circ}$ y $11^{\circ}$ aporta desde su perspectiva lo que busca en su clase.

"la idea siempre ha sido que los chicos desarrollen un discurso y para que eso suceda tiene que ser comunicado y se tienen que buscar estrategias de comunicación y cuando los profes se encarretan cada vez más con la apuesta de la escuela, ellos llegan a propuestas que son totalmente mediáticas, ó sea que le apuntan a los medios y ayuda a que comuniquen todo ese discurso que vienen construyendo, entonces claro que propuestas hay desde la escuela, evidentemente los proyectos. Por ejemplo: la profe de química quiso trabajar conciencia del cuerpo y de cómo se entiende la enfermedad y esas cosas digamos más perjudiciales para el cuerpo y como ellos muestran eso, entonces lo que hicieron fueron diferentes sketches, noticieros por ejemplo, en los q presentaban todos los resultados sobre las cuestiones químicas y biológicas del sida, ejemplo o el chikunguña, y aparte de eso también, si ellos entienden la química , como afecta, como aporta, como genera condiciones, también necesariamente no puedo cuidar a alguien que se está muriendo de deshidratación en una zona donde hay poco agua, entonces aparece el componente social, todo eso, como lo tienen que presentar en una nota o en una noticia, deben echar mano de todos estos aspectos que los ayuden a entender el fenómeno y además hace dos años yo quise trabajar en inglés la contracultura, buscamos videos en inglés y al final hicimos un video clip con música de la época de toda la progresión, entonces un video beam, una hippie bailando, imágenes, el viaje psicodélico y ellos a través de 
ese video que no tenía ni una sola palabra comunicaron lo que habían leído y escuchado, justamente es eso, tú tienes un montón de input, que escuchaste el discurso de Martín Luther King que escuchaste el debate de Malcon y Martin, que leíste esta historia o esta otra de la contra cultura de los 60, que viste este documental, de la aparición de la píldora, todo esto lo viste lo leíste, entonces que discurso construyes y cuando uno mira el hilo narrativo que construyeron así no hubiera uso hablado del inglés, se evidencia una postura frente a lo que vieron política y cultural de la época , buscamos distintas maneras de mostrar. " (Sabogal, 2017, entrevista).

Siguiendo la línea del desarrollo personal se encuentra que otro de los pilares fundamentales de la educomunicación, es la construcción de un discurso propio frente a lo que se consume en los medios y lo que se produce para los mismos, en este punto se encuentra a lo que Soarez (2003) llama ecosistemas educativos, en los cuales el objetivo principal es buscar esos espacios brindados por los medios y confrontados en las aulas donde los estudiantes gracias a estos pueden generar conocimiento propio, un paso más valioso que la misma memorización de un contenido específico. Como lo exponía el docente Sebastián Sabogal, la intención de todo lo que se realiza es que se construya un discurso y se tenga un conocimiento real de todo lo que se aprende, pues en esta medida el aprendizaje no es vacío. Entonces con estos ejemplos se puede comprender un poco la manera en la que se construye el conocimiento en la escuela mediática y es tomando todas las herramientas que tienen a su alcance, pero la principal y fundamental en todo esta es la de “comunicar", “crear", “cuestionar” y “aportar críticamente”.

La búsqueda de estos fines hace posible que los ciudadanos se apropien de y transformen los ecosistemas comunicativos y educativos de la ciudad e impulsen la producción mediática alternativa para hacer de la comunicación masiva una comunicación para la educación, aprovechando el poder que los medios tienen para informar y entretener, de modo que los diversos contextos sociales tengan la posibilidad de diseñar, revaluar y poner a funcionar sus propios agentes mediáticos y comunicativos. (Secretaría de Educación Distrital, 2004). 
Es necesario reconocer que los estudiantes son ciudadanos y que en sus manos tienen el reto de dotar de sentido de forma alternativa, los mensajes que circulan en los medios. La Mediática le apunta precisamente a esta premisa y es la de formar "agentes mediáticos y comunicativos" que tienen un impacto positivo en los "ecosistemas comunicativos". Por otra parte, no solo los directivos y docentes son conscientes de lo que se está brindando a los estudiantes, ellos mismos tienen la capacidad para reconocer aquellos aspectos que les aporta este tipo de educación. Giorgio de grado $11^{\circ}$ habla acerca de las cosas en las que el siente que es incluido en el proceso de aprendizaje.

"Me parece muy chévere la importancia de otros espacios que nosotros tenemos, que en otros colegios no se presentan, digamos de la clase de fotografía, la de comunicación, la de taller de texto, son espacios que en otras instituciones, digamos taller de texto e lenguaje ortografía todo se ve como de ladito y pues en cambio acá tenemos taller de texto, lenguaje, ortografía y todo es parecido, incluso filosofía y todo tiene que ver y de cierta forma siento que con algunas clases se ha logrado como entretejer como ciertas relaciones para que se complementen" (Lizcano, 2017, entrevista)

En esta medida se evidencia que los aportes que se brindan superan las simples ideas románticas de un modelo educativo alternativo, por el contrario, son la prueba fehaciente de que lo que la directora ha soñado para la institución, lo que los docentes han esperado de sus clases, se reconoce en los procesos más individuales de los estudiantes y son sus vidas personales.

Posteriormente en la búsqueda de ahondar en ese tema, se realizo un grupo focal con 6 estudiantes del grado $10^{\circ}$ y $11^{\circ}$, en el se abordo el tema de la educomunicación y cada uno hablo de los alcances de ver a la comunicación y educación en una sola rama, una de las reflexiones más importantes de este espacio fue la conciencia de cada estudiante al comprender que en la medida en la que el proceso educativo este mediado por la comunicación, la resolución de conflictos va a ser una tarea mucho más sencilla, en la medida en la que cada participante dentro de la escuela tiene una voz y un voto que le permite manifestar sus necesidades, como también sus inconformidades por medio de la palabra y no la censura de ella. 
En el grupo focal, se realizo un ejercicio de representación, en donde por grupos de a dos decidieron significar esta categoría usando una frase que para ellos resume el alcance de la educomunicación y la frase dice: "La lucha de toda persona es la lucha por ser recordado". A lo que hacen referencia en esta frase, es que todo aquello que ellos crean gracias al modelo educomunicativo es un paso y un peldaño más para dejar una marca en la historia y para convertir en palabras, impresos, fotografías y emisiones, que no se van a borrar. Ellos manifestaban también como su tarea principal además de crear estos productos, era entender que su labor principal dentro del lugar en el que se encontraban, era ser porta voces de esos conocimientos que se reflejaban por medio de lo que creaban.

Otro de los comentarios que habla de la manera en la que se contempla este aspecto dentro de las prácticas cotidianas en este taller fue uno que decía "a través de este énfasis estamos todos los días en contacto con el arte de la comunicación" al convertir la comunicación en un arte se entiende la manera en la que ésta se cultiva a diario y germina dentro de ellos como una pasión.

Ahora se presentará lo que se encontró referente a esta categoría en el documento que es el que orienta la práctica pedagógica "Educación media bivalente con énfasis en la producción y recepción critica de medios y nuevas tecnologías comunicacionales” y también en el de "Caracterización de la práctica pedagógica de la relación con el conocimiento y de la interacción social, que se dan en el trabajo por proyectos, eje de la innovación educativa en el centro educativo cel." Acto seguido se presentaran los aspectos relevantes tomados de cada uno de los documentos:

- Una escuela que valora el significado de los medios masivos de comunicación, como expresión legítima de la cultura contemporánea y que educa para una interacción critica de los jóvenes con la circulación massmediática de los saberes. Una escuela centrada en los medios de comunicación y en las nuevas tecnologías comunicacionales como una superación de las formas tradicionales de la transmisión de la información.

- Una escuela donde los jóvenes sean productores de medios que utilicen los lenguajes de la radio, la televisión, el video, los impresos, para expresarse y comunicar sus sensibilidades.

- Formación en el campo de la recepción crítica y producción de medios, como una forma de concretar los propósitos de la formación de competencias del saber hacer, y haber comunicar. 
- Educación para los medios: cada vez más la relación pedagógica debe ser su carácter dialógico, ya que a través de los escolares los medios están interpelando a la escuela y la familia. Diversas instancias son rotadoras de gran cantidad de información y son agentes activos que propone mensajes y exponen tipos de comportamientos para ser apropiados, interpretados y re significados.

- Necesidad de poner en práctica una pedagogía crítica de la representación para que este contrarreste el poder de los medios de difusión generando un conocimiento emancipatorio para las audiencias y fortalezca un intercambio más equitativo entre los diversos sectores sociales.

- El lenguaje y la comunicación de hecho hacen parte de uno de los pilares de la propuesta, es el dispositivo, el detonante de cada una de las acciones pedagógicas.

(Forero, 1999).

El primer documento titulado "Educación media bivalente con énfasis en la producción y recepción crítica de medios y nuevas tecnologías comunicacionales" comprende los principios básicos y alcances de este modelo dentro de la escuela, los elementos planteados en este permiten entender el sentido pedagógico de la institución y la forma en la que se tiene pensada esta educación media bivalente dentro de la práctica. Este documento es el PEI (Proyecto Educativo Institucional) en el que están condensados los principales objetivos de lo que se quiere cumplir en la Mediática. Es interesante ver que los elementos planteados en el PEI, como por ejemplo: el rol de cada uno de los miembros en el plantel educativo (docentes, estudiantes), el papel de la comunicación, los medios y el lenguaje, la formación crítica y el sentido emancipador de la misma, son componentes que se hacen evidentes en el discurso de aquellas personas que participaron en las entrevistas y grupos focales, como también en el desarrollo de las dinámicas cotidianas. Esto muestra que el PEI no es simplemente un documento más con palabras bien escritas, sino que es el corazón de la institución, es el reflejo de un deseo de transformación, desde las estructuras más básicas, hasta las más complejas, que se desenvuelven en el día a día.

Se puede también identificar que los principios pedagógicos de la Escuela Mediática tienen que ver con algunos de los principios educomunicativos que se han expuesto a lo largo de la investigación. Un ejemplo de eso es lo expresado por Huergo (2007) En donde se habla abrir un espacio dentro de la escuela para los medios de comunicación y las nuevas tecnologías, esto con el propósito de que se le de un giro a la educación como se conoce comúnmente y también 
para que estos medios se vean confrontados con la realidad. La inclusión de estos distintos canales, permite que en medio de ese proceso comunicativo los estudiantes puedan comunicar y expresar sus concepciones acerca del mundo, convirtiendo aquellas creaciones en los vehículos perfectos para sacar a flote sus ideas, discursos y convicciones. Esto es a lo que Freire (1970) le apunta al hablar de una comunicación dialógica donde se encuentran "sujetos interlocutores que buscan la significación de los significados" lo importante en esto, es que el producto mediático que se desarrolla es la excusa para que este proceso se de.

Otro punto valido para mencionar es el aporte de Parra (2000) en el hace referencia al campo educomunicativo como el que posibilita que se de un proceso de lectura crítica de los mensajes, pero que el paso inicial es poder acceder a esos conceptos de manera libre y productiva, dando herramientas a los distintos agentes de la sociedad para afrontar la seducción de los medios. En esta apuesta brindada se pueden encontrar varias similitudes con lo que se realiza en la Escuela Mediática: primero por que se abre el espacio para tener en cuenta los medios de comunicación y nuevas tecnologías, segundo por que se le da a los estudiantes la oportunidad de explorar cada uno de estos lenguajes comunicativos, proponiendo y gestando propuestas desde los mismos canales y teniendo en cuenta una pedagogía crítica que contrarreste el poder de los medios, así como lo expone Parra.

\subsection{Educación alternativa}

En otro orden de cosas, la siguiente categoría que se tiene en cuenta es la de educación alternativa que sin duda alguna hace parte fundamental de esta investigación, ya que en este espacio principalmente se busca darle fuerza a estas propuestas alternativas y mostrar sus alcances, con el fin de aportar de alguna manera a una renovación educativa y demostrar lo que posibilita la educación cuando se tiene en cuenta la palabra, la comunicación y los espacios de encuentro. Por lo tanto, a continuación se habla de aquellas características diferenciadoras de esta apuesta pedagógica. Para eso se tendrán en cuenta las percepciones y anotaciones de las personas que están involucradas dentro de la misma. 
Rectora: "Los ejes se articulan a las áreas, son el eje que atraviesa todas las áreas, entonces es un proyecto pedagógico integrado, a diferencia de la educación tradicional que se plantea en proyecto pedagógico agregado, es decir que casi es una colcha de retazos y se piensa que el conocimiento es aislado, que entonces lo de matemáticas, el profe de matemáticas solo entiende solo de matemáticas, el de lenguaje, no se entiende con lo matemático, etc. Suele pasar, acá se trata de integrar y se trabajar por proyectos, entonces se trabaja en una concepción que hemos acuñado acá en las investigaciones que hemos hecho que se llama pedagogía proyectiva" (Forero, 2017, entrevista).

Lo que se hace en la Escuela Mediática es trabajar cada área y materia específica teniendo como punto de partido los ejes, que son los que terminan involucrándose durante el proceso de enseñanza-aprendizaje. En virtud de ello, se puede ver como los estudiantes reconocen este trabajo, uno de ellos menciono que le sorprendía como todo lo que aprendía tenia que ver y estaba conectado. En esta medida, se comprende entonces el primer elemento diferenciador de esta escuela alternativa, con una de enfoque tradicional, pues no todas cuentan con ese diálogo intrínseco en su desarrollo.

Docente: "la educación tradicional está condicionada jmmm... a ti te dan las estructuras, a ti te pasan y te dicen tienes que hacer esto y está dentro de los procesos que uno hace, pero uno acá tiene la posibilidad de hacer su proyecto, de crear, de ir gestando su proyecto y de poderlo modificar durante el año. Entonces la elaboración del proyecto, uno con la escuela mediática hace la propuesta principal la entrega y de ahí en adelante, empieza a trabajarle a lo que es el proyecto como es. Entonces empiezas a crear, a darle vida a ese proyecto, desde donde tú quieras, entonces yo tengo la libertad de hacerlo como yo quiera y a mi gusto y de esa manera yo acá doy primeros auxilios, pues clases de primeros auxilios, todo lo que son principios básicos. Eeee de campamento, los preparo en la parte física aeróbica y muscular para lo que son deportes extremos, entonces esto lo hacemos en distintos lugares, los escojo yo, los armo yo, tengo la posibilidad de manipular mi proyecto a mi gusto y de la manera en la que lo quiera hacer" (Olaya, 2017, entrevista).

Otro factor que resulta relevante en la manera en la que se desarrollan las dinámicas pedagógicas y de planeación dentro de esta institución es la libertad que le dan al docente para crear, darle forma y direccionar el proyecto de área que va a implementar a lo largo del año. Esto demuestra que no se trata simplemente de una ruptura frente a lo tradicional en cuanto a 
los contenidos o a los elementos que se implementan, más bien, se trata de una quiebre completo al sistema que se contempla generalmente, en donde los profesores deben acogerse a un libro de texto y desarrollar una metodología en donde se permita cumplir con un sin fin de ítems. La Escuela Mediática, busca que así como sus estudiantes desarrollan todas sus habilidades, los docentes también y esto lo logran creyendo y confiando en su trabajo.

Docente: "En los lugares de educación tradicional en los que trabaje en ambos casos la cosa era que existía un enfoque muy heteroestructural, uno llega les explica lo que tienen que hacer un programa y si ese programa no se cumple, tengo que cortar temas y todos los temas están muy pegados a los estándares, que tienen una visión muy instrumental del inglés como del español, entonces en ese modelo, lo único que uno hacia era transmitir conocimientos, en la medida de lo posible, pero siempre desde esta visión de lo que está afuera, de lo q nos condiciona y tenemos que hacer porque nos dicen que es así, que debe ser hecho, en cambio acá en la escuela mediática cambia, porque al tener un proyecto los temas van surgiendo en la medida en la que uno los va necesitando, uno tiene por supuesto de una serie de mínimos, necesito desarrollar habilidades en inglés, entonces lo mínimo que tienen que saber si van a estar dos años conmigo, pero no se vuelve una camisa de fuerza, en el caso de las lenguas, el trabajo es más experimental entonces en la medida en la que van necesitando cosas, la necesidad comunicativa que tengan, entonces te pongo el ejemplo del año pasado , los chicos tenían que hacer unos podcasts, de los temas que quisieran, entonces lo que ellos iban aprendiendo de expresiones, tiempos, y lo que iban practicando obedecía a lo que querían comunicar con su podcast y no porque dijéramos desde el programa, es que tenemos que ver presente progresivo, entonces no es así. Es dependiendo de lo que quieran alcanzar, entonces esa es la diferencia, más que en términos de los contenidos también en términos de la actitud que tienen frente al estudio, porque claro si bien hay gente que viene acá al colegio y no con muchas ganas, o que emoción aprender, ósea, tampoco, eso sería una mentira, pero si la diferencia es clara en términos de que ellos vienen a hacer algo que ellos proponen, entonces lo que ellos proponen es lo que hacen y eso le da un poco más de compromiso, entonces hay una vinculación emocional y vinculaciones, con lo que están haciendo , entonces eso permite que las clases se desarrollen muchísimo mejor y por otro lado, en la educación tradicional, si tu miras en el IPN a lo que se le apunta es a que los chicos declaren conocimientos, lo que llaman conocimiento declarativo, ellos saben que es 
voz pasiva, que es tal cosa, que es tal otra y pueden decirte los autores más conocidos desde el romanticismo, hasta el final de los 90 en la literatura colombiana, pueden decírtelos, pero no saben qué hacer con eso, porque allá no se apunta nunca a la construcción de un discurso sobre las cosas a la construcción de un pensamiento sobre las cosas sino a la repetición de esas cosas, la construcción de estrategias, para memorizar las cosas, entonces esa sería la diferencia, como acá tenemos proyecto y productos, entonces los productos posibilitan la construcción de un discurso. Creo que es lo que más buscamos aquí. (Sabogal, 2017, entrevista)

Entonces no solo se puede destacar la libertad que tienen a la hora de planear sus proyectos pedagógicos, tiene que ver con lo ligadas que pueden llegar a estar sus propuestas pedagógicas con los ejes que atraviesa todo el programa que van a desarrollar a lo largo del año, pues esto les brindan un horizonte claro de lo que se espera de sus clases y sus aportes a la institución. Los docentes trabajan partiendo del hecho de que están siendo mediadores culturales y en esa medida comprenden que las necesidades de los estudiantes y de los cursos con los que trabajan varían, por eso sus programas tienen como principio rector esta realidad.

La educación pierde aquí la connotación que tradicionalmente ha tenido, de ser un proceso que supone la ilustración de uno a partir de otro, que supone el saber de uno y la ignorancia de otro, para ser vista como la puesta en juego de diversos saberes y formas de percibir la ciudad, de percibir el mundo para conformar a partir de ellas un proyecto común. (Secretaría de Educación Distrital, 2004)

En este apartado se comprende, como con la educación alternativa, se supera la mirada bancaria de la educación tradicional como la llama Freire. Se tiene en cuenta al educando como una parte valida del proceso, como un vocero de conocimiento y no solo como un receptor de la información. Es muy interesante ver la relación que existe entre el profesor y el estudiante, pues en realidad el docente entra a guiar y direccionar un proceso de exploración propuesto por el estudiante, no al contrario y lo que esto genera es una actitud diferente a la hora de aprender. La diferencia radica principalmente, en que cada uno de los participantes de la experiencia educativa está en un proceso de constante descubrimiento y creación.

Añadiendo a todo lo anterior, otro de los aspectos relevantes de esta experiencia es el componente del "vinculo" que expone el docente Sebastián Sabogal y es que los estudiantes al 
ser una parte activa de su proceso de aprendizaje tienen la posibilidad de trabajar sobre temas de su interés, lo que permite un mayor interés por parte de ellos y eso se evidencia a la hora de crear cualquier tipo de producto referido al tema de su preferencia.

Es significativa ver la importancia que se le da a la "creación de discurso" en el desarrollo de los proyectos elaborados por los docentes, pues de esta forma entra a mediar el aspecto educomunicativo también; ya que todo aquello que los estudiantes reciben de los distintos medios comunicativos, lo confrontan con su realidad por medio del conocimiento que reciben de sus docentes o que encuentran en distintas fuentes y posterior a todo ese proceso inicial de comprensión, se encargan de construir un conocimiento profundo del tema, que se convierte en últimas en el discurso que se va a ver reflejado en el producto que van a ejecutar.

Estudiante: "Uno siempre como que en todos los espacios diferentes al colegio, escucha que la educación es con base a una figura de autoridad entonces es un profe que siempre te dice como son las cosas, que te dice como son las cosas, como que a veces no cuenta y aunque a veces pasa en el salón como que, no que tu opinión no cuente sino que hay siempre una figura un poco de autoridad, este colegio en particular me enseña que la educación no es así y que quizás la manera más viable de una educación más integral para todo el mundo más incluyente es que todos nos enseñen igual sin distinciones de cosas él es el profe yo soy el q más lee, el que más sabe, sino q todos tenemos esos conocimientos entonces en vez de q cada uno se especialice, se trata de compartirlo. Y creo q es algo que le debo a este colegio, porque se da la oportunidad de hacer un debate, en las clases, de dar tus opiniones, de justificarlas, de tratar de seguir pensando en eso" (Lizcano, 2017, entrevistas).

Lo que menciona Lizcano, hace referencia también a la manera en la que se quiebra el sistema tradicional de la educación en la Mediática, pues las relaciones docente - profesor se transforman, ya la autoridad ganada a través de la distancia se vuelve respeto y admiración por aquellos seres que acompañan tu proceso de aprendizaje, es una relación de cercanía, escucha y construcción de conocimiento. A continuación se confirma con el testimonio de Bejarano: 
Administrativa: "En que los chicos son libres, en cuestión de que pueden expresar y decir e investigar y saber que han salido chicos muy bien preparados a defenderse de todo, esa es la gran diferencia" (Bejarano, 2017, entrevistas).

Entonces los elementos principales que diferencian a esta educación del resto, está en lo que metodológicamente ocurre al interior, las materias que se dictan, la manera en la que se enseñan, los roles de poder que se manejan y su estructura de por sí, habla de una educación que se aleja de las concepciones tradicionales y le apuesta a nuevas formas de dar participación a los estudiantes.

Con las distintos aportes realizados por directivos, docentes, estudiantes y administrativos se puede evidenciar los alcances de la educación alternativa, Mena (2013) y Cuesta (2009) explican la manera en la que la educación tradicional opera y la apuesta de esta propuesta pedagógica al romper los esquemas de normas, materias específicas, modelos de enseñanza cerrados, patrones de comportamiento esperados y lógicas de poder establecidas a través del autoritarismo, se abren posibilidades dentro de las instituciones educativas que son creadoras de escenarios en donde el aprendizaje es un disfrute, como lo menciona Freire (1991), la escuela se convierte en el espacio para poner en práctica libremente el ejercicio de la ciudadanía.

Otra de las contribuciones fundamentales de lo que se sustrajo del trabajo de campo es lo que menciona (Aguilar, 1993) frente a lo que es realmente la educación alternativa, no la que pone paños de agua tibia al problema educativo que se atraviesa, más bien, aquella que se encarga de transformar desde la base la educación cambiando toda la lógica prescrita desde la tradicional. La propuesta de la Escuela Mediática es revolucionaria en la medida en la que propone lo que ellos denominan pedagogía proyectiva que más allá de ser un trabajo por proyectos aislados, se trata de esfuerzos por trabajos que entrelacen todas las áreas del conocimiento, en donde se la información se entreteje y eso se hace evidente en lo que los mismos estudiantes, como por ejemplo lo que dice el estudiante de $11^{\circ}$ Giorgio Lizcano (2017), "todo tiene que ver con todo".

El fin de lo anterior con miras a como dicen Díaz (2010) y Quijano (2014) empezar a mirar la educación desde una mirada decolonial del poder y descentrar el conocimiento de aquellos países que colonizaron los territorios, pero también el conocimiento, abriendo paso a nuevos retos y conocimientos propios, desde una mirada crítica e histórica, esto es lo valioso de este 
modelo, que da voz a los estudiantes, permitiéndoles generar conocimiento desde el primer entorno en donde construyen ciudadanía, la escuela. Esta apuesta decolonial, se pone en práctica cuando se le da a los estudiantes la oportunidad de influenciar en los medios de una manera alternativa, dándoles el poder de ejercer su ciudadanía y haciendo parte de una transformación desde esta perspectiva.

Ahora bien se van a tener en cuenta aquellos elementos significativos de la "Caracterización de la práctica pedagógica de la relación con el conocimiento y de la interacción social, que se dan en el trabajo por proyectos, eje de la innovación educativa en el centro educativo cel." Este documento institucional, es el que orienta metodológicamente la práctica pedagógica de la Escuela mediática, en esa medida se hace conveniente resaltar los ítems más representativos y confrontarlos con la realidad. Entonces, lo que se encuentra en los principios de lo que se expone como alternativo, es lo que esencialmente escrito y tiene todo que ver con lo que ocurre en la cotidianidad, existe entonces una coherencia innegable y tangible.

- Nace por la necesidad de encontrar una manera de hacer que la educación sea algo más que un estadio de paso, en donde no se excluya a los jóvenes que reproducen la cultura y en portadores de ella, sino que por el contrario los incluya y les de voz.

- Una institución media, que gira alrededor de los medios y las mediaciones como conceptos integradores de una propuesta que resulta innovadora en un medio como el nuestro que no admite.

- Concepción de currículo abierto y pertinente: falible y con capacidad de apertura, contrición creativa y permanente, contextualización socio-económica y cultural.

- Es un proyecto de educación alternativa en la medida en la que se erige alrededor del reconocimiento del ser juvenil y del papel mediador de la escuela en la relación con la cultura un proyecto que irrumpe la tradición y que le pone la cara al nuevo siglo, que le extiende los brazos y la invita a trazar los nuevos mapas que orientaran la educación de mejores seres humanos.

- $\quad$ (Forero, 1999).

La relevancia de este, reside principalmente en que permite la comprensión otro elemento que hace alternativa esta institución y es su trabajo por proyectos, que no solo se lleva a cabo en el CEL, sino que además se tiene en cuenta en la media bivalente de la Mediática, este trabajo por 
proyectos permite que como lo dicen los docentes y los estudiantes los temas no estén aislados, por el contrario se nutren de las distintas áreas del conocimiento y se materializan a través de los distintos productos que se presentan, es de esta forma que aquello que se aprende no es simplemente un conocimiento más, se trata de un discurso implantado, procesado, dado a conocer he interiorizado en la vida de los estudiantes. En medio de la observación participante, se confronto lo que se contemplo como educación alternativa en los documentos y entrevistas y lo que se logro evidenciar desde el inicio permite ver la relación directa entre el discurso de la educación alternativa, con la práctica que es lo que se lleva a cabo.

"Desde el inicio la atmosfera del lugar habla de que algo distinto ocurre alli y no se trata únicamente de un misticismo más. El colegio queda ubicado en el centro y no tiene la estructura típica de uno, es más bien una casa antigua con pintura de color verde esperanzador y llantas de colores, que simulan un lugar de descanso para las plantas que los acompañan. Los anuncios pegados a las paredes contienen información administrativa, como algunos posters hechos por los estudiantes. Mientras espero a Hilda para nuestra primera reunión, una señora que viene a averiguar del colegio mantiene una conversación vía telefónica en la que dice el primer elemento que marco mi inicio el la Escuela Mediática "Este colegio es como de loquitos, los chinos no usan uniforme y hablan de libertad todo el tiempo, creo que eso le hace falta a mi hijo, por que esos otros colegios no le han servido”. Entonces acá es donde se entiende que para ser alternativo no se requiere de un discurso muy elaborado, las mismas prácticas hablan de lo que ocurre en ese lugar, se siente, se vive y se ve, sin necesidad de mucha propaganda lo que ocurre ya es evidente, desde la primera visita.

Con el paso del tiempo y de las visitas que realizaba, me daba cuenta de que no solo las personas externas reconocen el modelo alternativo de esta institución es algo que esta impregnado en la manera en la que los estudiantes, administrativos, directivas y docentes lo ven y encontrar esa congruencia habla de que los procesos que se están desarrollando son tan positivos que marcan a las personas que conforman esta experiencia. Ahora bien, no solo se trata de lo que ellos dicen, es el ambiente que se percibe y lo que se comprende viendo las dinámicas que se desarrollan, hablan más fuerte que todos los documentos que se puedan estudiar acerca del tema” (Diario de campo, 2017). 


\subsection{Cultura de convivencia}

A continuación, se presenta la manera en la que se evidencia la cultura de convivencia dentro de la Mediática y la forma en la que se percibe a diario, esto con el fin de comprender como se construye este cohabitar gracias a los esfuerzos que teje dentro de esta institución educativa. Entonces se pondrán en consideración aquellos juicios de los sujetos que están asociados a este espacio, podría decirse que a lo que se encontrará acto seguido son los testimonios y opiniones de las personas involucradas en la escuela, para descifrar las mécanicas de cultura de convivencia que se llevan a cabo dentro de la Mediática.

- Madre de familia: "Yo pienso que en esencia el colegio que un escoge para sus hijos es el máximo que uno puede encontrar, con lo que se acerca a sus ideales de vida... yo encontré cierta solidaridad un afecto que no se encuentra en un colegio tradicional y en los niños eso también se empieza a vivenciar como madre de familia. La interacción se concibe así en una acción estructurante organizadora de la concepción de sí mismos, del mundo y de los demás... es decir: con fundamento en las múltiples posibilidades humanas" (Sánchez, 2017, entrevista).

- Madre de familia: "Mira cuando yo llegue a este colegio, dije encontré un lugar mágico en el centro de Bogotá , nunca pensé que existiera (... )me di cuenta que existe otra sociedad, dentro de la que vivimos caótica... si existe y es este lugar, cuando yo llego acá me doy cuenta que la forma de trato, de convivencia, la forma en la que los chicos llevan las relaciones emocionales es totalmente diferente, es una sociedad diferente, en que la forma de hablar, de expresarse, la forma crítica, en la que ellos se manifiestan ante los demás, en que lo hacen, de una manera muy fraterna muy bonita muy respetuosa, a pesar de que son chicos adolescentes y que si... y en su vocabulario no es esa jerga ordinaria, que uno escucha, por fuera, es un poco más moderada, es un poco más atinada en las cosas, no dejan de tener palabras vulgares, son chicos, no? Pero en la forma de expresarse con los demás es diferente" (Olaya, 2017, entrevista).

Los testimonios de estas madres de familia son de suma importancia, ya que en este se pueden considerar distintos fundamentos, que hacen que la Escuela Mediática se vuelva un caso apropiado para esta investigación. Se puede entender que lo que un padre de familia busca para su hijo es un espacio en donde pueda desarrollar todas sus capacidades, pero además en donde 
se materializan sus ideales y expectativas para sus hijos, en este caso, la apuesta de los papas que escogen este lugar para ellos es la búsqueda de otro tipo de educación, otra clase de espacio, con unos principios distintos al resto; el punto que llama la atención acá, es que inclusive los papas comprenden las diferencias explicitas de la Mediática y no necesitan de un discurso, de publicidad o de una fachada que prometa para hablar de lo que es el Colegio. Ellos pueden ver las relaciones de respeto y tolerancia en las que se enmarcan los vínculos que existen dentro de su socialización cotidiana, en donde caben "todas las posibilidades humanas" ya que en la medida en la que hacen el ejercicio de reconocimiento propio, se esta abriendo una ventana hacia la comprensión del resto de formas de vida.

Debido a lo anterior, los padres pueden saber que sus hijos estar recibiendo una formación integral en donde el aspecto más importante es su reconocimiento propio y sus distintas formas de comprender todo lo que le rodea. En esta medida al tener un contacto inicial con la Mediática se pueden ver y evidenciar elementos diferenciadores, es por este motivo que en muchas situaciones la experiencia dentro esta institución se puede concebir como un lugar "mágico" por que las prácticas que se llevan a cabo dentro de esté lugar son distintas al resto y por que en medio de lo que se considera el común denominador existe un caso que es diferente, demostrando que otro tipo de realidades están esperando por ser construidas

- Estudiante: "Yo personalmente creo que el colegio ayuda mucho y cambia a las personas, por ejemplo yo que estoy desde chiquita he visto ir y venir a muchas personas, los chicos más nuevos en nuestro curso llevan tres años, y cuando llegaron, eran chicos muy distintos, a como los recuerdo, eran personas distintas, serias, a veces agresivas, y realmente es un espacio que te das cuenta $y$ transforma a las personas, porque les da la oportunidad de descubrirse, entonces eso hace como que la convivencia sea más fácil. Más bonita, amena... y pues por ejemplo, como algo personal, yo como que interactuó mucho con las personas, por ejemplo con los de $10^{\circ}$ que son los otros de la mediática, como que tú los vez y puede que uno no sea cercano, pero tú te ríes, con la persona, así nunca hablen, puedes entablar una conversación (...) Las personas por ejemplo me he transformado por ellas y gracias a mi misma, pero por medio de los otros y no sé cómo que en general yo de verdad de tantos años digo que es mi otro hogar, ellos son mi familia, como esa otra parte que tú tienes, 
gran parte de lo q quiero ser es por las experiencias q he tenido acá y por q esto es una construcción tuya junto a los demás" (Córdoba, 2017, entrevista).

De hecho, lo que se expone en este apartando es precisamente lo que dice Parra (2000) cuando menciona como gracias al encuentro con el otro es posible crear una comunidad, y esto es lo que ocurre en la Escuela Mediática que en la medida en la que se propician tantos espacios de encuentro con sus pares se construye comunidad, pues aprenden a cohabitar con el otro. Es en ese proceso de negociación de relaciones y códigos de cultura de convivencia que están tan marcados que terminan impregnando a todo aquel que llega, quiere decir que se ha consolidado de manera tan fuerte este concepto que tiene un impacto positivo en aquellos que llegan a hacer parte de la institución.

Como dice Illera (2005) entienden que no existe una única manera de pensar, que se pueden encontrar otros modos de ver la vida, comprenden que la realidad no está condicionada por su manera de verla, pues cada escenario de la vida es diverso y aquellos que lo residen son testigos de esta verdad. Ese es el inicio de todo, el fundamento para lo que ocurre en la Mediática y de hecho el éxito de sus prácticas. En la medida en la que se trabaja con los mensajes que circulan en general, no solo en los medios, sino también en los discursos de sus pares, se construyen otro tipo de posibilidades frente al respeto y de la forma de pensar del otro.

- Administrativa: "Pues acá ellos son felices, ósea hay padres de familia que cuando los chicos salen de vacaciones y vienen a pagar, empiezan a preguntar, pero cuando van a entrar de vacaciones, tal día y contestan, pero es que mi niño me tiene desesperado, que ya quiere entrar, entonces es un espacio que los hace felices” (Gómez, 2017, entrevista).

- Administrativa: "Aquí trabajamos como en familia, no es que el profe y nosotros, es una familia, todos debemos estar en un mismo circulo, pero los directivos y socios quieren que trabajemos en familia y que estemos bien porque así mismo trabajamos mucho más tiempo" (Bejarano, 2017, entrevista).

Lo que dicen las personas que trabajan en el área administrativa, es relevante, ya que muestra una vez más que lo que ocurre dentro de la Mediática es algo que es verídico. Cuando ellas se 
refieren a la escuela como un lugar en el que los estudiantes quieren estar, donde se les permite ser felices y donde cada miembro hace parte de una pequeña gran familia, se entiende también el aspecto diferenciador, pues todos los que hacen parte de la experiencia educativa son importantes y lo evidencian.

Es importante detenerse en estas intervenciones y comprender que cada una de las personas que hablan, lo hacen desde otras miradas totalmente distintas, las primeras son dos madres de familia, la segunda es de la docente Margarita, la siguiente la de la estudiante del grado $11^{\circ}$ Sofía, la cuarta y la quinta de las secretarias académicas de la Mediática, lo que nos puede brindar un espectro amplio y claro frente a lo que todos los involucrados conciben la forma en la que está constituida la cultura de convivencia.

- Rectora: "Este espacio es un espacio altamente democrático y altamente participativo, los chicos son sujetos de derechos eso ya es un enfoque, por principio trabajamos con, por y para los derechos humanos. Entonces son los chicos y chicas sujetos de derechos, entonces tienen voz y voto, en muchas de las decisiones que se toman, obviamente que habrá unas decisiones institucionales que no tienen a lugar que discutamos. Que le discutimos a llegar temprano a un lugar , pero como nos movemos, como trabajamos, hay discusión en eso (...) Además, los maestros en la escuela mediática, como su nombre lo indica es un mediador, entre la cultura escolar y la cultura juvenil y este espacio es un foro de negociación de cultura (...) los jóvenes y las jóvenes son interlocutores válidos, si, entonces todo eso es construcción de cultura democrática y la comunicación no es digamos piramidal, ósea es horizontal, somos como una familia, las señoras del aseo, son tan queridas como los profesores, todos tenemos acá cosas que aportar, entonces nos tratamos con afecto y cuando se medía el afecto en un proceso pedagógico es muy fácil aprender" (Forero, 2017, entrevista).

Lo que habla la rectora de la institución no solo hace referencia a la forma en la que se construye la cultura de convivencia en este lugar, hace un aporte a una de las premisas más importantes de esta investigación y es la forma en la que a través de lo que se posibilita dentro de esta institución, se esta generando un mayor impacto en los estudiantes que están ejerciendo su ciudadanía desde este primer escenario. Tiene todo que ver con la postura política que a lo largo del texto se tiene en cuenta y responde al principal alcance de la educomunicación y es la manera en la que este genera cultura de convivencia, efectuando 
Más allá de visiones instrumentales o funcionales que vinculan la educación y la comunicación tan sólo superficialmente, la política debe entender la comunicación como un proceso constitutivo de las relaciones sociales que se encuentra en la base misma de la democracia y no sólo como la interacción mediática de usuarios o audiencias con las tecnologías y los medios de información y comunicación. Así mismo, la educación debe ser entendida como un proceso constante de reconstrucción y apropiación de la cultura que permea la vida de la ciudad. (Secretaría de Educación Distrital, 2004)

Es precisamente la visión profunda que se da de la comunicación y la educación, la que permite que cada estudiante dote de sentido su rol dentro la sociedad, aportando positivamente a la construcción de relaciones basadas en el respeto, en la escucha y en la comprensión de la realidad que circunda al otro.

- Docente: "Ellos llegan a descubrir su mundo también, y como llegan a descubrir el mundo, ellos se reconocen como individuos porque acá se trabaja la construcción del individuo, entonces si yo soy un individuo el otro también lo es, ese es el secreto de la armonía que hay acá, ellos acá desde chiquitos están juntos, han jugado, es por eso que tú nunca vez una pelea marcada, porque la concepción completa del aprendizaje desde una percepción completa de descubrimiento , implica descubrir al otro siempre, que no es otra concepción que está en otras colegios o en el sistema tradicional que educarse es ver quien saca la mejor nota, que es mire haber usted como hace desde la siete hasta las dos, no es eso, sino que gente que se reconoce como individuos, como sujetos de derechos, es eso, porque no existe la noción de competencia, desde la lógica de no tener notas empieza a surgir eso, ahora la otra cosa es esta, cuando tu incentivas a que los muchachos comuniquen, discutan, compartan, eso implica debate, entonces si ellos desde chiquitos están debatiendo, porque ellos tienen sus proyectos personales, entonces tienen que averiguar sus cosas y exponerlas a los demás, esta misión de muéstrame que quieres aprender y como lo aprende y como lo quieres mostrar es yo te reconozco como otro sujeto y acá eso es lo que se facilita, entonces si acá tú te fijas, las relaciones son realmente buenas, entre todos las personas, pero es por esto, por nuestra concepción del aprendizaje de nuestra concepción de cómo se muestra o que se aprende y para que se aprende siempre está la construcción de individualidad y alteridad" (Sabogal, 2017, entrevista). 
Es por lo anterior que se puede comprender que la construcción de cultura tiene todo que ver con una formación sana de convivencia escolar de cualquier institución, en este punto Aguilar \& Betancourt (2000) mencionan la importancia de entender la cultura juvenil y hacen la invitación de entender a los estudiantes y a la carga emocional, histórica y cultural de cada uno. Lo anterior, se relaciona directamente con lo que menciona Hilda y Sebastián en sus comentarios y es básicamente volver a los estudiantes portadores validos de voz y voto, los jóvenes necesitan reconocimiento y en esta medida para ellos la construcción de ciudadanía desde la participación se convierte en un ejercicio mucho más sencillo, pues se está quebrando el modelo en el que los jóvenes no tienen nada que aportar y por lo tanto no hacen nada frente a lo que ocurre en su País.

Es precisamente el reto que Rocha (2000) plantea a los estudiantes y a los docentes, el de crear puentes de comunicación en donde todos construyan, no solo unos cuantos. Es este el potencial creador de una cultura democrática, en la que se construye convivencia, pero además se aporta para la creación de una ciudadanía joven interesada en la transformación de los problemas sociales que los circunden.

Considero que la veracidad en gran medida de esta apuesta pedagógica tiene que ver con la coherencia entre lo que se dice y lo que se hace. Es a lo largo del trabajo de campo que se comprende como la dinámica de la institución está marcada y guiada por unos principios básicos que se respetan y hacen parte de la manera en la que cada miembro de la institución concibe este lugar. Lo que se demuestra con las declaraciones de los estudiantes, docentes, directivos y administrativos es que como dice Ortega (2000) el estudiante al ser consiente del espacio y el contexto en el que se encuentra, puede entender sus relaciones sociales desde una perspectiva justa, en la que la empatía y el reconocimiento del otro priman.

Lo anterior, abre paso a lo que se abordó en el grupo focal referente al tema de la cultura de convivencia. Entender la forma en la que los estudiantes entienden este aspecto dentro de su colegio, permite seguir ampliando el panorama de este aspecto . 
Estudiante: “Acá existe respeto, tolerancia, yo lo veo como la manera en la que podemos descubrirnos a nosotros mismos en el proceso de aprendizaje sin imponernos, con unas bases, pero no diciéndonos que hacer específicamente" (Córdoba 2017, grupo focal).

Estudiante: "Cada uno se relaciona como quiere con las personas, a ti no te lo inculcan, solo te dejan ser porque no es autoritario. Tu aprendes a tomar tus decisiones en medio de las clases no porque el profesor te diga cómo hacerlo, sino por qué estar con el otro te capacita para hacerlo" (Sajándome, 2017, grupo focal).

Estudiante: "Siento que nos enseñan a respetar a los otros y el pensamiento diferente, que no se trata de acabarlo sino de enriquecerlo" (Lizcano, 2017, Grupo focal).

Estudiante: "yo creo que uno tiene mucha voz dentro del colegio nos ayuda a tener una convivencia sana y eso nos lleva a tomar decisiones positivas, nos dan la oportunidad de que si tenemos un problema lo podemos hablar y ser escuchados“(Vélez, 2017, Grupo focal).

En los testimonios anteriores se encuentra la clave de gran para parte de lo que se logra en la Mediática, ya que tiene que ver con la posibilidad que proporcionan a los estudiantes para que tengan criterios firmes en cuanto al descubrimiento propio, para que en ese orden de ideas se reconozca al otro y es este reconocimiento del otro el que hace que los estudiantes puedan ser independientes tomando decisiones que respeten la integridad de los que los rodean. Un ejemplo de lo anterior es uno de los comentarios escritos por alguno de los estudiantes en la actividad representativa del árbol.

"Nos dan la libertad de usar el diálogo como impulsor de vida, sin embargo, este va en decadencia cuando nos convencemos de que nuestra vida vale más que la de los demás" (Grupo focal, 2017).

La construcción de esta clase de discursos frente a la convivencia y la no convivencia resulta confrontante, en la medida en la que demuestra que el respeto parte del principio inicial de la misma vida y el valor de la vida del otro. Profundizar en la manera en la que los estudiantes contemplan las dinámicas de coexistencia dentro de su colegio se convierte en la forma perfecta, para comprender el porque es un ejemplo de convivencia. 
De ese modo, se estará cultivando la responsabilidad ciudadana potencial de nuevas generaciones. Conocerse y entenderse a sí mismo es el preámbulo para la comprensión de otras personas, lo cual es el objeto de la inteligencia interpersonal: cómo interactuar con los otros, cómo comprender sus personalidades, cómo entender las diferencias, cómo respetar las distintas visiones del mundo. (Hernández, 2001).

Lo que se ve con este apartado que hace Hernández (2001) es que la responsabilidad ciudadana que se esta construyendo a través de este primer constructo de convivencia dentro de la escuela va a ser fundamental en el papel que van a desempeñar en sus distintos contextos. Lo anterior parte de un concepto que se trabaja fuertemente en la Escuela Mediática y es la inteligencia interpersonal, esto es claro por sus distintos esfuerzos direccionados al desarrollo de las habilidades sociales de los estudiantes, todo con el fin de que puedan participar activamente dentro de la sociedad.

A continuación se presentan los elementos que se toman de los documentos institucionales que se tuvieron en cuenta en la revisión documental. En este caso se toman elementos fundamentales del documento de regulación de la convivencia.

- En la concepción de cultura de convivencia se concibe al ser humano como un ser político, que está en la capacidad de participar en la toma de decisiones sobre las pautas de convivencia social y somete sus opiniones a la discusión política.

- El nuevo paradigma será de respeto por las diferencias: la democracia tendrá expresiones reales en un pluralismo en los diversos órdenes de la vida social, cultura, relación y política hasta las relaciones entre las etnias, los ceos y las relaciones interindividuales en la vida cotidiana.

- La construcción colectiva de las normas de convencía es necesario el ejercicio del respeto por las normas y la obediencia a las sanciones que ocasiona su incumplimiento, todo lo cual no contradice, sino que confirma, un ambiente educativo participativo y democrático como rector de nuestro proyecto educativo institucional.

- Funcionamos bajo un principio de autorregulación: donde se aplica el concepto de autonomía, planteada como unos procesos de capacidades para participar en procesos de autorregulación en los que se pretende consolidar principios morales sustentados en criterios de justicia, equidad, tolerancia y ecuanimidad.

- En este proceso se da la posibilidad de descubrir al otro y pactar con él a través de la negociación y el diálogo que genera consensos y disensos, es decir un proceso permanente de interacción, democrático y no autoritario. 
- La interacción social y el ambiente escolar entran en juego. pueden ser contenidos en una acción altamente comunicacional que trasciende los espacios, afecta los sujetos y se consolida mediante una serie de discursos validados colectivamente, consolidando la propuesta desde una visión proyectiva que amplia y auto determina desde el conceso, el conflicto, las tensiones y búsquedas alternativas de interacción.

(Forero, 1999).

Este documento contiene los pactos y compromisos que se deben tener en cuenta para que el desarrollo de las actividades pedagógicas planteadas se lleven a cabo en el marco del empatía y respeto. Este documento no es simplemente un manual de normas escritas por los directivos y docentes, es un compendio de acuerdos creado participativamente y con la colaboración de los estudiantes. Este elemento es sustancial en la medida en la que demuestra que lo que está escrito en el PEI y lo está impregnado en la argumentación de los miembros del plantel, es totalmente afín. El enfoque educomunicativo de la Mediática permite que la ciudadanía se construya desde estos espacios, brindando a los estudiantes la posibilidad de ser conscientes de su entorno y su responsabilidad con el mismo, se trata de un compromiso en doble vía, en el que al poder usar su voz y manifestar sus ideales, encuentran un espacio para por medio de la palabra crear y construir un cohabitar con sus pares más humano y más sensato. En este espacio el uso del lenguaje y el habla es supremamente importante porque no solo tiene un potencial creador, la voz circula y en esa medida la convivencia se construye peldaño a peldaño o podría decirse que palabra a palabra.

Frente a lo que se expuso en el aspecto teórico y lo que se encuentra los documentos institucionales, confrontado con la realidad se permitió constatar la forma en la que la educomunicación se hace evidente en las prácticas, ya que se evidencia como a través de la palabra se soluciona y gestiona cualquier tipo de conflicto, acuerdo o ordenanza; el ambiente familiar que se siente alrededor y que cada miembro de la institución manifestó posibilita la comprensión de la manera en la que se construye la cultura de convivencia en esta institución y es a través de la escucha y el uso del lenguaje como gestor de ambientes mediados por el afecto y el respeto. 
Ver la manera en la que se relacionan los estudiantes en el diario vivir, escuchar a los estudiantes hablando con los docentes, estar en medio de una reunión y ver a los estudiantes entrar con calma a la oficina de Hilda la rectora sin temor, sino más bien con familiaridad; observar a los administrativos cómodos con su trabajo y una sonrisa en su rostro, fijarse en la forma en la que cada estudiante manifiesta sus ideas y hace parte del proceso educativo, habla precisamente del ambiente que se propicia en este entorno y ratifica el por que el modelo educomunicativo, aporta a la construcción de cultura de convivencia y disminuye notablemente las prácticas de violencia escolar, pues precisamente un ecosistema en donde el afecto se siente de una manera tan real y donde los conflictos se gestionan por medio de la palabra, no se encuentre una solución.

Lo cierto es que analizar aquellos comentarios e interpretaciones acerca de la violencia escolar resulta relevante, en la medida en la que permiten ampliar la manera en la que se desarrolla la cultura de convivencia y la relación de esta con la disminución de este aspecto. Para lograr una comprensión considerable de este factor, se tienen en cuenta las percepciones de los miembros del plantel educativo, por medio de sus testimonios en las entrevistas y grupos focales, a continuación se presentan las apreciaciones de la rectora y un estudiante, en donde se revela si este fenómeno es común.

- Rectora: "Frente a los conflictos hay que gestionarlos, no llamarlos de otra forma, existen, somos y estamos replicando la sociedad en un nicho, que por muy afectivo, también hay dificultades, entonces se gestionan los conflictos, se les hace frente” (Forero, 2017, entrevista).

- Estudiante: "Se trata de charlas de cómo hacer un acompañamiento y no se trata de poner memorandos, y cuando alcances cierta cantidad te expulsamos o te suspendemos y ya, acá se hace más de charlas, si hay problemas de dos personas, se conversa con los compañeros del salón para que esto no siga pasando" (Martínez, 2017, entrevista).

Lo que se puede entender de estas intervención es que definitivamente, si bien, los conflictos no dejan de existir en cualquier tipo de educación, ni siquiera en la Mediática ya que "Entre los chicos también hay problemas pero cuando tu comparas con otros colegios, otros lugares, la convivencia es muchísimo mejor" Sabogal (2017). Desde esta mirada alternativa lo que se busca es saber gestionarlos para que no se vuelvan algo imposible de manejar. Es en esta medida en la que se puede dar cuenta dentro de las dinámicas del mismo centro educativo que 
la violencia no es palpable como en otras instituciones. También resulta fundamental ver la manera en la que no lo desconocen, por que si bien la violencia escolar se puede disminuir, el conflicto no se va a desaparecer, y que es un rasgo característico de los seres humanos y es común teniendo en cuenta que la escuela es un espacio cultural en el que se esta mediando y se están experimentando tensiones constantemente, sin embargo, acá la diferencia radica en como se gestionan.

- Estudiante: "Pues existen problemas, porque nada es perfecto, pero no sé, todo es muy distinto, cosas como el bullying y el matoneo, no se ven, ósea si hay cosas que se deben mejorar porque pues siempre esta eso, las diferencias y eso pero así como que aquí alguien sufra de maltrato súper fuerte no, porque es un espacio en el que puedes encontrarte a ti mismo y así entender a los demás" (Córdoba, 2017, entrevista).

Paralelamente a la comprensión de esta temática de violencia dentro de la escuela se tienen en cuenta los puntos mencionados por Ortega \& Mora-Merchán (2007) en los que se dice que estos comportamientos violentos estan configurados debido a la violencia estructural que es simplemente el reflejo la sociedad en la que nos encontramos, sin embargo, esta teória perderia un poco su validez teniendo en cuenta que los estudiantes de la escuela mediática hacen parte de este entorno, sin embargo, no son el reflejo de estos comportamientos. El punto de partida para la solución de estos conflictos, siempre será por medio del diálogo. Entonces, con los testimonios anteriores se puede entender desde la visión de los estudiantes que realmente contemplar la violencia escolar o le bullying dentro de esta institución se hace realmente difícil y se debe principalmente a que tienen la oportunidad de encontrarse consigo mismos y en esta medida reconocer al otro.

Estudiante: "Siento que nosotros somos privilegiados por estar en un espacio en el que no se ve tan palpable la violencia a gran escala, como en los colegios distritales en donde a veces tenemos la oportunidad de hacer servicio social y nos damos cuenta como lo que es la educación en Colombia y como se les enseñan temas que alguien cree que tienen que ver y así no les sirva pues lo deben ver. En este espacio es un tema muy denso porque cuando se ve es extraño (...) entonces como que es muy extraño cuando existe un casi de violencia marcado" (Sajándome, 2017, grupo focal). 
El esboso de información brindado anteriormente, legitima el hecho de que la violencia escolar en la escuela mediática tiene indices más bajos de este fenómeno, frente a los distintos establecimientos educativos que tienen que dar frente a diario a esta problemática.

Estudiante: "El año pasado que hice el servicio social con quinto, en un colegio oficial, habían niños a los que siempre los trataban mal, otro que siempre los trataba mal. Ese fue mi acercamiento más grande a la violencia escolar y lo sentí muy fuerte ni siquiera siendo estudiante de hay solo ayudante. Todo tiene que ver diría yo que con la manera en la que nos enseñan a escuchar a los otros desde pequeños (Lizcano, 2017, grupo focal).

Los estudiantes son conscientes de que el espacio en el que comparten con sus compañeros es diferente a lo que cualquier otro adolescente puede vivir en su colegio, ya que ellos realizan prácticas en colegios con otros enfoques, lo que demuestra que al tener un espacio en el que pueden contrastar su realidad alternativa, con la tradicional, diferencian y entienden que este fenómeno no es latente como en otros establecimientos educativos. Ver la reacción de los muchachos frente a los casos de violencia naturalizados en otros ambientes, es una prueba clara de que estas dinámicas agresivas no se presentan en la Escuela Mediática y tienen mucho que ver con la manera en la que a través de la comunicación se gestan estos espacios de cultura de convivencia en el colegio. Es gracias a los distintos espacios mencionados anteriormente que cada estudiante puede comunicar sus ideas, hacer valer sus opiniones, defender sus discursos y en consecuencia a esto puede en el mismo sentido validar aquello que sus compañeros expresan, pues es un proceso en doble vía, en el que cada individuo construye su conocimiento, aprendiendo a respetar y valorar el juicio que cada uno edifica.

Ahora bien, el análisis de la información que se realizo, permitió el cumplimiento de los objetivos propuestos al inicio de esta investigación, lo primero que se ejecuto teniendo en cuenta el planteamiento del primer objetivo fue identificar los procesos educomunicativos que se llevan a cabo en la Escuela mediática y aportan a la construcción de una cultura de convivencia. Examinar estos elementos a la luz de las técnicas planteadas en el diseño metodológico facilito su entendimiento. Los elementos que aportan a la cultura de la convivencia encontrados fueron: 


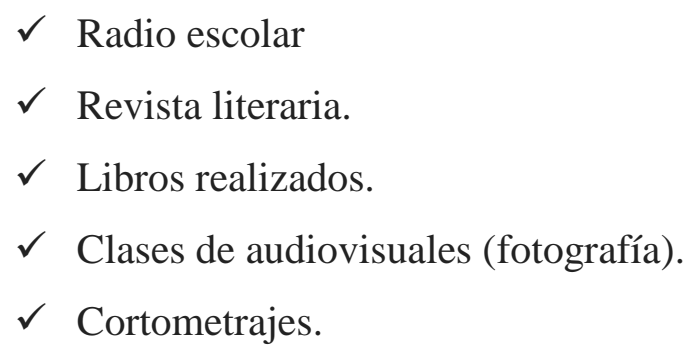

Acto seguido a la identificación de estos elementos, se procede al cumplimiento del segundo objetivo, en el que se determinaron los elementos característicos de estos procesos educomunicativos entorno a la construcción de cultura de convivencia dentro de la Escuela Mediática. Puntualizar en los elementos característicos de estos factores se hace relevante en la medida en la que dan cuenta de los aportes reales y fundamentales que hacen que la disminución de violencia escolar sea un aspecto tangible dentro de esta institución.

La Escuela Mediática cuanta con un enfoque educomunicacional que se sustenta básicamente en tres aspectos que se mencionaron anteriormente "el uso, recepción y critica de medios y nuevas tecnologías, los idiomas (inglés y francés) y las artes" (Forero, 2018, entrevista). Estos hacen parte de una manera amplia de concebir la comunicación y los lenguajes que se encuentran dentro de este espectro tan amplio. El aspecto en el que se centra la atención en esta investigación es el inicial que responde a las formas en las que se puede comprender el fenómeno de los medios y las nuevas tecnologías en la escuela, sus usos, alcances y críticas.

El primer medio que se encuentra en la Mediática es la radio escolar que es manejada por los estudiantes del grado $10^{\circ}$, ellos aprenden teoría y práctica radial, los elementos básicos que les permiten tener conocimiento de este medio, por ejemplo: aprenden a hacer escaletas, emisiones, tienen talleres de locución, redacción, dicción; todo esto los ayuda a comprender las dinámicas que se manejan dentro de este canal de comunicación. Ahora bien, el uso de la emisora tiene una única audiencia que son sus compañeros del colegio, es por eso que se busca posibilitar otros espacios en los que los estudiantes puedan llevar a cabo estas actividades y probar otros equipos y lugares, uno de esos son la emisora de la universidad Distrital, el Gimnasio Moderno, entre otras, eso lo explica la rectora Hilda Forero. "La radio es formadora de corrientes de opinión, de valoraciones, de estéticas" (Secretaría de Educación Distrital, 2004). 
Por su parte los estudiantes hablan acerca de la emisora, refiriéndose a ella como un espacio importante para poder aprender a manifestar sus ideas sin vergüenza, mencionan que en ocasiones por inconvenientes técnicos es difícil sacarle el provecho a esta como se debería, debido a que la emisora está construida domésticamente y su alcance es muy limitado. Sin embargo y a pesar de los por menores, lo realmente importante de esta experiencia es la formación que brinda a los estudiantes, en la medida en la que modela en los muchachos el buen uso de la palabra, es un espacio simbólico para escuchar y ser escuchado, para poner en manifiesto ideales y formas de pensar.

Es evidente que el ciudadano urge ser escuchado, ¿por quién?, por su familia, por la autoridad, por la sociedad. La voces de las audiencias son reveladoras, en este ejercicio, aparentemente intrascendente de dar la palabra, la ciudadanía reclama derechos: el derecho a la diferencia (social, racial, sexual, política), a la información (se cuestiona a los medios en los medios), a la salud y la educación (responsabilidades del Estado y de las instituciones). (Secretaría de Educación Distrital, 2004).

Entonces en este aspecto el elemento más fundamental, es que el uso de la radio, tiene un primer fin y es el de dar voz a los estudiantes, es decir hacerlos interlocutores validos de su proceso académico. La palabra entra a jugar un papel fundamental y construye un camino de comprensión, diálogo y congruencia en las relaciones sociales. Saber comunicar, poner en manifiesto ideas y exceptivas de vida, se vuelve elemental a la hora de mediar y gestionar cualquier clase de conflicto. Por ese motivo, el punto que aporta la radio a la Escuela Mediática es este.

Otro ejemplo de herramienta educomunicativa que se desarrolla en la Mediática es la revista literaria que se llama ciudades de piedra, hacen un lanzamiento al año. La rectora Hilda Forero, explica la importancia de este espacio simbólico que comparten con los estudiantes por medio de la revista, ya que no solo se trata de un producto sin sentido, sino que hace parte de su historia y en esa medida su significado trasciende. Los estudiantes de $10^{\circ}$ se encargan de realizar todo el diseño de la revista ya que uno de sus ejes temáticos es el arte y es por este que se dictan materias como diseño gráfico y artes visuales, materias que luego aportan a la construcción de cada edición y le dan a los muchachos las herramientas para poder materializar 
sus ideas y hacer uso de las herramientas informáticas y tecnologías. En este punto la revista literaria no es solo un proyecto de la clase de español en el que se escoge el texto mejor estructurado, sino que se convierte en el espacio en el que los estudiantes construyen de manera conjunta una memoria que va a ser guardada con el paso del tiempo, se trata de sus palabras, sus criterios, sus pensamientos plasmados en algo tangible.

El estudiante que comprueba la utilidad de su labor, siente liberar en su interior una imperiosa necesidad de actuar, buscar y crear. A medida que escriben y ven sus escritos publicados y leídos, va despertando su curiosidad, su apetencia de conocer más. Buscan ellos mismos, experimentan, discuten, reflexionan. (Secretaría de Educación Distrital, 2004).

El factor de la motivación en la escuela es fundamental, para comprender la manera en la que se construye cultura de convivencia. En la medida en la que los estudiantes comprenden que tienen un espacio en donde pueden materializar lo que aprenden, exponer sus ideas y aportar de alguna manera en su entorno, el cohabitar se vuelve más sencillo, pues se tiene la tranquilidad de que son sujetos validos en su proceso de aprendizaje.

La libertad de expresión y de prensa, en particular, es el derecho sobre el cual se fundamenta el periodismo. La empresa periodística sirve al bienestar público en la medida en que hace posible el derecho a la información y, a su vez, la escuela está al servicio del derecho a la educación. La prensa y la escuela se encuentran en la intersección de derechos y libertades. (Secretaría de Educación Distrital, 2004)

El punto que se destaca en esta parte es importante, pues también responde a la apuesta política de esta investigación, ya que es desde aca que se puede articular el alcance educomunicativo. Entender que la escuela también es encargada de aportar a el ejercicio consciente de ciudadania en donde se respetan los derechos, como por ejemplo el de la libertad de expresión es fundamental; es aca donde se consolida una construcción de convivencia, ya que se tiene la capacidad para que los que estan en ese contexto escolar puedan sentir que forman parte de algo. 
El día que se hace el lanzamiento de la revista, los estudiantes se encargan de contar lo que quieren reflejar en esta revista, algunos de los papas participan y hablan acerca de este espacio y al final se hace una reflexión al respecto. Esta es una actividad en la que todos están involucrados, los estudiantes se encargan de contar los asuntos de los que se habla en la revista y el por qué. Así es que se puede evidenciar que no se trata solo de un material de entrega, es un espacio en el que se construye convivencia en la medida en la que se integran todos los agentes importantes del proceso educativo, padres de familia, docentes, estudiantes y directrices, con un solo fin, celebrar la palabra y lo que ella representa.

En la Escuela Mediática se trabaja con un énfasis especial y es el de la pedagogía proyectiva que permite que cada área sea trabajada con la modalidad de proyecto, eso quiere decir que el trabajo por proyectos se maneja en el ámbito personal y también institucional, esta metodología termina materializándose en distintos elementos como los que se mencionaron anteriormente un ejemplo de esto son los libros que ellos elaboran, que tratan acerca de distintos temas (antologías poéticas, literatura fantástica, guerra y literatura, historia, política y literatura, entre otros), en estos se trabaja como en la revista literaria, ellos se encargan del diseño de este; pero aparte de eso en estos se hace un compendio de sus producciones escritas (realizadas en una materia que se llama taller de producción y redacción textual en español y en inglés), son sus reflexiones y escritos plasmados. Hilda explica que el valor de los libros está en el proceso creativo de los mismos, pues desarrolla su pensamiento lógico, sus habilidades comunicativas y su pensamiento crítico. Antes de que los muchachos realicen sus textos en esta materia, primero se pasa por un periodo de discusión y debate acerca de cada tema, en esta medida lo que ellos escriben responde a la necesidad que tienen de comunicar el discurso que han construido después de haber comprendido el fenómeno que se está estudiando.

Por otra parte, es importante reconocer que lo que se realiza en la Escuela Mediática no únicamente tiene que ver con lo impreso, también tienen clases de fotografía y audiovisuales en los que realizan cortometrajes y otra clase de material enfocado a lo visual. Para esto los estudiantes de grado $11^{\circ}$ tienen un profesor que es realizador de cine y televisión con el que hacen cortometrajes, documentales y video clips. Al realizar esta clase de materiales audiovisuales no solo se está aprendiendo la técnica implícita, se está estudiando la temática 
específica desde distintas visiones y voces, se está dando a conocer la postura de aquel que detrás de la cámara, al mismo tiempo esa realidad se está confrontando con lo que encuentran en los medios y en su contexto y ese es el principal aporte que se hace a la construcción de cultura de convivencia, pues en la medida en la que se comprenda la realidad de una manera diversa, de esta misma forma el nivel de reconocimiento y aceptación frente a los punto de vista de los otros va a incrementar notablemente. Los aportes del video en la clase tienen que ver con aportes como los siguientes:

Propiciar el debate y el diálogo conlleva presentar e intercambiar los elementos de información disponibles para facilitar el acuerdo o aclarar los puntos de vista sobre los asuntos de interés público en la resolución de conflictos locales, nacionales e internacionales.

La promoción cultural busca estimular la producción y circulación de bienes culturales. Difundir las obras artísticas y culturales para preservar el patrimonio del pasado; ensanchar el horizonte cultural del presente y despertar la imaginación, las ansias estéticas y la capacidad creadora de los sujetos.

La integración nos invita a facilitar el acceso a la diversidad de mensajes que necesitan todas las personas, grupos, naciones para conocerse y comprenderse mutuamente, y para entender las condiciones, los puntos de vista y las aspiraciones de todos los demás (Secretaría de Educación Distrital, 2004).

Entonces teniendo en cuenta los postulados anteriores, se destacan aquellos que se evidencian en la Mediática; por ejemplo el hecho de que a la hora en la que se realiza cualquier material audiovisual se comprende la problemática del tema a fondo. Además después de comprender a profundidad el elemento de estudio se generan nuevos discursos que aportan culturalmente y terminan afectando positivamente la que se contemplan las cosas, subvirtiendo el orden establecido y abriendo espacios en donde se escuchen otras voces.

Ser autónomo para producir video permite una cercanía con la realidad y la vida de los otros (Secretaría de Educación Distrital, 2004). Entonces el aporte de este elemento es que 
permite una comprensión amplia del panorama social, las problemáticas desencadenadas en distintos contextos, las apuestas culturales nuevas y las realidades de aquellas personas que circundan esos espacios. Es por esto que se aporta a la cultura de convivencia, ya que se preocupa por profundizar en la comprensión del otro y es en ese intercambio en el que se desarrolla empatía y se mejoran las relaciones interpersonales.

Todo lo anterior hace parte de la modalidad de trabajo por proyectos que se fomenta en la Mediática, todos entrelazados, tejidos entre sí, con un solo horizonte y propósito llevar a los estudiantes a ser partícipes de su proceso de aprendizaje, el fin mismo de todas las estrategias educomunicativas es darle voz a los estudiantes, se trata de darles validez en el proceso educativo, para que de la misma forma ellos en un futuro puedan dar voz a quienes están a su alrededor.

Los apuntes anteriores, hacen parte de aquellos elementos educomunicativos que se lleva a cabo dentro de la Escuela mediática y por qué estas permiten que las dinámicas estén diferenciadas y enmarcadas por el buen trato y las buenas relaciones. En este punto, se da el cumplimiento del tercer objetivo en el cual es importante resaltar cuales son esos elementos que se generan dentro de esta institución, que como se evidencio anteriormente terminan posibilitando el desarrollo de muchas habilidades, pero también aportan de manera implicita a la disminución de violencia escolar dentro de la escuela. Es por eso que subsiguientemente se exponen algunas líneas de acción que se han identificado a partir de este estudio:

- "Integrar nuevas tecnologías y lenguajes al aula de clase" Comprender que el uso de la palabra y de los distintos lenguajes que circundan la realidad son necesarios he importantes en la escuela. Por lo tanto no se pueden desconocer, estamos rodeados por distintos medios que se deben empezar a integrar en el aula de clases y no se pueden ignorar o censurar de ninguna manera.

- "Hacer conscientes a los estudiantes de que lo que aparece en los medios, configura la realidad" Los educandos necesitan espacios en los cuales su conocimiento esté vinculado a su realidad más cercana, es por esto que acercar lo que se encuentra en los medios a su aprendizaje resulta importante, en la medida en la que se confrontan los contenidos vistos en los distintos dispositivos tecnológicos con las áreas vistas dentro 
del colegio, se abre un terreno de debate, que posibilita el desarrollo critico de cada estudiante.

- "No limitarse a enseñar contenido, generar discursos" Declarar conocimiento y memorizar información, muchas veces se confunde con aprender. Sin embargo, la realidad es otra, en la medida en la que los estudiantes pueden vivenciar aquello que aprenden y entenderlo desde distintos puntos de vista este aprendizaje encuentra un significado más amplio que el que le puede ofrecer un término escrito en un libro. En esta medida y al asimilar las distintas aristas de aquello que se aprende se puede debatir lo estudiado y de esta forma permitir que se exponga aquello que se aprendió de la teoría, al realizar este ejercicio los estudiantes generan ciertos discursos internos.

- "Permitir espacios de construcción de conocimiento conjunto" El aprendizaje es un proceso que se da de diferentes maneras, sin embargo, cuando este es compartido se amplían las posibilidades y modos de comprensión, pues es en este punto en el que se comprende lo estudiado en conjunto, que se amplifican sus significados.

- "Crear comunidades comunicativas" Cuando el centro de la educación no es el contenido, sino el discurso que se construye compartiendo con otros, se empiezan a gestar maneras de cohabitar distintas a las tradicionales, pues gracias a esta oportunidad que se da de validar el conocimiento individual y grupal, se está también creando un sentimiento de familiaridad, en el que tu voz vale y tu opinión es valiosa, por lo tanto puedes verbalizar sin temor aquello que opinas.

- "Empoderar a los jóvenes y la cultura juvenil dentro de las instituciones educativas" En este punto lo más importante es primero reconocer que existe una cultura juvenil y que esta es muy diversa, cambiante, contiene códigos y ordenes características. Por lo general, antes que nada para identificar dicha cultura, es esencial escuchar y compartir 
con los que son portadores de esta. Cuando se amplían los espacios para escuchar, compartir ideales, generar conocimiento y reconocer al otro no solo se está aprendiendo, además se está posibilitando una conciencia de participación, que va a incidir directamente en su ejercicio de ciudadanía.

- "Integrar a todos los agentes educativos (padres de familia, docentes, estudiantes, directivas) en las apuestas que se realicen" Hacer partícipes a los estudiantes de sus procesos educativos es relevante, pero cuando a esto se adhieren los padres de familia, la motivación es mucho más grande.

- "La única manera de solucionar un conflicto es enfrentándolo" Reconocer el conflicto es la manera más adecuada para de salir de él, brindar las herramientas a los estudiantes para que hagan frente a las problemáticas que afrontan a diario se vuelve sumamente relevante pues en esta medida van a aprender a gestionarlos de la mejor manera.

- "Familiaridad antes que escolaridad" El éxito de la Escuela mediática está en el enfoque familiar que tienen, los estudiantes, los administrativos, los docentes, manifiestan que se sienten en familia y eso permite que cada miembro de este plantel educativo se sienta a gusto, es por esto que se piensa que cambiar el ambiente escolar, frio y normativo, por el familiar y consensuado puede aportar a la construcción de convivencia.

- "El proceso es más importante que el fin" Los productos educomunicativos que se quieran implementar en el aula de clases no pueden ser más importantes que lo que se desarrolla en su proceso, el lanzamiento de una revista literaria no sustituye todo el trabajo detrás de ella, porque en su construcción esta su riqueza, el estudio de los temas, los debates en clase, los escritos que son el reflejo del discurso que se generó, son la muestra de esto. 
- "Dejar ser, para construir un seremos" Cuando los estudiantes se sienten importantes dentro de su proceso de aprendizaje, son escuchados y valorados, reproducen estos comportamientos con sus compañeros, es decir que pueden de la misma manera escuchar, respetar y valorar la opinión del otro, porque el ejercicio del "ser" es algo en doble vía.

Las líneas de acción expuestas anteriormente, son parte de algunos de los elementos que se consideran más relevantes si se quiere empezar a gestionar la problemática de violencia escolar con miras a un modelo educomunicativo que construya y gestione espacios de cultura de convivencia. Todo lo anterior, confirma que la educación alternativa que propicia un enfoque educomunicativo, aporta a la contrucción de cultura de convivencia y por lo tanto, contribuye a la disminución de violencia escolar. 


\section{Conclusiones y recomendaciones}

Después de haber realizado un recorrido por lo que sucede en la Escuela Mediática, su apuesta y modelo; se hace necesario hablar de aquellos elementos que terminan de develar la importancia de lo que está escrito en estas líneas, como por ejemplo: reconocer los factores más relevantes, sus alcances y algunas de las conclusiones más sobresalientes que se consiguen de esta investigación, es por eso que acto seguido se presentan estos elementos que orientaron al reconocimiento de los factores mas relevantes en medio de este esbozo de información. En el mismo orden de ideas y se exponen algunas líneas de acción tendientes a la mitigación de la violencia escolar teniendo en cuenta el factor educomunicativo.

- Pensar en una verdadera transformación educativa desde las nuevas alternativas pedagógicas e incluso pretender un nuevo modelo de participación por medio de la educomunicación, en donde las voces de los involucrados en los procesos educativos sean escuchados, implica una tarea que comprende distintas problemáticas y necesita la creación de nuevos espacios es por esto que contemplar la posibilidad de más instituciones que hagan apuestas como las de la Escuela Mediática de carácter alternativo, se convierte en una premisa hacia el desarrollo de las distintas sociedades, en donde se comprendan otras prácticas de convivencia gestadas desde el mismo ejercicio pedagógico.

- La educación alternativa es gestora de transformaciones sociales y de desarrollo, en la medida en la que aporta formando ciudadanos críticos que tienen otra perspectiva de ver lo que sucede a su alrededor. La Escuela Mediática al empoderar a sus estudiante como responsables de su conocimiento y al hacerlos partícipe de su proceso de aprendizaje, posibilita la concepción de participación y por lo tanto, aporta a la formación de ciudadanos que participan activamente en sus entornos cercanos.

- La Educomunicación es la encargada de formar a los estudiantes para que puedan comprender el mundo de los medios de una manera diversa y crítica, en esta medida se preocupa por generar ecosistemas de aprendizaje mediados por las nuevas tecnologías. Comprender el funcionamiento de esos distintos lenguajes, requiere de un tiempo de 
debate en el que se profundice acerca de lo que está ocurriendo, esos momentos de dialogo posibilitan la formulación de discursos personales y la comprensión de la realidad desde unos lentes críticos.

- Los procesos educomunicativos que se desarrollan entorno a la cultura de convivencia en la Escuela Mediática son: la revista, la emisora, los productos audiovisuales, los impresos. Cada proyecto educomunicativo que se ejecuta, esta mediado siempre por el diálogo y la construcción de conocimiento por medio de la opinión del otro, esto posibilita el desarrollo del respeto por la opinión del otro y por tanto aporta a la construcción de cultura de convivencia.

- La crítica de la comunicación y los medios es uno de los elementos característicos de los procesos educomunicativos y de lo que ocurre en la Escuela Mediática, ya que los estudiantes al ser receptores de medios, también son productores y en esa medida la perspectiva se amplia.

- El objetivo de la Escuela Mediática no es simplemente generar un producto audiovisual o literario, la apuesta de esta institución va direccionada a la construcción del discurso que se da entorno al tema que se trabaja en el proyecto. En esta medida se trata de una educación liberadora como dice Freire (1970) en la que prima el aprendizaje a partir del conocimiento del otro

- En la medida en la que se reconoce al ser juvenil dentro del proceso de aprendizaje, se le da voz y se le invita a participar activamente de las decisiones que guían su proceso, este no solo se encuentra más vinculado al acto de aprender, sino que además es capaz de escuchar, comprender y debatir las ideas de sus pares, construyendo conocimiento en conjunto.

- La violencia escolar es innegable, sin embargo, dentro de la Escuela Mediática esta problemática disminuye, esto es gracias a que en esta institución educativa el sentimiento de comunidad es tangible y la convivencia esta mediada por la tolerancia y el respeto del punto de vista del otro.

- La manera en la que se solucionan los conflictos esta ligada a la negociación, el diálogo y el consenso; el modelo educomunicativo de la Mediática propone un constante 
encuentro con el otro, donde la fraternidad y respeto por la opinión de los otros, aporta a las interacciones cotidianas.

- las dinámicas institucionales dan cuenta de que la construcción de cultura de convivencia mediada por la educomunicación, no solo se queda en el discurso, sino que se convierte en una realidad que hace que La Escuela Mediática, sea ese espacio en el que se aprende, se construye conocimiento y se gesta transformación social desde el ejercicio de la ciudadanía.

El caso de La Escuela Mediática se vuelve una experiencia que contribuye al ejercicio de buenas prácticas de convivencia mediadas por la educomunicación, en la medida en la que distintos elementos pedagógicos que se tienen en cuenta en esta aportan ideas y abren nuevas formas de ver la educación desde una mirada más flexible y brindan herramientas a esas instituciones en las que persiste la violencia escolar, aportando de esta manera a un cambio social en el que se tiene en cuenta el desarrollo personal por medio de la educación. 


\section{Referencias bibliográfica}

Garreton, P. (2014). Estado de la convivencia escolar, conflictividad y su forma de abordarla en establecimientos educacionales de alta vulnerabilidad social de la provincia de concepción, Chile. Chile: Universidad de Córdoba, Servicio de Publicaciones.

Escalante, Y. (2011). Implementación de una propuesta didáctica centrada en las competencias emocionales y comunicativas para la solución de conflictos en el aula de clase. Preira: UNIVERSIDAD TECNOLOGICA DE PEREIRA.

Alfaro, M. a. (2010). La optimización de los resultados de la reforma educativa para enfrentar la violencia escolar mediante la utilización de la televisión. EL SALVADOR, C.A.: ANTIGUO CUSCATLÁN.

Garcia, P. D. (2015). La Comunicación: mediadora en la resolución de conflictos escolares en la Institución Educativa Villamar. Bogotá: Universidad Distrital Francisco José de Caldas.

Gonzalez, L. (2001). La comunicación educativa en el aula: una alternativa para la enseñanza de las Teorías de la Comunicación. Acatlán: UNAM FES-Acatlán.

Mendoza, Y. (2011). Educomunicación para la sostenibilidad ambiental. Bucaramanga: universidad de Santander .

Santos, C. J. (2016). Cultura de paz, educomunicación y TIC en Colombia. Red de Revistas Científicas de América Latina, el Caribe, España y Portugal , 609-637.

Prieto, D. (2005). El interaprendizaje como clave de la educomunicación. Mediaciones , 40.

Parra, G. (2000). Bases epistemológicas de la educomunicación, definiciones y perspectivas de su desarrollo. Quito - Ecuador: Abya Yala.

Villarruel, M. (2011). Pedagogia de la comunicación. Quito , Ecuador: Universidad Politécnica Salesiana. 
Valderrama, C. E. (2007). Ciudadania y comunicación: saberes, opiniones y haceres escolares. Bogotá: IESCO - CU.

Cuesta, R. (2009). Felices y escolarizados crítica de la escuela en la era del capitalismo. Barcelona - España : OCTAEDRO.

Chaux, E. (2013). Violencia escolar en Bogotá: avances y retrocesos en cinco años. Bogotá: Universidad de los Andes - Escuela de Gobierno Alberto Lleras Camargo.

Rocha, C. (2000). La comunicación en el conflicto escolar: El caso de la escuela en Bogotá . Mediaciones , 75 .

Nusbaum, M. (2012). Crear Capacidades, propuesta para el desarrollo humano. Buenos Aires: Paidos.

Alvarado, L. (2008). Caracteristicas más relevantes del paradigma socio - critico. Sapiens .

Díaz-Bravo, L., Torruco, U., \& Martínez, M. (2013). La entrevista, recurso flexible y dinámico. ELSEVIER , 167.

UNICEF. (2011). Violencia escolar en América Latina y el Caribe Superficie y fondo. Panama: unicef.

Ministerio de educación. (16 de Marzo de 2012). Ministerio de educación. Recuperado el 15 de Agosto de 2016, de mineducacion:

http://www.mineducacion.gov.co/observatorio/1722/article-300099.html Oficina Regional de Educación en América Latina y el Caribe Santiago. (2014). Cultura de Paz en la escuela Mejores Prácticas en la Prevención y Tratamiento de la Violencia Escolar. Santiago de Chile: Oficina Regional de Educación en América Latina y el Caribe Santiago.

Estella, A. M. (2005). LA VIOLENCIA ESCOLAR: PERSPECTIVAS DESDE NACIONES UNIDAS. REVISTA IBEROAMERICANA DE EDUCACIÓN , 42.

Coslado, Á. B. (2012). Educomunicación: desarrollo, enfoques y desafíos en un mundo interconectado. Foro de Educación , 175.

Ocaña, A. O. (2015). Enfoques y métodos de investigación en las ciencias sociales y humanas. Bogotá: Ediciones de la U.

Sampieri, E. (2010). Metodología de la investigacíon. México: McGRAW-HILL / INTERAMERICANA EDITORES, S.A. DE C.V.

Arellano, E. O. (2012). Epistemología de la Investigación Cuantitativa y Cualitativa: Paradigmas y Objetivos. Revista de Claseshistoria , 62. 
Galeano, E. (2009). estrategias de investigación social cualitativa. Medellin: Carrera editores.

Anguera, M. T. (1981). Observación en la escuela. Madrid: Piramide.

Estupiñán, M. C. (2004). Alfabetización académica y lectura inferencial. Pereira: Editorial Papiro.

Campoy Aranda, T., \& Gomes Araújo, E. (2011). Técnicas e instrumentos cualitativos de recogida de datos. España: Editorial EOS.

Henao Ramirez, R., \& Lopez Peralta, D. (2014). Narrativas de jóvenes sobre los sentidos de convivencia pacifica en la escuela. Manizales: CINDE.

ambiental, E. p. (2011). Educomunicacion para la sostenibilidad ambiental. Bucaramanga: Universidad de Santander.

El universal. (22 de Mayo de 2013). Recuperado el 29 de Septiembre de 2016, de El universal: http://www.eluniversal.com.co/cartagena/internacional/siete-de-cada-diezninos-en-latinoamerica-son-victimas-de-matoneo-120465

Mella, O. (23 de marzo de 2000). Grupos Focales. Técnica de investigacion cualitativa. CIDE, 38.

Gómez, C. E. (2012). Escolaridades alternativas en Bogotá Sentidos emergentes en la práctica educativa . Bogotá: Pontificia Universidad Javeriana.

Freire, P. (1991). Pedagogía de la contradicción. España: Anthropos.

Espuñes, E. F. (2015). Educomunicación Las Tecnologías de la Información y la Comunicación, en la educación. Segovia: Universidad de Valladolid.

Huergo, J. (2007). La comunicación en la educación: Coordenadas desde América Latina. FISEC-Estrategias - Facultad de Ciencias Sociales de la Universidad Nacional de Lomas de Zamora , 35-52.

Soares, I. d. (2005). Caminos de la educomunicación: utopías, confrontaciones, reconocimientos . Nómadas , 2007.

Bustamante, P. (2007). Educomunicación: una estrategia para la participación y educación ciudadana. Colombia: Universidad Técnica Particular de Laja.

Kaplun, M. (2002). Una pedagogía de la comunicación. La Habana: Caminos.

Soares, I. d. (2003). Educomunicación: comunicación y tecnologías de la información en la reforma de la enseñanza americana. Diálogos de la comunicación , 176. 
Cavazos, J. R. (Enero-Junio de 2013). Una mirada a la pedagogía tradicional y humanista. 45.

Salazar, I., \& Ramírez, M. (2007). Surgimiento de la educación en la República de Colombia, ¿En que fallamos? Bógota: Banco de la República.

Mena, N. P. (2013). Transformación y crisis de la escuela: algunas reflexiones sobre el caso colombiano. Pereira: Universidad del Tolima. CREAD .

Quijano, A. (2014). Cuestiones y Horizontes De la Dependencia Histórico-Estructural a la Colonialidad/Descolonialidad del Poder. Buenos Aires: CLACSO.

Freire, P. (1970). Pedadogía del oprimido. Brasil: Siglo ventiuno .

Guerrero, M. E. (1990). Educación alternativa, pedagogía de la pregunta y participación estudiantil. México: Facultad de Filosofía y Letras Universidad Nacional Autónoma de México.

Díaz, C. (2010). Hacia una pedagogía en clave decolonial: entre aperturas, búsquedas y posibilidades. Tabula Rasa , 217-233.

Aguilar, J. .. (1993). La transformación de la escuela en Colombia: De las innovaciones educativas a las alternativas pedagógicas. Bogotá: Cuadernos de REFLEXIÓN EDUCATIVA. . Ortega , R., \& Mora-Merchán , J. (2007). Actuando contra el bullying y la violencia escolar. El papel de los medios de comunicación, las autoridades locales y de Internet [E-Book]. Germany : Empirische Paedagogik e. V..

Bandura , A., \& H. Walters, R. (1974). Aprendizaje social y desarrollo de la personalidad. Rinehart and Winston: Alianza Universidad, Alianza Editorial.

Olweus, D. (1998). Conductas de acosa y amenaza entre escolares . Madrid : Dan Olweus .

Sarmiento, Á. S. (2005). Violencia entre compañeros en la escuela. España: Centro Reina Sofía para el Estudio de la Violencia.

Ortega, R. (2000). "La Convivencia Escolar: qué es y cómo abordarla". Programa Educativo de Prevención de Maltrato entre compañeros y compañeras. España: junta de andalucia.

Tuvilla, J. (2001). Propuestas prácticas para la resolución de conflictos. Almería: BAS, E.

Palomero, J. E., \& Fernández, M. R. (2001). La violencia escolar: Un punto de vista global. Revista Interuniversitaria de Formación del Profesorado , 48.

Mockus, A. (2003). Cultura ciudadana y comunicación. Revista la tadeo , 68. Bustamante, P. (2008). Comunidad ciudadanía y valores. Quito: OCLACC. 
Crovi, D. (2004). El entramado reticular de la educación. Una mirada desde la comunicación. México: Gedisa.

Prats, J. F. (2005). Educomunicación y cultura participativa. España : Gedisa.

Palacios, J. (1978). La cuestión escolar. Barcelona: Laia.

UNESCO. (1993). Thinkers on education. Paris: UNESCO.

Cuervo, E. C. (2003). ACOSO ESCOLAR: CARACTERIZACIÓN, CONSECUENCIAS Y

PREVENCIÓN. Bogotá: Universidad Nacional de Colombia Departamento de Estadística.

Illera, M. d. (2005). CONVIVENCIA Y CULTURA CIUDADANA: DOS PILARES

FUNDAMENTALES DEL DERECHO POLICIVO. 280.

Aguilar, J. F. (1998). De viajes, viajeros y laberintos. Bogotá : Coleccion investigaciones.

Aguilar, J. f., \& Betancour, J. (2000). Contrucción de cultura democrática. Bogotá : IDEP.

Gómez, A. P. (1995). La escuela, encrucijada de culturas. Sevilla: Díada.

Forero, H. (1999). Educación media bivalente con énfasis en la producción y recepción crítica de medios y nuevas tecnologías comunicacionales. Bogotá: UPN.

Condori, P. T. (2014). Sentido de convivencia y contrucción de saberes válidos. Lecturas en Psicologia , 57.

Ortega, R. (2001). Construir la convivencia para prevenir la violencia escolar. Aula de innovación educativa .

Alzate, R. (2007). Teoría del conflicto. Madrid: Universidad complutense.

Ortiz, A. (2015). Enfoques y métodos de investigación en las ciencias sociales y humanas. 2015: Ediciones de la U .

Packer, M. (1985). La investigación hermenéutica en el estudio de la conducta humana. American Psychologist .

Secretaría de Educación Distrital. (2004). Comunicación y escuela: orientaciones para la incorporación, usos y apropiación de los medios de comunicación en las instituciones educativas de Bogotá. Bogotá: Universidad Nacional de Colombia.

Hernández, G. D. (2001). Desafios de la educomunicación y alternativas pedagógicas. Revista cientifica de información y comunicación , 333-345. 


\section{A. Anexo 1: Ficha de observación}

\section{Ficha observación participante}

\begin{tabular}{ll}
\hline FICHA N & 1 \\
NOMBRE: & Lorena Ayala Carvajal \\
INSTITUCIÓN: & Escuela mediática \\
FACTORES & Procesos comunicativos en el aula de clase, resolución de conflictos, convivencia, patrones culturales. \\
CLAVES EN LA & \\
OBSERVACION: & \\
\hline
\end{tabular}




\title{
B. Anexo 2: Entrevistas
}

\author{
ENTREVISTA
}

Preguntas orientadoras a la comunidad académica de la Escuela Mediática.

Directivos:

- ¿Cuál es el enfoque de la escuela mediática? 1 objetivo

- ¿Por qué el enfoque mediático?

- ¿Por qué considera el factor comunicativo un elemento tan importante en la vida de los estudiantes?

- ¿Existen casos de violencia escolar en este colegio?

- ¿De qué manera se abordan los casos de violencia escolar en este colegio?

- ¿Existen problemas de convivencia escolar en este colegio?

- ¿De qué manera se abordan los problemas de convivencia escolar en este colegio?

- ¿En su experiencia el enfoque comunicativo ha facilitado nuevos procesos de resolución de conflictos orientados a la construcción de convivencia?

- ¿Cómo podría describir las prácticas de convivencia que facilita el enfoque educomunicativo de la institución?

- ¿Cómo cree que se evidencia el enfoque educomunicativo en los salones de clase?

Docentes:

- ¿Hace cuánto trabaja en la Escuela Mediática?

- ¿En qué otros lugares ha trabajado?

- ¿Cuál podría ser la diferencia entre sus experiencias anteriores y la escuela mediática? catalogaría esta experiencia en la escuela mediática como una propuesta innovadora o alternativa? ¿Por qué?

- ¿Cuáles son esos factores que hacen de esta experiencia una alternativa distinta en medio de la educación tradicional?

- ¿Cuál es el enfoque de la escuela mediática?

- ¿Por qué el enfoque mediático?

- ¿Por qué considera el factor comunicativo un elemento tan importante en la vida de los estudiantes?

- ¿Qué iniciativas se han generado en la escuela mediática, desde el componte comunicativo en aras de favorecer el desarrollo de las clases?

- ¿Cómo podría ejemplificar la convivencia entre los estudiantesde la Escuela Mediática?

- ¿A comparación de los otros lugares en los que usted ha trabajado, los

Niveles de violencia escolar en esta institución aumentan o disminuyen?

- ¿Cree que esto se debe al enfoque comunicativo que tiene la escuela mediática?

Estudiantes:

- ¿Hace cuánto estudia en la escuela mediática?

- ¿ ¿Ha estudiado en otros colegios que tienen pedagogía tradicional?

- ¿Siente que la forma en la que le enseña en la escuela mediática es diferente a otras clases de educación más tradicional?

- ¿Cuál podría ser la diferencia entre sus experiencias anteriores y la escuela mediática? Podría decir que esta experiencia en la escuela mediática es una propuesta innovadora o alternativa? ¿Por qué?

- ¿Cuál es el enfoque de la escuela mediática? 1 objetivo 
- ¿Por qué el enfoque mediático?

- ¿Por qué considera el factor comunicativo un elemento tan importante en la vida de los estudiantes?

- ¿Existen casos de violencia escolar en este colegio?

- ¿De qué manera se abordan los casos de violencia escolar en este colegio?

- ¿Existen problemas de convivencia escolar en este colegio?

- ¿De qué manera se abordan los problemas de convivencia escolar en este colegio?

- ¿Cómo considera que se evidencia el enfoque educomunicativo en los salones de clase?

- ¿Cuál es el aporte que ha hecho el enfoque comunicativo de la escuela mediática, a su formación como ser humano? 1 objetivo

Personal administrativo

- ¿Qué labor desempeña en esta institución?

- ¿Hace cuánto trabaja en la Escuela Mediática?

- ¿Ha trabajado en otras instituciones educativas?

- ¿Qué diferencia cree que existe en la manera en la que enseñan en esta institución a comparación de las otras en las que ha trabajado?

- ¿Existen casos de violencia escolar en este colegio?

- ¿De qué manera se abordan los casos de violencia escolar en este colegio? 


\section{Anexo 3: Grupo focal}

FICHA GRUPO FOCAL \# 1

\section{Objetivo de la investigación:}

Analizar los procesos educomunicativos entorno a la cultura de convivencia en la educación alternativa. Estudio de caso: Escuela Mediática de Bogotá.

Objetivo del grupo focal:

- Comprender nociones que tienen los estudiantes acerca de la violencia escolar, educomunicación y cultura de convivencia.

- Identificar los procesos educomunicativos que se están desarrollando entorno a la construcción de una cultura de la convivencia en la Escuela Mediática

- Determinar el nivel de participación de los estudiantes con las propuestas educomunicativas que se gestan en la institución educativa.

\section{Actividad introductoria (Presentación, rompe hielo):}

- Actividad de presentación.

- Se le da al grupo un tiempo específico (tal vez 5 minutos) para escribir una lista de todo lo que tengan en común donde van a evitar lo obvio. Cuanto el tiempo se acabe pregunta al grupo cuantas cosas tienen en la lista. Como diversión y luego se comparten.

Preguntas orientadoras:

¿Saben que es la educomunicación? ¿Qué creen que es la educomunicación? (En caso de que los estudiantes no conozcan el termino se les explicará de que se trata)

¿Creen que la educomunicación puede hacer que las clases sean diferentes?

¿Consideran que en su institución se lleva a cabo un proceso educomunicativo? ¿Por qué?

¿Qué es la violencia escolar y la convivencia para ustedes?

¿Para ustedes existe una relación entre la educomunicación y la convivencia? ¿Por qué?

¿Creen que la educomunicación puede ayudar a que los casos de violencia escolar se reduzcan en las instituciones educativas? ¿Cómo?

¿De qué formas pueden participar los estudiantes en procesos educomunicativos dentro de la institución?

\section{Actividades estimulo:}

Esta primera actividad "árbol de palabras" permitirá ver el acercamiento que tienen los estudiantes a su realidad dentro del colegio, referente a la violencia escolar, convivencia, educomunicación. 


\begin{abstract}
Se tendrán tres árboles y cada uno con el tema en el que se quiere profundizar, los estudiantes pasaran de 2 en $\mathbf{2}$ y con post hits pegaran lo que creen está relacionado con cada palabra y como viven esto en su institución. La idea es que roten y cada grupo de dos personas termine pasando por los tres árboles.

Posteriormente se pegaran los 3 árboles en un lugar visible y se analizarán los resultados y se realizarán preguntas basadas en lo que colocaron en los árboles. En este tiempo se buscará una relación entre cada uno de los términos y qué relación tienen (esto se va a compartir en el grupo).

Para lograr identificar las maneras en las que los estudiantes se involucran en los procesos educomunicativos, se retomará una de las preguntas orientadoras en donde se menciona este aspecto ¿De qué formas pueden participar los estudiantes en procesos educomunicativos dentro de la institución?). La pregunta anterior se repetirá con la intencionalidad de identificar los espacios de participación estudiantil, pero en esta ocasión se buscará la relación entre los tópicos iniciales y a lo que responden cada uno de los momentos de participación en los que se desenvuelven los estudiantes. Esto permitirá ver la forma en la que esos tiempos participativos y educomunicativos responden a la construcción de cultura de convivencia y por tanto mitigación de la violencia escolar.
\end{abstract}

\title{
PARTICIPANTES GRUPO FOCAL
}




\section{Anexo 4:Cronograma}

\begin{tabular}{|c|c|c|c|c|c|c|c|c|c|c|c|c|c|c|c|c|c|c|c|c|c|c|c|c|c|c|}
\hline \multirow{2}{*}{ Actividad / Meses / Semanas } & \multicolumn{2}{|c|}{ Marzo } & \multirow{2}{*}{\multicolumn{2}{|c|}{\begin{tabular}{|l|l|l|}
\multicolumn{3}{|c|}{ Mayo } \\
1
\end{tabular} \mid \begin{tabular}{l|l}
3 \\
\end{tabular}}} & \multirow{2}{*}{\multicolumn{2}{|c|}{ 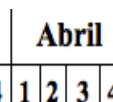 }} & \multicolumn{2}{|c|}{ Junio } & \multicolumn{3}{|c|}{ Julio } & \multicolumn{2}{|c|}{ Agosto } & \multicolumn{3}{|c|}{ Septiembre } & \multicolumn{3}{|c|}{ Octubre } & \multicolumn{4}{|c|}{ Noviembre } & \multicolumn{3}{|c|}{ Diciembre } \\
\hline & 1 & \begin{tabular}{l|l|l}
2 & 3 & 4 \\
\end{tabular} & & & & & \begin{tabular}{l|l|l}
4 & 1 & 2 \\
\end{tabular} & \begin{tabular}{|l|l|}
2 & 3 \\
\end{tabular} & \begin{tabular}{|l|l}
4 & 1 \\
\end{tabular} & 23 & \begin{tabular}{|l|l}
3 & 4 \\
\end{tabular} & 12 & \begin{tabular}{l|l}
3 & 4 \\
\end{tabular} & 1 & \begin{tabular}{l|l}
2 & 3 \\
\end{tabular} & 4 & 1 & 23 & 4 & 1 & 2 & 3 & 4 & 1 & & 3 \\
\hline $\begin{array}{l}\text { isita preliminar: observación y } \\
\text { ecorrido }\end{array}$ & & & & & & & & & & & & & & & & & & & & & & & & & & \\
\hline $\begin{array}{l}\text { Selección de propuestas que se van } \\
\text { a identificar }\end{array}$ & & & & & & & & & & & & & & & & & & & & & & & & & & \\
\hline Selección de estudiantes & & & & & & & & & & & & & & & & & & & & & & & & & & \\
\hline $\begin{array}{l}\text { Realización de entrevistas } \\
\text { estudiantes }\end{array}$ & & & & & & & & & & & & & & & & & & & & & & & & & & \\
\hline $\begin{array}{l}\text { Realización de entrevistas docentes } \\
\text { y directivos }\end{array}$ & & & & & & & & & & & & & & & & & & & & & & & & & & \\
\hline $\begin{array}{l}\text { Recolección de Características a } \\
\text { Dartir de entrevistas }\end{array}$ & & & & & & & & & & & & & & & & & & & & & & & & & & \\
\hline Grupos focales con estudiantes & & & & & & & & & & & & & & & & & & & & & & & & & & \\
\hline $\begin{array}{l}\text { recopilación de información } \\
\text { relevante en los grupos focales }\end{array}$ & & & & & & & & & & & & & & & & & & & & & & & & & & \\
\hline
\end{tabular}




\section{E. Anexo 5: Revisión documental}

- Educación media bivalente con énfasis en la producción y recepción critica de medios y nuevas tecnologías comunicacionales. Forero Forero, Hilda Marina / Tesis (Magister en Desarrollo Educativo y Social)._Universidad Pedagógica Nacional (UPN) - CINDE, 1999.

- Documento de la regulación de la convivencia. Centro Educativo Libertad (CEL).

- Caracterización de la práctica pedagógica de la relación con el conocimiento y de la interacción social, que se dan en el trabajo por proyectos, eje de la innovación educativa en el centro educativo CEL. Autoras: Alcira Aguilera Morales / Adriana María Martínez Lara / Magister en Desarrollo Educativo y Social por el Centro Internacional / Universidad Pedagógica Nacional (2009). 


\title{
F. Anexo 6: Consentimiento informado
}

\section{CONSENTIMIENTO INFOAMADO ENTARSTA}

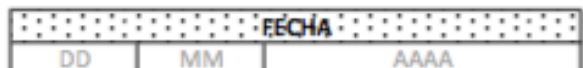

Yo,

identificado(a) con el documento

NOMBRE DEL PARTICIPANTE por voluntad propia doy mi consentimiento para la participación en la entrevista para la realización de la investigación CIUDAD DE EXPEDICIÓN

y la Pontificia Universidad Santo Tomás conforme lo establece el

que está llevando a cabo la Estudiante Lorena Ayala

Manifiesto que recibi una explicación clara y completa del objeto del proceso de entrevista y el propósito de su realización. También recibi información sobre la filmación y la forma en que se utilizarán los resultados.

Así mismo, me han informado que únicamente tendré derecho a solicitar y a que me sea entregada mi calificación en dicha entrevista.

Doy mi consentimiento para que los resultados sean conocidos por parte de

y la Universidad Santo Tomás.

NOMBRE ENTDDAD CONTRATANTE

Hago constar que he leido y entendido en su totalidad este documento, por lo que en constancia firmo y acepto su contenido.
\end{abstract}

FIRMA DEL PARTICIPANTE 


\section{G. Anexo: Matriz metodológica y de}

\begin{tabular}{|c|c|c|c|c|}
\hline 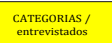 & Evocomuncacáon & 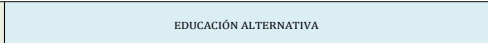 & VOLNCACA ISOLLAR & 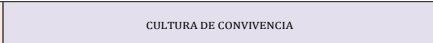 \\
\hline 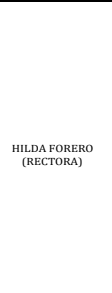 & 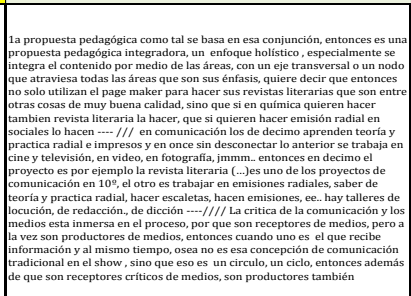 & 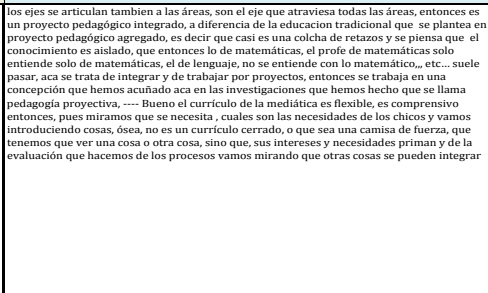 & 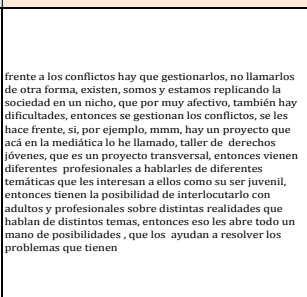 & 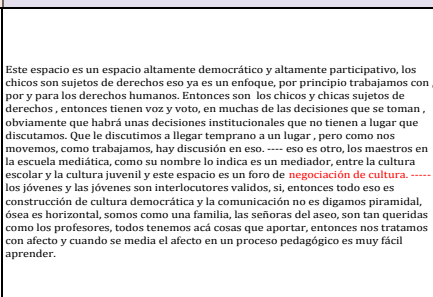 \\
\hline 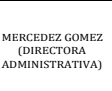 & & 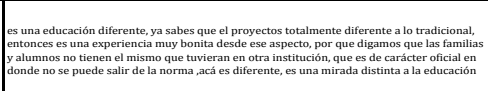 & & 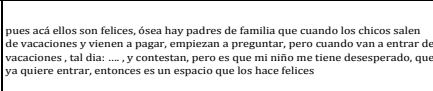 \\
\hline 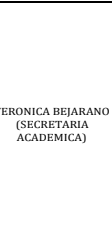 & & 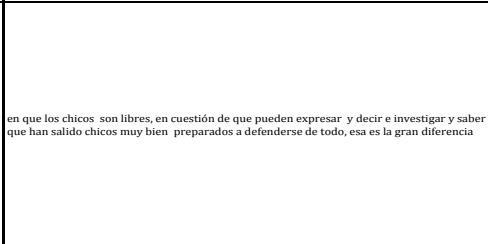 & & 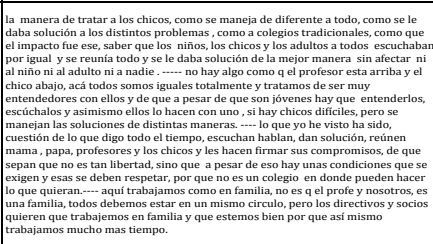 \\
\hline 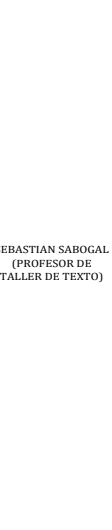 & 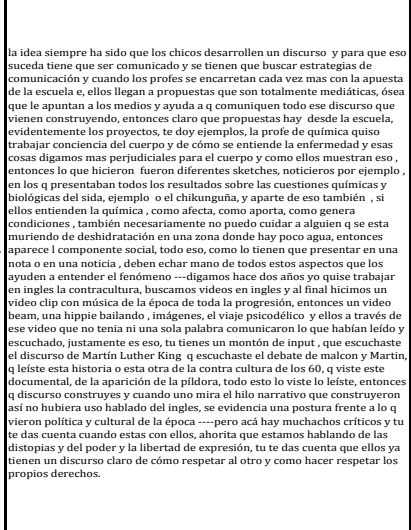 & 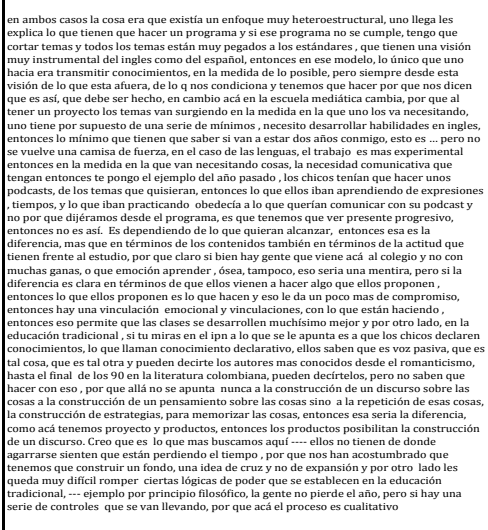 & 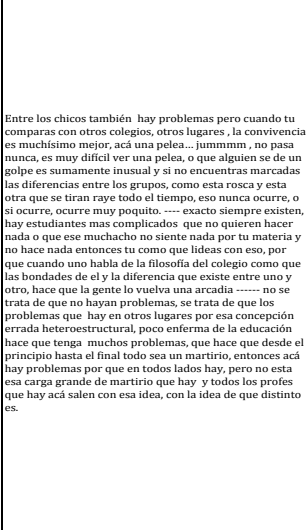 & 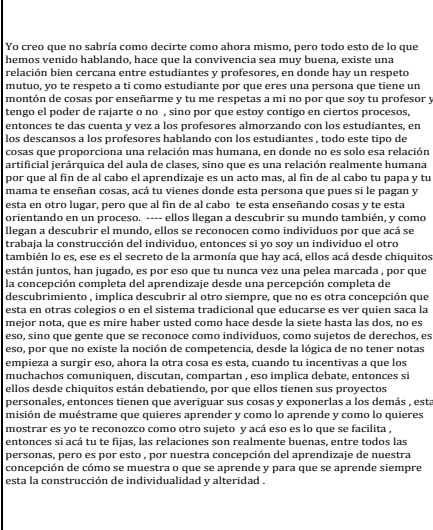 \\
\hline 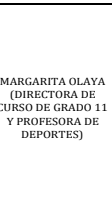 & 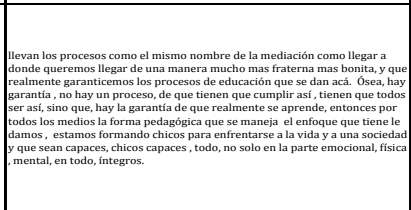 & 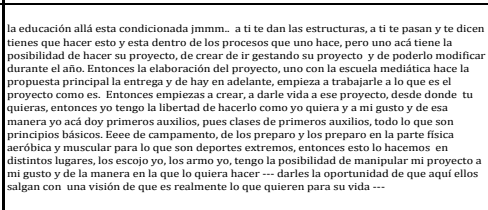 & 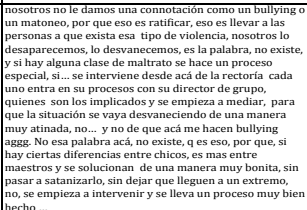 & 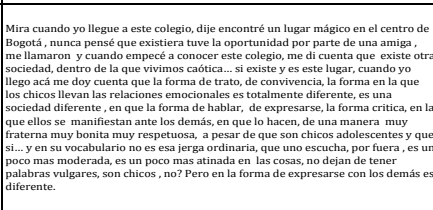 \\
\hline 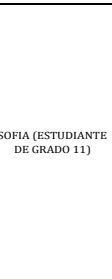 & 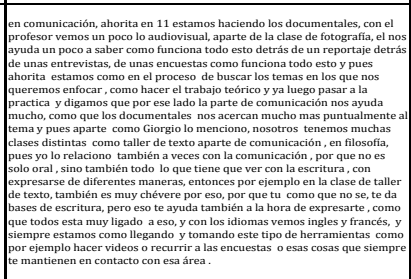 & 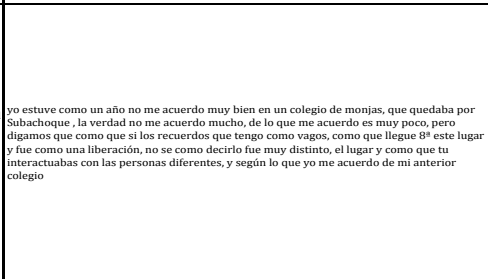 & 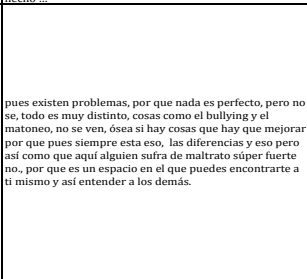 & 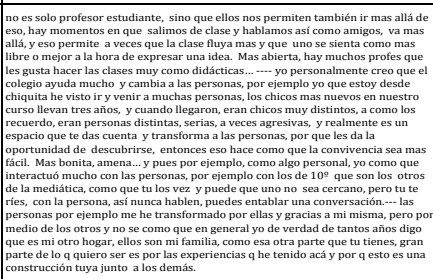 \\
\hline 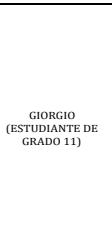 & 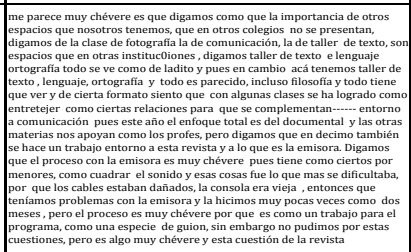 & 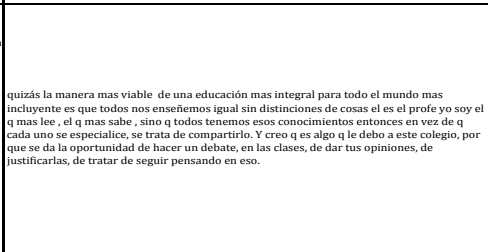 & 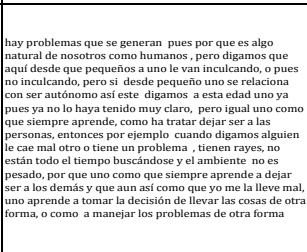 & \\
\hline 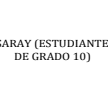 & & 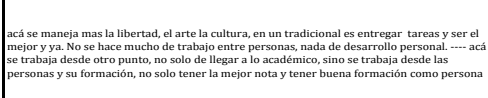 & 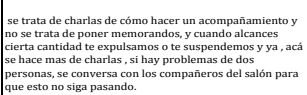 & 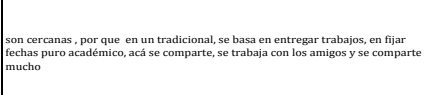 \\
\hline 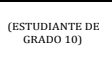 & 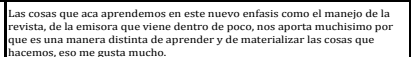 & & 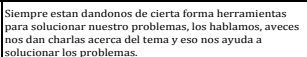 & \\
\hline
\end{tabular}

